\title{
CHARACTERIZATION OF ASF1 AND GCN5 IN THE CILIATED PROTOZOAN TETRAHYMENA THERMOPHILA
}

\author{
By \\ Abdel Rahman Karsou
}

BSc., Laboratory Medicine, Applied Science University, 2002

\author{
A thesis \\ presented to Ryerson University \\ in partial fulfilment of the \\ requirements for the degree of \\ Master of Science \\ in the program of \\ Molecular Science \\ Toronto, Ontario, Canada, 2011 \\ (C) Abdel Rahman Karsou 2011
}


I hereby declare that I am the sole author of this thesis or dissertation.

I authorize Ryerson University to lend this thesis or dissertation to other institutions or individuals for the purpose of scholarly research

\section{Abdel Rahman Karsou}

I further authorize Ryerson University to reproduce this thesis or dissertation by photocopying or by other means, in total or in part, at the request of other institutions or individuals for the purpose of scholarly research.

Abdel Rahman Karsou 
Ryerson University requires the signature of all persons using or photocopying this thesis. Please sign below, give address and date.

$\begin{array}{lll}\text { Name } & \text { Sign } & \text { Address }\end{array}$

1. 


\title{
Characterization of Asf1 and Gen5 in the ciliated Protozoan Tetrahymena thermophila
}

MSc. 2011

Abdel Rahman Karsou, Molecular Science, Ryerson University.

\begin{abstract}
One method of regulating accessibility of DNA is chromatin remodelling via histone post-translational modifications (PTM). Adding an acetyl group to the lysine residues $(\mathrm{K})$ on the core histone $\mathrm{H} 3$ is one of these chemical modifications. Acetylation of $\mathrm{H} 3$ on lysine 56 (H3K56ac) is an important histone alteration that is conserved among most if not all eukaryotes including humans. Several histone acetyl transferases (HAT) have been shown to be responsible for H3K56ac in different organisms including Gen5 and p300/CPB in human cells and Rtt109 in fungi including the yeast Saccharomyces cerevisiae. In addition the histone chaperone Asfl, is also required for these modifications in yeast and human cells. The ciliated protozoan Tetrahymena thermophila is an effective model organism for studying the function of histone PTMs in certain processes including meiosis and RNA interference. Here, I show that tGcn5 has $\mathrm{H} 3$ acetylation activity and that tAsf1 binds Histone $\mathrm{H} 3$.
\end{abstract}




\section{Acknowledgments}

I am very thankful for the opportunity to do research at Ryerson University. I am highly indebted to Canada for giving me the opportunity to come and be part of this amazing country.

I would like to thank my supervisor Dr. Jeffrey Fillingham for his continued support and for giving me this amazing project and for always making time to help.

I would like to thank Dr. Ronald Pearlman, Dr. Jyoti Garg and Anita Samardic for the help they provided me at York University.

I would like to thank all the lab team, and special thanks goes to Ernest Radovani for being a good lab colleague and for being very supportive. 


\section{Table of Contents}

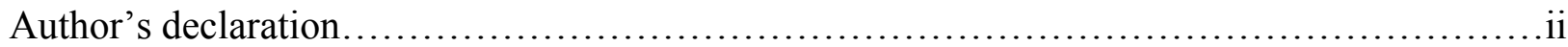

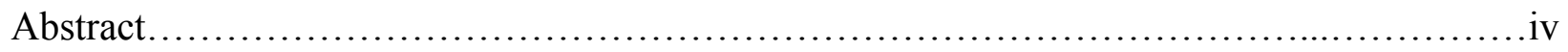

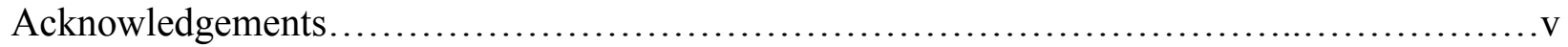

Table of Contents..................................................................

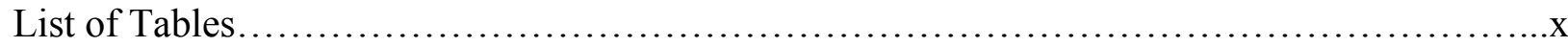

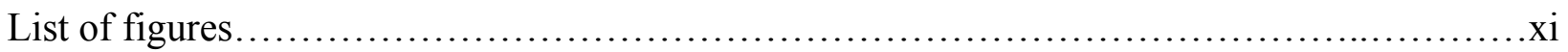

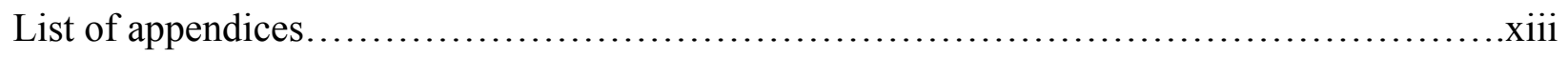

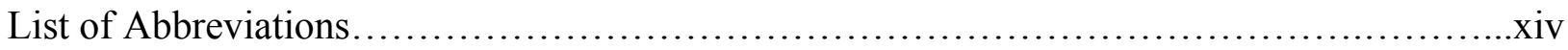

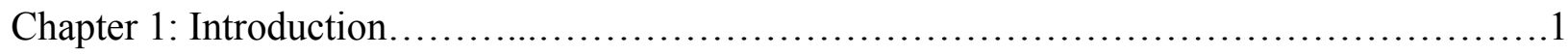

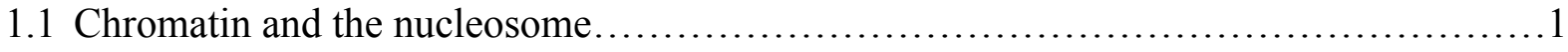

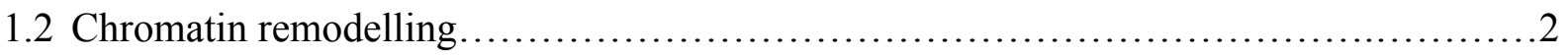

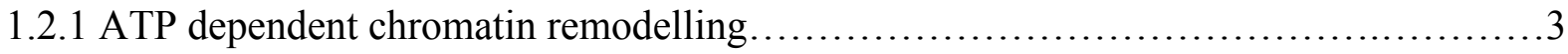

1.2.2 Post translational modification...............................................

1.2.3 The Histone code........................................................

1.3 Chromatin assembly.........................................................

1.4 Histone chaperones..........................................................

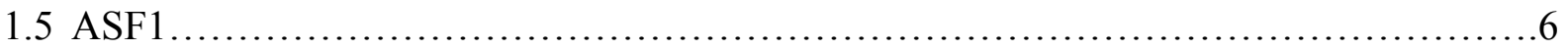

1.6 Replication dependent versus replication independent chromatin assembly..............7

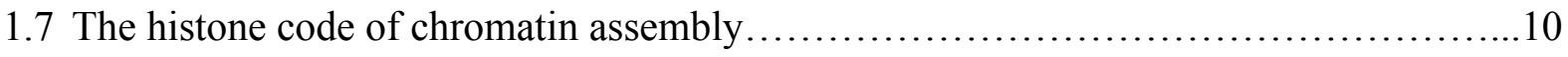

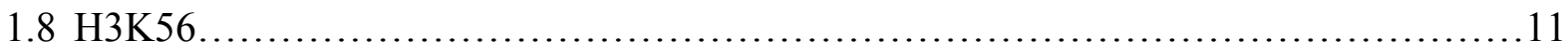

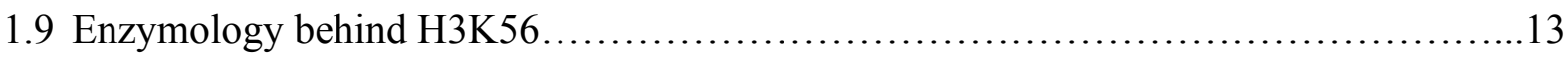

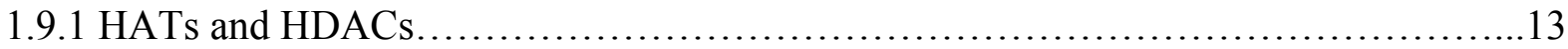




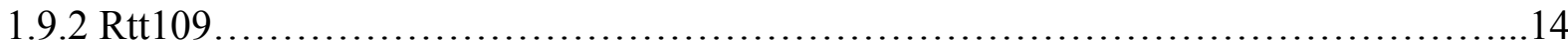

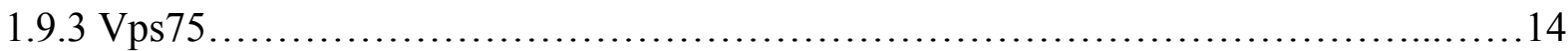

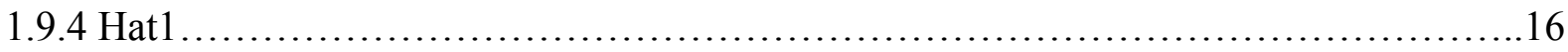

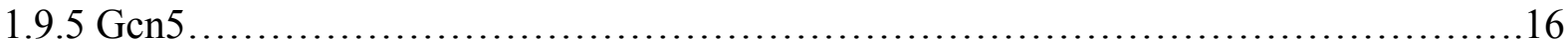

1.10T. thermophila as a model..................................................... 18

1.11 Research question and approach............................................. 19

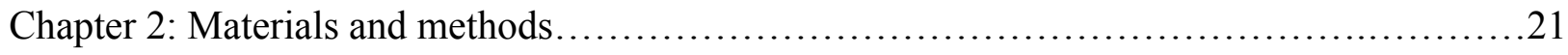

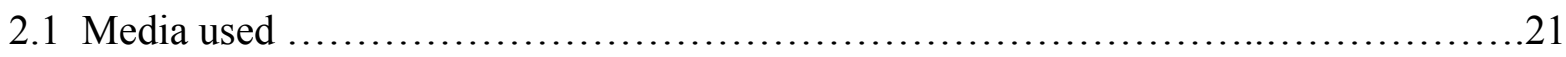

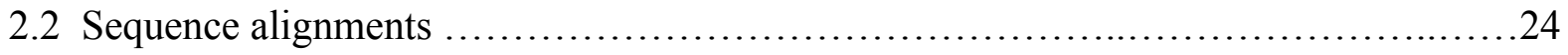

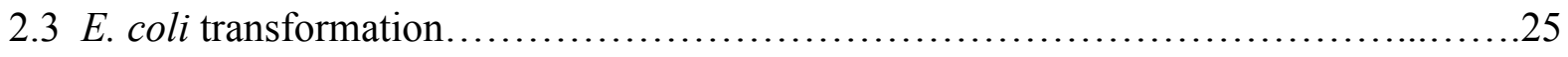

2.4 DNA Isolation from E.coli ( Alkaline Lysis Miniprep Method)........................25

2.5 DNA isolation from E. coli for sequencing ....................................26

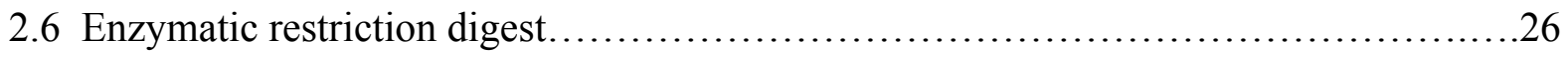

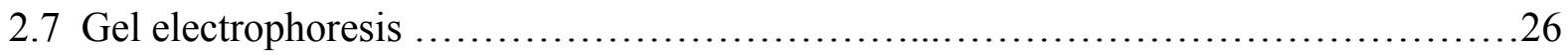

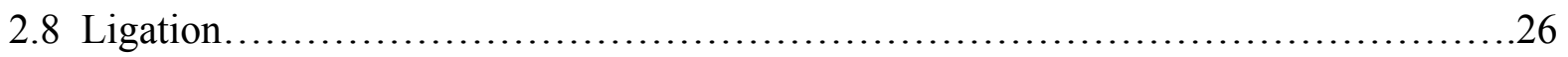

2.9 PCR "Polymerase Chain Reactions"............................................... 27

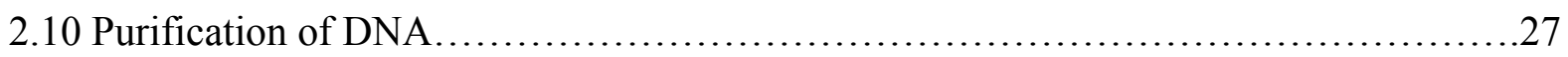

2.11 Genomic DNA extraction from $S$. cerevisiae .....................................27

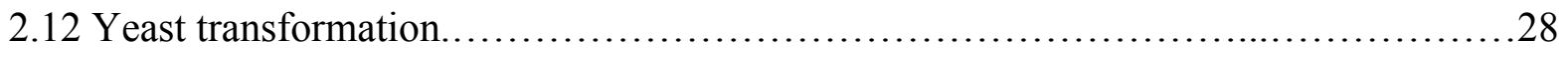

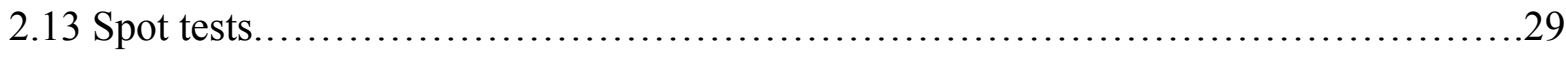

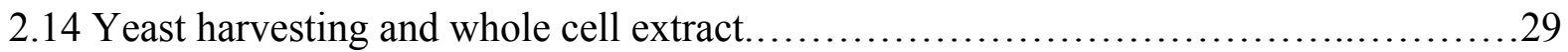

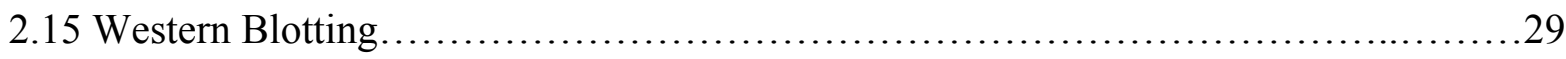

2.16 Protein expression induction...................................................... 
2.17 Nickel agarose affinity chromatography (protein purification) $\ldots \ldots \ldots \ldots \ldots \ldots \ldots \ldots \ldots \ldots \ldots \ldots \ldots$

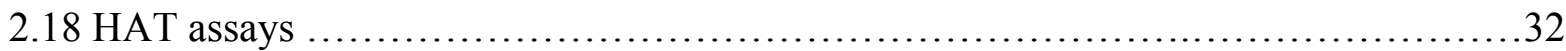

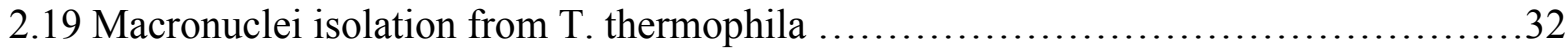

2.20 Histone purification from $T$. thermophila...................................... 33

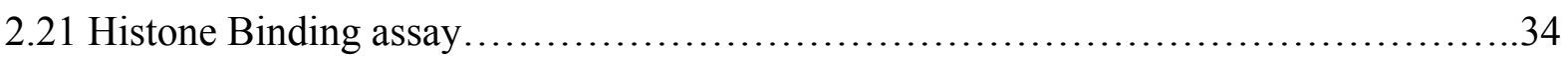

Chapter 3: Results.................................................................

3.1 Conservation of Asf1 and Gen5 between humans, yeast and T. thermophila.............35

3.2 Construction of $T$. thermophila synthetic genes (tGCN5,tASF1) $\ldots \ldots \ldots \ldots \ldots \ldots \ldots \ldots . \ldots \ldots$

3.3 Preparation of template DNA for amplification of yeast ASF1, ASF1N, RTT109 and GCN5

3.4 Amplification and molecular cloning of T. thermophila and yeast ASF1, ASF1N and GCN5 .44

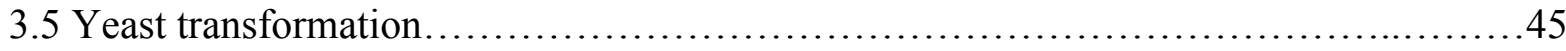

3.6 tASF1 and tGCN5 do not rescue the growth defect of $\Delta a s f 1$ and $\Delta g c n 5$ in yeast.......47

3.7 In Vivo acetylation assays on yeast transformed mutants.........................50

3.8 Expression of recombinant tAsf1, tAsf1N, yGen5 and tGen5 .....................55

3.9 Purification of recombinant proteins expressed in E. coli..........................59

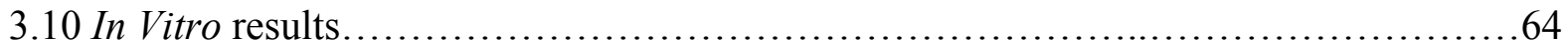

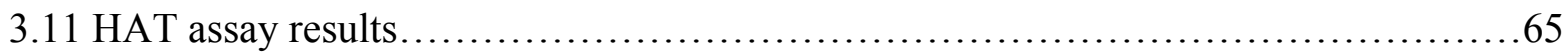

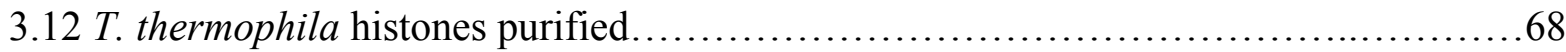

3.13 In Vitro histone binding assay results....................................... 70

3.13.1 tAsf1 binds both chicken and T. thermophila $\mathrm{H} 3-\mathrm{H} 4$ in vitro.....................72

3.13.2 tAsf1N binds both chicken and Tetrahymena $\mathrm{H} 3-\mathrm{H} 4$ in vitro.....................73 
Chapter 4: Discussion. .75

4.1 Rtt109 and yGen5 have two separate pathways for H3K9 acetylation...................75

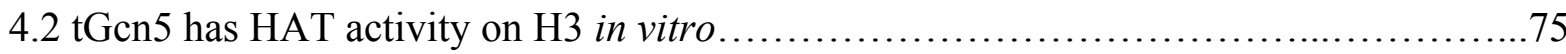

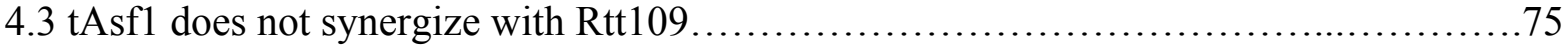

4.4 tAsf1 binds to $\mathrm{H} 3$ in a way that does not resemble yAsf1.........................76

4.5 tAsf1 binds H3-H4 through its highly conserved N-terminal domain..................76

4.6 tGen5 have a different structural mechanism for interacting with $\mathrm{H} 3$ than $\mathrm{yGcn} 5 . . . . . . .76$

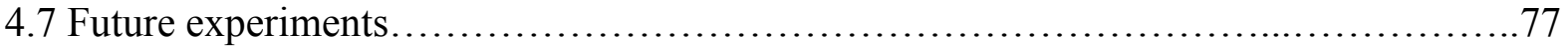

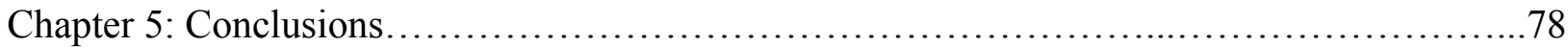

Chapter 6: Appendices......................................................... 79

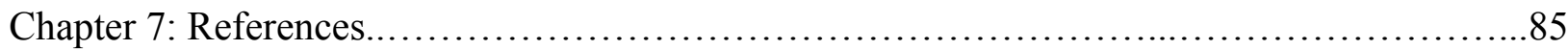




\section{List of Tables:}

Table 1: PTM enzymology...................................................... 18

Table 2 . The composition of media used for culturing $E$. coli $\ldots \ldots \ldots \ldots \ldots \ldots \ldots \ldots \ldots \ldots \ldots \ldots \ldots \ldots \ldots$

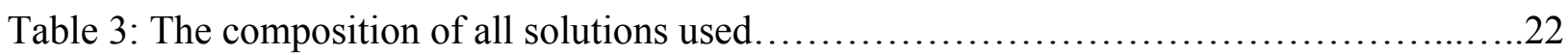

Table 4: Similarity of Gen5 of indicated species with the entire region of tGen5..............35

Table 5: Similarity of the entire region and N-terminal domain of indicated species with

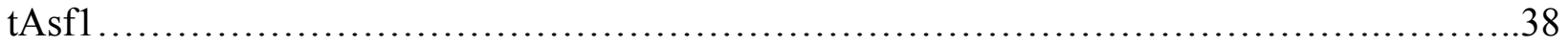

Table 6: Characterization of $\Delta a s f 1$ and $\Delta g c n 5$ single and double mutants..................46

Table 7: Characterization of $\Delta r t t 109$ and $\Delta g c n 5$ single and double mutants..................46

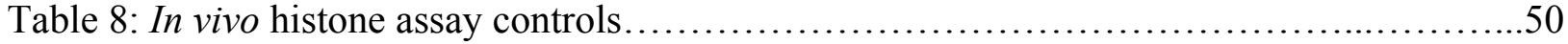

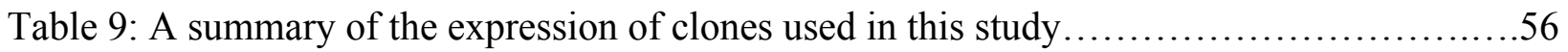




\section{List of Figures:}

Figure 1: Replication dependent chromatin assembly.................................. 8

Figure 2: Model for Rtt109 and Asf1 in H3 acetylation in S. Cerevisiae......................15

Figure 3: Gcn5 structure is well conserved among eukaryotes...............................

Figure 4: Asf1 is very well conserved at its N-terminal domain...........................39

Figure 5: Modifications made to tASF1 to correspond to universal genetic code...............41

Figure 6: Modifications made to tGCN5 to correspond to universal genetic code..............42

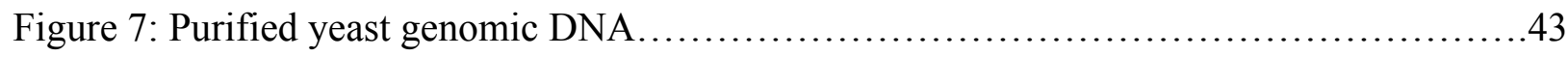

Figure 8: Restriction enzymes digestion for verification of molecular cloning...............45

Figure 9: Growth spot tests, Growth comparison for $t A S F 1$ and $t A S F 1 N \ldots \ldots \ldots \ldots \ldots \ldots \ldots . \ldots . \ldots . \ldots . \ldots$

Figure 10: Growth spot tests, Growth comparison for $t G C N 5 \ldots \ldots \ldots \ldots \ldots \ldots \ldots \ldots \ldots \ldots \ldots \ldots$

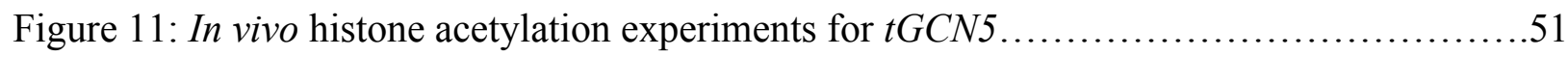

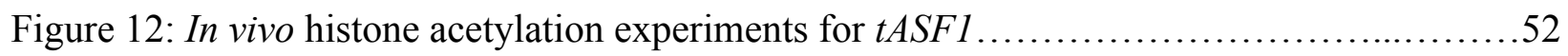

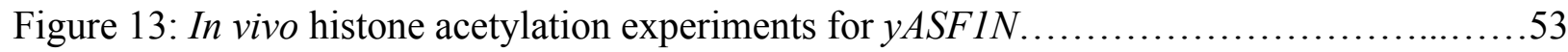

Figure 14: Coomassie-Blue stained SDS-PAGE of whole cell lysates from BL21 (DE3) E. coli transformed with indicated plasmids.............................................57

Figure 15: Coomassie-Blue stained SDS-PAGE of whole cell extract of BL21 (DE3) E. coli transformed with indicated plasmids expressed in different temperatures for 4 hours at $1 \mathrm{mM}$

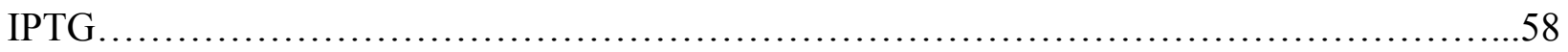


Figure 16: Coomassie-Blue stained SDS-PAGE of whole cell lysate of BL21 (DE3) E. coli transformed with indicated plasmids and expressed in several IPTG concentrations for 4 hours at $30^{\circ} \mathrm{C}$ .59

Figure 17: Coomassie-Blue stained SDS-PAGE of different aliquots from the purification of tASF1, tASF1N, tGCN5. .61

Figure 18: Coomassie-Blue stained SDS-PAGE of different aliquots from the purification of yGen5 and tGen5 62

Figure 19: Coomassie-Blue stained SDS-PAGE of different aliquots from the purification of tAsf1N. .63

Figure 20: In vitro HAT assays with chicken core histones..................................65

Figure 21: Purified T. thermophila histones...............................................69

Figure 22: yAsf1N histone binding Assay ................................................ 71

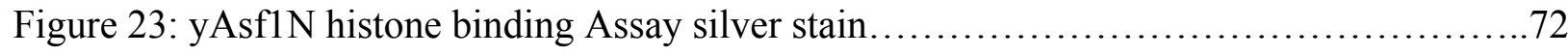

Figure 24: tAsf1 histone binding Assay ............................................... 73

Figure 25: tAsf1N histone binding Assay ................................................ 74 


\section{List of Appendices:}

Appendix 1 The sequences for the Tetrahymena thermophila synthetic genes and all primers...79

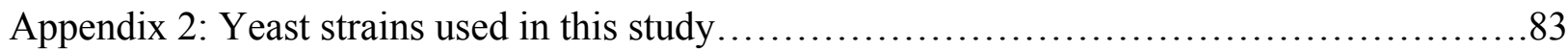




\section{List of abbreviations:}

Ac: Acetylated/acetylation

Asf1: Anti-Silencing factor 1

BLAST: Basic Local Alignment Search Tool

Caf1: Chromatin Assembly Factor1

DNA: Deoxyribo-Nucleic Acid

ds: double stranded

dd: Double distilled

GCN5: General Control of Amino acid Synthesis 5

HAT: Histone Acetyl Transferase

H3: Histone H3

H4:Histone H4

NLS: Nuclear Localization Signal

rpm: round per minute

Rtt109: Regulator Of Ty1 Transposition Protein 109

$\mathrm{K}:$ Lysine

PTM: Post-Translational Modification

WCE: Whole Cell Extract

WT: Wild Type 


\section{Chapter 1: Introduction}

\subsection{Chromatin and the nucleosome}

Chromatin is a thread-like structure that is composed of DNA and proteins to package DNA in the nucleus of the cell. Its functions are to package DNA into a smaller volume so that it can fit in the nucleus, to provide the physical scaffolds for DNA that makes segregation of chromosomes during mitosis and meiosis possible, to prevent DNA damage, and to control gene expression and DNA replication. Chromatin can be generally classified into two types which consist of euchromatin and heterochromatin. Euchromatin contains DNA coding active genes and is structurally "loose" to allow access to DNA polymerase that replicates DNA and RNA polymerases that transcribe RNA from DNA. Euchromatin is generally associated with the interphase of the cell cycle. The second type is heterochromatin that is tightly packaged and is associated with structural proteins and generally contains transcriptionally inactive genes (Aunuziato, 2008).

There are three levels of DNA packaging. First DNA wraps around histone proteins forming nucleosomes which are repeating structures and also is defined as a "beads on a string" structure. Afterwards, multiple nucleosomes wrap into a $30 \mathrm{~nm}$ wide fibre consisting of nucleosome arrays. Finally there is higher level packaging of the $30 \mathrm{~nm}$ fibres in the metaphase chromosome which occurs during chromosome segregation in mitosis and meiosis. (Fischle et al., 1999).

The structural unit of chromatin is the nucleosome. The nucleosome is composed of a short stretch of DNA and a histone octamer. It achieves packaging of the DNA by wrapping around it 147 base pairs (bp) of DNA. In the nucleus, histones are arranged as an octamer. The histone octamer is made of two dimers of histone $\mathrm{H} 2 \mathrm{~A}$ and $\mathrm{H} 2 \mathrm{~B}(\mathrm{H} 2 \mathrm{~A}-\mathrm{H} 2 \mathrm{~B})$ which are arranged 
on either side of a tetramer of histone (H3-H4) (Luger et al., 1997 \& 2003). Nucleosomes are regularly spaced along DNA forming the beads-on-a-string structure. Histone H1 plays a role in the $30 \mathrm{~nm}$ fibre by interacting with DNA at the entry and exit of each nucleosome (Travers, 1999).

Histones have a globular domain within the nucleosome that functions to interact with the DNA and a N-terminal tail protruding on the outside of the nucleosome which is thought to have in post translational modifications. Histones goes through several biological and chemical processes such as chromatin remodelling, assembly/disassembly and post translational modifications (PTM) (Luger et al., 1997).

\subsection{Chromatin remodelling}

Despite the compact packaging of chromatin, DNA must be accessible to proteins involved with processes such as transcription, replication, recombination, and repair. This accessibility is carried out by several mechanisms, including ATP-dependent chromatin remodelling (Tang et al., 2010), exchange of histone variants (Draker et al., 2009), and posttranslational chemical modification (PTM) of histones (Barth et al., 2010). Enzymes involved in PTM pathways chemically modify mostly the N-terminal tails or very rarely at the junction between the N-terminal tail and the globular domain of histone proteins. They perform this to alter the structure of chromatin and provide recognizable binding sites for other regulatory proteins. Many chromatin associated proteins contain domains within them that bind these chemical groups such as the bromodomain, which recognizes acetylated lysine residues (Zentner et al., 2010). Through direct interactions with histone modifications, other proteins are targeted to specific post translational modification sites on chromatin, like transcriptionally active regions 
that are abundant in $\mathrm{H} 3 \mathrm{~K} 4 \mathrm{me} 3$ marks, or repressed regions which are tri-methylated at $\mathrm{H} 3 \mathrm{~K} 27$ (Schuettengruber et al., 2007).

\subsubsection{ATP dependent chromatin remodelling}

ATP dependent remodelling is achieved by shuffling core histone particles along the DNA strand revealing other regulatory elements such as transcription factor binding sites. This process is carried out by ATP dependent protein complexes (Tang et al., 2010). Many of these enzymes are required for diverse and specific embryonic development of different cell types including pluripotency (Gao et al., 2008), cardiac development (Lickert et al., 2004), dendritic morphogenesis and self-renewal of neural stem cells (Yoo et al., 2009). It has been demonstrated that deletion or mutation of these proteins often leads to apoptosis or tumorigenesis as a consequence of dys-regulation of cell cycle control (Vissers et al., 2004 and Layman et al., 2009).

The first chromatin remodelling proteins that were identified are the SWI/SNF (Switching defective/Sucrose nonfermenting) family of proteins (Hirschhorn et al., 1992). A member of this family is RSC (Remodel the Structure of Chromatin) complex which was discovered based on homology of its ATPase subunit STH1 and shared Arp7 and Arp9 subunit with ySWI/SNF (Cairns et al., 1996). Both SWI/SNF and RSC complexes appear to regulate gene expression (Sudarsanam et al., 2000). Other families of chromatin ATP dependent chromatin remodelers are the INO80, the ISWI and the CHD family of proteins that function within large macromolecular structures to affect chromatin dynamics and thus regulate transcription (Hargreaves and Crabtree, 2011). 


\subsubsection{Post Translational modification}

Another class of chromatin remodelling is ATP independent post-translational modification (PTM) which is crucial for regulating the functions of chromatin. PTMs involves serine, threonine and tyrosine phosphorylation, lysine ubiquitination, sumoylation, methylation and acetylation, arginine methylation, and proline isomerization. The lysine residue is a target of different PTMs (Kouzarides, 2007 and Ruthenburg et al., 2007).

\subsubsection{The Histone code}

It has been hypothesized that histone post-translational modifications act as a "code" which is read by other proteins to silence or to transcribe certain genes (Strahl and Allis, 2000). An examples of a "reader" complex that silences genes is the SIR (Silent information regulators) complex in S. cerevisiae which requires H4 amino acid residues 16 to 29 for Sir3 binding (Hecht etal, 1995). Histone H4K16 acetylation dominantly prevents Sir mediated heterochromatin spreading (Kimura et al., 2002). In telomeric heterochromatin formation, the double-stranded telomeric DNA-binding protein Rap1 physically interacts with Sir4 and recruits the whole Sir complex to the telomeres (Lue et al., 2002). Once recruited to telomeres, Sir2 deacetylates the H4K16ac marks and hence silences the genes contained in that chromatin region (Imai et al., 2000).

Example of "reader" proteins that activate transcription are the ones that contain a Chromodomain. A class of such proteins is the chromodomain helicase DNA-binding (CHD) family of ATP-dependent chromatin remodelers. Proteins in this family have emerged as important regulators of cellular differentiation (Zentner et al., 2010). CHD proteins function in the nucleus by binding to the nucleosome and regulating gene transcription (Zentner et al., 
2010). It has been shown that CHD7, a member of the CHD family, tracks H3K4me and promotes transcription (Shnetz et al., 2009). CHD7 is mutated in human CHARGE (Coloboma of the eye, Heart defects, Atresia of the choanae, severe Retardation of growth and development, Genital abnormalities, and Ear abnormalities) syndrome, a multiple organ development disorder that affects several body functions such as hearing, vision, cardiac, craniofacial, and nervous system development (Vissers et al., 2004). There are several lines of evidences that CHD7 binds thousands of sites in the genome and thus is a redundant protein involved in regulation of gene expression (Shnetz et al., 2009).

\subsection{Chromatin assembly}

The tight compaction of nuclear DNA profoundly influences DNA replication, transcription, recombination, and repair. The interactions between the basic lysine and arginine residues of histones with the acidic DNA make the nucleosomal unit of chromatin a highly stable structure. For the cellular machinery to access DNA, chromatin must be disassembled so that DNA is freely available. Afterwards, the DNA has to be reassembled into chromatin (Ransom et al., 2010). The reassembly process is carried out by a class of proteins called histone chaperones. (Groth et al., 2007)

\subsection{Histone chaperones}

Histone chaperones (HC) bind histones after synthesis in the cytoplasm and then escort them into the nucleus. They also aid in their deposition into nucleosomes during different processes such as DNA replication, repair, and transcription. Furthermore, HC have a crucial role, directly or indirectly, in PTMs (Avvakumov et al., 2011). The functions of HC are often 
linked to ATP-dependent chromatin remodeler complexes that use the energy produced from ATP hydrolysis to break histone-DNA interactions during nucleosome disassembly and to redeposit histones during reassembly (Haushalter and Kadonaga, 2003).

Histone chaperones are a diverse network of proteins that have little sequence similarity and are relatively acidic which facilitates their interaction with the basic histones. Many of them have a hydrophobic $\beta$-sheet motif which is also involved in interacting with histones (English et al., 2006). Some HCs that lack the $\beta$-sheet motif have other structures that allow them to bind histones. For example, Chz1 has an irregular chain as well as $\alpha$-helices that mediate the interaction with H2B dimers and the histone variant H2A.Z (Zhou et al., 2008).

\subsection{ASF1}

The histone chaperone Anti-silencing function 1 (Asf1) is a highly conserved HC among eukaryotes both structurally and functionally. It is found in two isoforms in human cells, Asfla and Asflb (Das et al., 2009). The N-terminal 155 residues of Asf1 form a globular core that consists of an immunoglobulin-like fold (Daganzo et al., 2003; Mousson et al., 2005). Asf1 that contains only this globular core (Asf1N) has been shown to function as the full length Asf1 including binding to Hir protein that is required for gene silencing (Daganzo et al., 2003). It has been demonstrated that Asf1 binds to a heterodimer of histones H3 and H4 (English et al., 2005). More specifically, the C-terminus of histone $\mathrm{H} 3$ is one of the interfaces that interacts with Asf1 (Munakata et al., 2000). Structural mapping have shown interactions of the C-terminal end of H3 peptide (residues 122-135) with a highly conserved and acidic amino acid sequence on the concave surface of Asf1 (Mousson et al., 2005). This histone H3 peptide is of 3 helixes, which is a crucial part of a four-helix bundle that forms the $\mathrm{H} 3: \mathrm{H} 3$ dimerization site in the nucleosome 
(Luger et al., 1997). Furthermore, a mutation in the middle of the H3-interacting region of Asf1 that replaces Valine 94 with an Arginine residue (V94R) abolished the interaction with histone H3 (Mousson et al., 2005). This data indicates that the region that mediates H3:H3 dimerization in the $\mathrm{H} 3 / \mathrm{H} 4$ heterotetramer is also the region of $\mathrm{H} 3$ that binds to Asfl and thus explains why Asf1 binds a dimer of $\mathrm{H} 3-\mathrm{H} 4$ instead of a tetramer as found in the nucleosome (Mousson et al., 2005).

In the nucleus, the association of $\mathrm{H} 3-\mathrm{H} 4$ with Asf1 is required for $\mathrm{H} 3 \mathrm{~K} 56 \mathrm{ac}$ by an acetyltransferase (Collins et al., 2007; Driscoll et al., 2007; Han et al., 2007; Recht et al., 2006; Fillingham et al., 2008). Additionally, Asf1 can recruit other acetyltransferases for acetylation of H4 (Fillingham et al., 2008). Asf1 is also involved in transcription activation (Adkins et al., 2004) and chromatin disassembly or reassembly during the process of transcriptional elongation (Schwabish and Struhl, 2006). Furthermore, it has been found that most non DNA-associated histones are bound to Asf1 (Groth et al., 2005; Tagami et al., 2004), which underscore its importance in the role as an important histone chaperone in eukaryotes. Asfl is the only $\mathrm{HC}$ that has a role in both replication-dependent and replication-independent chromatin assembly which will be talked about in more details in the next section (Nakatani et al., 2004).

\subsection{Replication dependent versus Replication independent chromatin assembly}

During the $\mathrm{S}$ phase of the cell cycle where the genome is duplicated, there is also high level of histone synthesis to assemble the nascent strands of DNA. HCs function to assemble histones into new nucleosomes. In DNA replication, existing nucleosomes are disassembled and removed to facilitate access for the DNA replication fork. Newly synthesized DNA is then repackaged into nucleosomes. The re-assembled nucleosome is comprised of both parental and 
newly synthesized histones. This process is called replication coupled (RC) nucleosome assembly and it plays a major role in the inheritance of epigenetic information (Groth et al., 2007; Morrison and shen, 2009). During progression of DNA replication, the hexameric MCM27 helicase complex advances ahead of the replication fork and unwinds the dsDNA to facilitate DNA polymerase passage, and in doing so it disrupts existing histone-DNA binding and releases the parental histones (Gambus et al., 2006). A histone chaperone such as Asf1 then forms an Asf1-H3-H4 complex (Groth et al., 2007). Asf1 also binds to newly synthesized H3-H4 dimers during DNA replication and after directing their acetylation presents all bound acetylated H3-H4 to Caf1, which in turn assembles the dimers into replicating DNA by physically interacting with proliferating cell nuclear antigen (PCNA) (Stillman, 1986) (Figure 1).

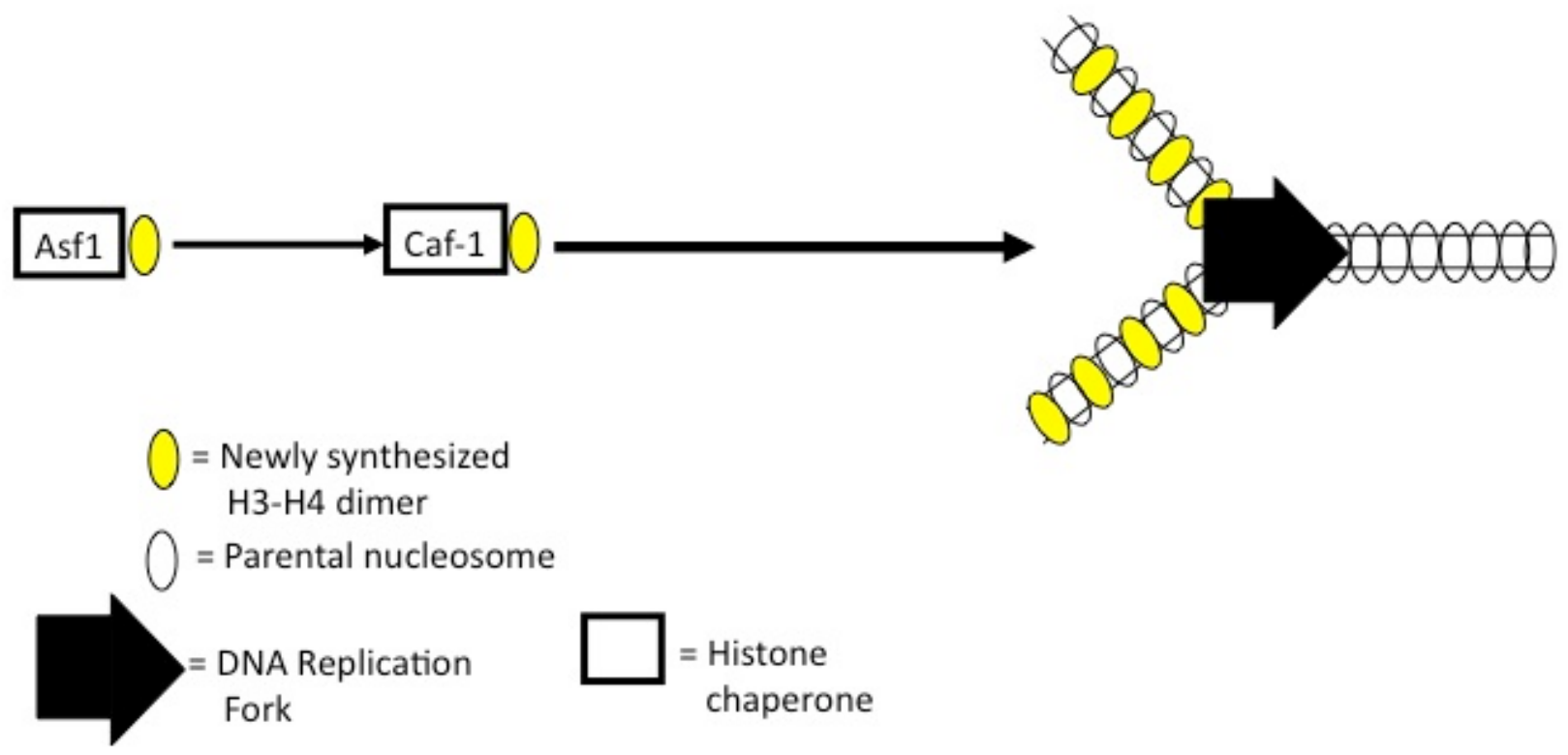

Figure 1: Replication dependent chromatin assembly: In this model Asfl binds to H3-H4 dimers and present them to Caf- 1 which in turn assembles them.

Replication independent chromatin assembly involves nucleosomes disassembly and reassembly during DNA repair or transcription (Avvakumov et al., 2011). During DNA repair, the process is referred to as Access-Repair-Restore; the process begins with chromatin 
disassembly to permit the repair machinery access to the site of damage, followed by repair of the DNA lesion and the final step involves re-establishing the pre-existing chromatin structure, including PTMs (Smerdon, 1991).

During DNA damage repair the chromatin structure around the break site is altered or completely disassembled to make DNA accessible. The type of modifications involved in this process varies with severity of damage and also the method of repair. In homologous recombination repair (HRR) of double strand breaks (DSBs), removal of nucleosomes and resection of DNA to generate single stranded free DNA overhangs is needed for recombination of the damaged DNA with homologous sequences (Rossetto et al., 2010). After repair is complete, chromatin returns to its original state. This process is aided by Asfl and subsequently CAF1 (Rocha and Verreault, 2008). Nucleosomal involvement in non-homologous end joining repair (NHEJ) is still unclear but is being extensively investigated (Kanikarla-Marie et al., 2011)

In transcription, chromatin is disassembled to facilitate transcription. Nucleosomes are very stable protein-DNA complexes that create significant obstacles in the way of the transcription machinery by blocking the production of transcripts (elongation) (Williams and Tyler, 2007). At the start of transcription HCs work with ATP-dependent chromatin remodelers and histone modifiers to alter or remove nucleosomes that occlude the promoter DNA sequences (Li et al., 2007a). After transcription initiation, same or different HCs work together with histone-modifying and chromatin-remodeling enzymes to allow the progression of RNA polymerase II (RNAPII) along the genes' coding regions. A model exists which predict that histones are modified in front of the RNAPII (mainly by acetylation) as it progresses, promoting the dissociation of histone-DNA interaction and thus the disassembly of nucleosomes with the 
aid of different HCs, including FACT, Nap1, Asf1, HIR/HPC, and Spt6. Subsequently, the same HCs mediate nucleosome re-assembly after RNAPII has passed through (Li et al., 2007).

\subsection{The histone code of chromatin assembly}

Newly-synthesized histone $\mathrm{H} 3-\mathrm{H} 4$ dimers are acetylated before being assembled into nucleosomes (Roth et al., 2001). Histone H4 acetylation at lysines 5 and 12 is conserved from yeast to humans (Ai and Parthun, 2004; Kleff et al., 1995; Sobel et al., 1995). Patterns of acetylation on newly-synthesized H3s are not as conserved; In HeLa cells, acetylation of newly synthesized histone $\mathrm{H} 3$ is barely detectable, while in Tetrahymena new $\mathrm{H} 3$ is acetylated at $\mathrm{H} 3 \mathrm{~K} 9$ and H3K14 but in Drosophila it is acetylated at H3K14 and H3K23 (Benson et al., 2006; Sobel et al., 1995). In yeast cells, newly synthesized H3 is mainly acetylated at lysine 56 (H3K56ac) (Masumoto et al., 2005).

In addition to $\mathrm{H} 3 \mathrm{~K} 56 \mathrm{ac}$, in yeast, newly synthesized $\mathrm{H} 3$ is acetylated at $\mathrm{H} 3 \mathrm{~K} 9$ and H3K27 (Kuo et al., 1996). Evidence shows that several lysine residues in the N-terminus of H3 (K9, K14, K18, K23, and K27) are important for nucleosome assembly (Li et al., 2008; Ma et al., 1998; Qin and Parthun, 2002).

It has been shown that histones carrying the H3K56ac co-purify with the histone chaperone Caf-1 and that $\mathrm{H} 3 \mathrm{~K} 56 \mathrm{ac}$ promotes chromatin assembly during the $\mathrm{S}$ phase of the cell cycle. This PTM is believed to enhance the ability of the HCs CAF-1 and Rtt106 to bind histone $\mathrm{H} 3-\mathrm{H} 4$ and then assemble them into nucleosomes. In S. cerevisiae deletion of either ASF1 or RTT109 as well as a mutation in H3K56 highly diminishes the co-purification of CAF-1 and Rtt106 (a histone chaperone) with H3. This suggests that H3K56ac is required for their binding. It was observed that Rtt106 and Cac1 (the large subunit of CAF-1) have stronger binding affinity 
to $\mathrm{H} 3-\mathrm{H} 4$ when they were hyper-acetylated in vitro. They bound unmodified $\mathrm{H} 3-\mathrm{H} 4$ to a lower extent $\mathrm{H} 3-\mathrm{H} 4$ which indicates direct interaction with H3K56ac. This data suggested that H3K56ac is required for H3-H4 assembly into chromatin by CAF-1 and Rtt106 (Chen et al., 2008 and $\mathrm{Li}$ et al., 2008). It has been postulated that the specific recognition of H3K56ac by CAF-1 and Rtt106 extends the "histone code" hypothesis (Strahl and Allis, 2000) to include nucleosome assembly (Fillingham and Greenblatt, 2008).

\subsection{H3K56}

Several groups have reported histone H3 Lysine 56 as a site for acetylation that controls gene expression in the budding yeast $S$. cerevisiae (Masumoto et al., 2005; Ozdemir et al., 2005, and $\mathrm{Xu}$ et al., 2005). This modification has been also reported in the fission yeast, Schizosaccharomyces pombe (Haldar and Kamakaka, 2008), in Drosophila (Xu et al., 2005) and in humans (Das et al., 2009). What makes Lysine 56 in H3 unique is its location in the nucleosome; It is the last amino acid residue of the $\alpha-\mathrm{N}$-helix terminal tail, which precedes the globular domain of histone H3. Furthermore, it has been shown that histone-DNA interaction at this entry and exit points (H3K56) in the nucleosome is weakened by H3K56 acetylation (Masamuto et al., 2005). H3K56ac is thought to promote transcription (Rufiange et al., 2007) and it is also involved in the response to DNA damage during nucleosome reassembly following repair and replication of DNA that is a result of DNA insults caused by DNA damaging agents (Miller et al., 2006, Haldar and Kamakaka, 2008). H3K56ac is found in the newly synthesized $\mathrm{H} 3$ until it is incorporated into the nucleosome and it persists until the $G_{2} / M$ where it is removed by the histone deacetylases Hst3 and Hst4 (Celic et al., 2006 and Masumuto et al., 2005). 
It has been shown that the binding of $\mathrm{H} 3$ with Rtt106 is barely detectable in cells that lack H3K56ac, whereas the association of $\mathrm{H} 3$ with CAF-1 is only reduced in cells lacking this modification suggesting that while H3K56ac is the only site for binding with Rtt106 other modifications on $\mathrm{H} 3$ may also regulate the binding of $\mathrm{H} 3$ with CAF-1 (Li et al., 2008). It was also shown that the function of H3K56ac in nucleosome assembly appears to be conserved in mammalian cells (Das et al., 2009).

H3K56ac is also present in, the protozoan T. themrophilla (Shahbazian et al., 2007). Recent mass spectrometry results have shown abundant H3K56ac on newly synthesized histones in Tetrahymena (Cosgrove, 2007). Initial Western blot (WB) data also shows localization of H3K56ac in the macronucleus of T. themrophilla (Garg and Pearlman, unpublished).

H3K56ac has shown to be a promising target for clinical applications. It has been found that the inhibition of the histone deacetylase enzymes induces hyperacetylation of histones, which causes cell cycle arrest and cell death in cancer cells but not in normal cells (Santini et al., 2007). In addition, yeast cells that lack or are deficient in H3K56ac age more rapidly and have shorter life spans (Dang et al., 2009). Furthermore, normal yeast cells have shown decreasing levels of H3K56ac as they age (Dang et al., 2009). It has also been shown that decreased H3K56ac levels lessens longevity in yeast (Feser et al., 2010).

Interestingly, the enzymology behind H3K56ac biology appears to be an effective target for anti fungal treatment; it has been shown that reduced levels of H3K56ac sensitize Candida albicans to genotoxic and antifungal agents. Targeted pharmacological alterations in Rtt109 (a fungal specific enzyme that catalyses the transfer of acetyl group to H3K56) resulted in reduced H3K56ac levels and thus reduced virulence in a mouse model with C. albicans infection. This could be applied to other yeast infections (Wurtele et al., 2010). 


\subsection{Enzymology behind H3K56}

The enzymatic reaction of acetylation is carried out by a histone acetyl transferase (HAT), which transfers an acetyl group from acetyl CoA to the target lysine residue. The acetyl residues are removed by a class of enzymes called Histone Deacetylases (HDACs) (Roth et al., 2001) HATs and HDACs function in multi-protein complexes that can posses different functions, including PTM and nucleosome remodeling activities, as well as interactions with gene activators and transcription factors (Naar et al., 2001). Furthermore, HATs can have directed activity against non-nucleosmal (free) or nucleosomal histones (Ohba et al., 1999).

\subsubsection{HATs and HDACs}

Several HATs have been identified among species. There are three major groups of HATs: GNATs (Gcn5-related N-acetyltransferases), p300 (E1A-associated protein of 300 kDa)/CBP (CREB-binding protein), and MYST proteins (Allis et al., 2007; Lee and Workman, 2007). The p300/CBP group is unique to metazoans such as humans (Goodman and Smolik, 2000). In humans H3K56 acetylation is mediated by CBP/p300 (Das et al.,2009), P/CAF (Nagy et al., 2007) and Gcn5 (Tjeertes et al., 2009).

HDACs are divided into the Rpd3/Hda1 and the Sirtuin families. In humans, the Sirtuins contains HDAC1, 2, 3 and 8 (class I is similar to yeast Rpd3), HDAC4, 5, 6, 7, 9 and 10 (class II is a homolog of yeast Hda1), and HDAC11 (class IV) (Yang and Seto, 2008). In the Sirtuin family, there are seven members in humans (SIRT1-7 which is related to yeast Sir2; also known as class III HDACs) (Haigis and Guarente, 2006). Both HATs and HDACs are catalytic subunit of multi protein complexes (Lee and Workman, 2007). 


\subsubsection{Rtt109}

In S. cerevisiae, H3K56ac is catalyzed by Rtt109 (Collins et al., 2007; Driscoll et al., 2007; Han et al., 2007) and is dependent upon the histone chaperone Asfl (Recht et al., 2006) (Figure 2). It has been suggested that Rtt109 specificity is determined in vivo by the histone chaperones it is using; H3-H4 or Rtt109 is altered by the chaperone in a manner that leads to a specific acetylation on $\mathrm{H} 3 \mathrm{~K} 9$ or H3K56 (Fillingham et al., 2008). It has been suggested that the K56 residue is exposed when $\mathrm{H} 3$ is bound to Asf1 (Antczak et al., 2006). Rtt109 itself could also be promoting its specificity supported by the fact that $\mathrm{H} 3 \mathrm{~K} 9$ and $\mathrm{H} 3 \mathrm{~K} 56$ are the only lysine residues in $\mathrm{H} 3$ to be followed by ST residues which could explain Rtt109 specificity of these sites and it can be explained why Rtt109 alone cannot acetylate H3K9 when bound to Asfl by that Asf1 could be having an inhibitory effect on Rtt109 (Fillingham et al., 2008). It has also been demonstrated that S. cerevisiae Rtt109 promotes genome stability and resistance to DNAdamaging agents, and does that by functionally cooperating with Asfl to maintain normal chromatin structure (Driscoll et al., 2007, Han et al., 2007)

\subsubsection{Vps75}

Vps75 is an H3-H4 histone chaperone that belongs to the Nap1 family (Selth et al., 2007). It has also been shown that Vps75 co-purfies with Rtt109. Vps75 is involved in stabilizing the HAT and is essential for H3K9ac by Rtt109 in vivo in S. cerevisiae (Fillingham et al., 2008) (Figure 2).

Deletion of VPS75 results in very slight decrease on H3K56ac levels during the S phase of the cell cycle and does not alter DNA sensitivity to genotoxic agents as deletion of ASF1 or RTT19 does (Han et al., 2007b) suggesting that the Rtt109-Vps75 complex functions 
independently from Asf1-dependent H3K56ac (Han et al., 2007 and Tsubota et al., 2007). Biochemical analyses of Vps75 has shown that it supplies Rtt109 with histone substrates and stimulate its HAT activity (Berndsen et al., 2008 and Park et al., 2008). Vps75 significantly enhances Rtt109 activity to acetylate H3K9, H3K23, and H3K27 (Burgess et al., 2010 and Fillingham et al., 2008). In the current understanding, Rtt109 requires both Asf1 and Vps75 to acetylate $\mathrm{H} 3 \mathrm{~K}$, whereas it only needs Asf1 to bind to the $\mathrm{H} 3-\mathrm{H} 4$ dimer to acetylate $\mathrm{H} 3 \mathrm{~K} 56$ (Fillingham et al., 2008).

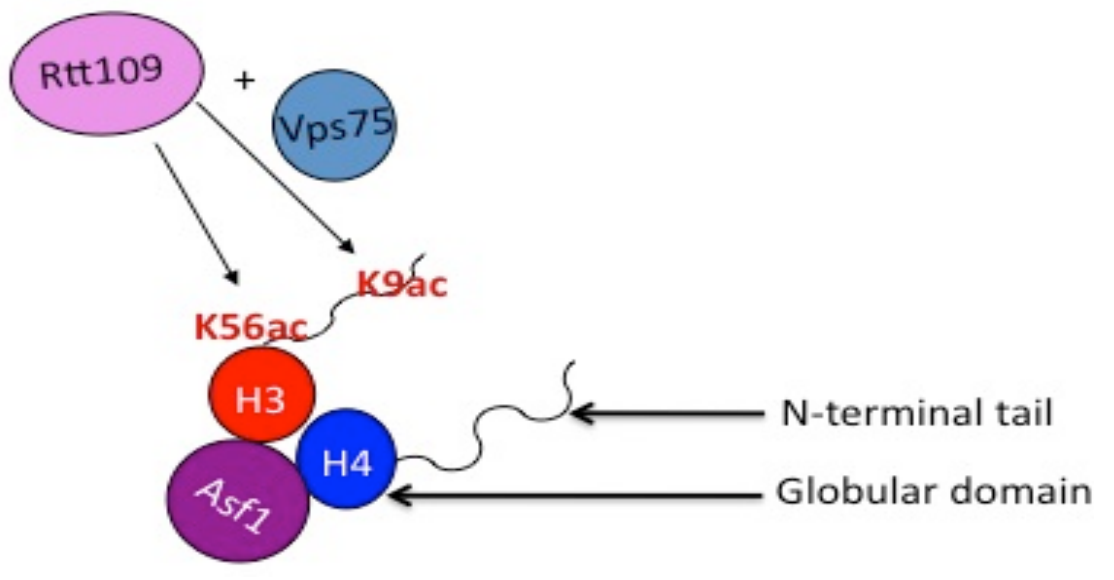

Figure 2: Model for Rtt109 and Asf1 in $\mathrm{H3}$ acetylation in S. Cerevisiae: Rtt109 acetylate both $\mathrm{H} 3 \mathrm{~K} 9$ and H3K56. It needs Asf1 to bind to $\mathrm{H} 3-\mathrm{H} 4$ dimer for both and needs Vps75 for $\mathrm{H} 3 \mathrm{~K} 9 \mathrm{ac}$ only.

Vps75 also has Rtt109-unrelated functions in chromatin dynamics that are related to transcription; analysis of epistatic miniarray profiles showed that VPS75 genetically interacts with factors involved in transcription regulation and additional genetic and biochemical experiments revealed a close relationship between Vps75 and RNAPII. In addition, Vps75 is recruited to activated genes in an Rtt109-independent manner. Furthermore, it has been shown that Vps75 might have a role in histone $\mathrm{H} 2 \mathrm{~A} / \mathrm{H} 2 \mathrm{~B}$ eviction/deposition during transcription. (Park et al., 2008 and Selth et al., 2009) 


\subsubsection{Hat1}

Hat1 is a member of the GNAT superfamily of HATs and is an evolutionary conserved protein. In S. cerevisiae it interacts with Asf1 and is part of a protein complex that includes Hat2 and Hif1 (Ai and Parthun, 2004 and Poveda et al., 2004). Hat1 is recruited by Asf1 to carry out H4K5/12ac, two marks that are associated with histone deposition into nucleosomes (Fillingham et al., 2008).

Homologs of Hat1 have been isolated from chicken, maize, Xenopus laevis, yeast and humans (Eberharter et al., 1996; Parthun et al., 1996 and Ahmad et al., 2000). Despite the fact that Hat 1 is highly conserved among eukaryotes, it is not essential for the viability of yeast and vertebrate cells, as are the acetylation marks at H4K5/12 (Ai and Parthun, 2004; Barman et al., 2006). Experiments have revealed that Hat1 also plays a role in telomeric silencing which needs both the catalytic activity of the enzyme and its sub-cellular localization (Kelly et al., 2000; Parthun, 2007). Interestingly, Hat1 has been shown to bind H3-H4 in the cytoplasm and then localize to the nucleus (Ejlassi-Lassallette et al., 2011) Furthermore, Hat1 is now known to bind in yeast nuclei to Hifl which is a histone chaperone that interacts specifically with $\mathrm{H} 3-\mathrm{H} 4$ (Ai and Parthun, 2004).

\subsubsection{Gen5}

The first transcription-related HAT to be identified was the Tetrahymena p55 protein which is a homologue of the $S$. cerevisiae Gen5 (Brownell et al., 1996). Gen5 was originally identified through genetic screens as a transcriptional co-activator in yeast (Grant et al., 1998) 
and before that in Tetrahymena which linked histone acetylation and transcriptional stimulation (Brownell et al., 1996).

Gcn5 is a subunit of several transcription regulatory complexes including SAGA, SLIK and ADA in yeast. All of these Gcn5-containing complexes regulate transcription. In $S$. Cerevisiae, Gcn5 has been shown to catalyze nucleosomal H3K9ac (Grant et al., 1999).

In vitro studies have shown that the activity and specificity of Gen5 is regulated by its associated complexes; recombinant yeast Gcn5 acetylates core histones on H3K9/18 but shows no activity on nuclesomal H3 (Kue et al., 1996), As a subunit of the SAGA complex however, Gcn5 can acetylate both free and nucleosomal H3K9/18 (Grant et al., 1999). On the other hand, the SAGA and ADA complexes acetylate both free and nucleosomal H3. While ADA acetylates K14 and K18 of nucleosomal H3, SAGA acetylates both nucleosmal K14 and K18 to a lesser degree as well as nucleosomal K23 and K9 (Grant et al., 1999). Cells lacking Gcn5 are sensitive to DNA damaging agents, which strongly suggests that Gcn5, in addition to its role in gene transcription, also has a role in DNA replication and DNA repair through acetylation (Choy and Kron, 2002; Tamburini and Tyler, 2005). It has been shown that cells lacking GCN5 are more sensitive to DNA damaging agents probably due to the loss of enzymatic activities of Gcn5 (Burgess et al., 2010). It has also been demonstrated that GCN5 genetically interacts with genes that are involved in DNA replication, DNA damage response, and nucleosome assembly. In addition, cells that have had GCN5 deleted or have been mutated at five lysine residues in the Nterminus of histone $\mathrm{H} 3$ (K9, K14, K18, K23, and K27) show decreased deposition of newly synthesized $\mathrm{H} 3$ into replicating DNA which indicates reduced binding of $\mathrm{H} 3$ to CAF-1. These results show that Gcn5 promotes nucleosome assembly by acetylating H3 lysine residues at the N-terminus which in turn contributes to the H3 binding with CAF-1 (Burgess et al., 2010). It has 
also been shown that Rtt109 and Gen5 are in parallel pathways for H3K9ac (Fillingham et al., 2008, Burgess et al., 2010). S. cerevisiae PTM enzymology is summarized in Table 1.

\begin{tabular}{|l|l|l|l|}
\hline Modification & H3K56ac & H3K18ac & H3K9ac \\
\hline Enzymes involved & Rtt109+Asf1 & Gcn5 & Rtt109-Vps75+Asf1 \\
& & & and Gcn5 \\
\hline
\end{tabular}

Table 1: PTM enzymology: PTM are shown with the enzymes required for acetylation in $S$. cerevisiae.

\subsection{T. thermophila as a model:}

Tetrahymena thermophila is a ciliated unicellular protozoan. This model organism is convenient for the molecular genetic study of several processes including telomere replication (Blackburn et al., 2006), RNA interference (Mochizuki K, 2010), and large scale genome rearrangements (Yao et al., 2005). In addition, over the years T. thermophila has been a vital model organism for chromatin research. As discussed before, p55 was identified as the protein responsible for HAT activity in a biochemical assay made possible by Tetrahymena's unique biology (Brownell et al., 1995). The p55 gene was then cloned and became the first gene identified encoding a HAT in any organism (Brownell et al., 1996). As stated earlier, the p55 gene was found by comparative sequence analysis to be homologous to yeast GCN5. As discussed earlier, the finding of a HAT by sequence comparison with known transcriptional activators linked histone acetylation to transcriptional co-activation (Brownell et al., 1996).

Tetrahymena thermophila has a dimorphic nuclei. It contains a transcriptionally active somatic macronucleus, which makes it a rich source of acetylated chromatin. The macronucleus is not inherited. T.thermophila also has a micronucleus that is inherited sexually and sexual 
reproduction can be induced by starvation (Elliot, 1973), thus making it a genetically and biochemically tractable model for several biological processes including meiosis and RNAi. (Yao and Chao, 2005)

Tetrahymena thermophila has abundant H3K56ac modification (Shahbazian et al., 2007) but comparative sequence analysis indicates that no gene exists in its sequenced genome homologous to either yeast RTT109, metazoan CBP/p300 or P/CAF (Karsou and Fillingham, unpublished). As discussed above, T. thermophila encodes p55/GCN5, a gene homologous to human Gcn5 which can catalyze H3K56ac in human cells (Tjeertes et al., 2009). In addition, Gcn5 catalyzes H3K9ac, a modification also catalyzed by Rtt109 in S.cerevisiae (Fillingham et al., 2008) and S. pombe (Radovani and Fillingham, unpublished). Gcn5 is highly conserved among eukaryotes, which suggests an important role for it in $\mathrm{H} 3$ acetylation.

\subsection{Research question and approach:}

The goal of my thesis research involves trying to characterize tGen5 activity in vitro and more specifically if it has H3K56ac activity, my main hypothesis is that it does. The enzymology behind H3K56ac has not been well characterized in any other organism other than yeast and humans.

To accomplish this I will determine if tGen5 can catalyze H3K56ac in vitro in the presence or absence of either tAsf1 or yAsf1. In addition, I am using molecular genetics to assess the degree to which tGen5 or tAsf1 can restore wild type functions of the respective mutant backgrounds in yeast. The goal of this research is to provide a basis to understand the phenotypic role of Gcn5 and Asf1 in yeast which will lead to further downstream genetic studies designed to assess the function of these important genes in Tetrahymena itself. If we find the H3K56 HAT in 
Tetrahymena we can start experiments to see if it has a role in DNA rearrangements, RNAi, or meiosis. 


\section{Chapter 2: Materials and methods}

\subsection{Media used:}

The composition of all growth media used is listed in table 2. All solutions are listed in table 3. Unless otherwise noted, all competent cells, enzymes, DNA ladders and reagents were acquired from New England Biolabs. Catalogue numbers are in parentheses. All small scale centrifugation (1.5 ml or less) were performed using a Sorvall MC 12V microcentrifuge. Large scale centrifugations ( $2 \mathrm{ml}$ to $50 \mathrm{ml}$ ) was performed using IEC Centra CL3 centrifuge.

Table 2. The composition of media used for culturing $E$. coli.

\begin{tabular}{|c|c|}
\hline Media & Contents \\
\hline SOB pH 7.0 (1L) & 20 g Bacto-tryptone \\
\hline SOC $(100 \mathrm{ml})$ & $\begin{array}{l}97 \mathrm{ml} \mathrm{SOB} \\
1 \mathrm{ml} 2 \mathrm{M} \text { glucose } \\
1 \mathrm{ml} 1 \mathrm{M} \mathrm{MgCl} \mathrm{Mg}_{2} \\
1 \mathrm{ml} 1 \mathrm{M} \mathrm{MgSO}_{4}\end{array}$ \\
\hline YT (1L) & 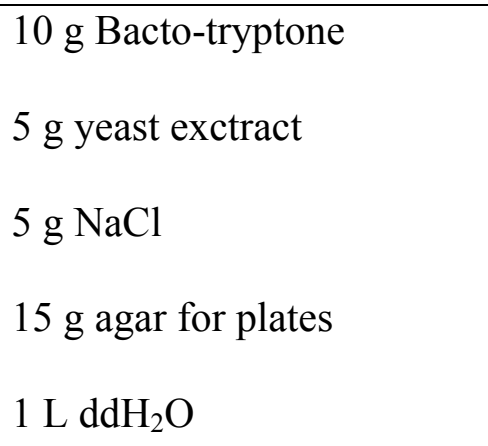 \\
\hline YT+ Ampicillin (402 ml) & $\begin{array}{l}400 \mathrm{ml} \mathrm{YT} \\
2 \mathrm{ml} \mathrm{Ampicillin}(10 \mathrm{mg} / \mathrm{ml})\end{array}$ \\
\hline YT+ Kanamycin $(402 \mathrm{ml})$ & $\begin{array}{l}400 \mathrm{ml} \mathrm{YT} \\
2 \mathrm{ml} \text { Kanamycin }(10 \mathrm{mg} / \mathrm{ml})\end{array}$ \\
\hline
\end{tabular}


Table 3: The composition of all solutions used.

\begin{tabular}{|c|c|c|}
\hline Method & Solution & Contents \\
\hline \multirow[t]{2}{*}{ Agarose Gel Analysis } & $\begin{array}{l}0.8 \% \text { Agarose Gel } \\
(50 \mathrm{ml})\end{array}$ & $\begin{array}{l}0.4 \mathrm{~g} \text { agarose in } 50 \mathrm{ml} 1 \mathrm{x} \\
\text { TEB (Microwave for } 2-3 \\
\text { minutes), } 5 \mu 1 \text { of Ethidium } \\
\text { Bromide } 5 \mu \mathrm{g} / \mathrm{ml}\end{array}$ \\
\hline & 10x TEB buffer $\mathrm{pH} 8.0(4 \mathrm{~L})$ & $\begin{array}{l}10 \mathrm{~g} \text { TRIS base } \\
5.5 \mathrm{~g} \text { Boric acid } \\
0.93 \text { EDTA } \\
4 \mathrm{~L} \mathrm{H}_{2} \mathrm{O} \\
\text { Add } \mathrm{HCl} \text { until } \mathrm{pH} \text { is } 8.0\end{array}$ \\
\hline \multirow{3}{*}{ Miniprep } & $\begin{array}{l}\text { Miniprep Solution } 1 \text { (400 } \\
\mathrm{ml})\end{array}$ & $\begin{array}{l}10 \mathrm{ml} \text { 1M TRIS pH } 8.0 \\
8 \mathrm{ml} 0.5 \mathrm{M} \text { EDTA } \\
9 \mathrm{ml} 40 \% \text { glucose } \\
373 \mathrm{ml} \mathrm{H}_{2} \mathrm{O}\end{array}$ \\
\hline & $\begin{array}{l}\text { Miniprep Solution } 2(10 \mathrm{ml}) \\
\text { (prepare fresh) }\end{array}$ & $\begin{array}{l}1 \mathrm{ml} 10 \% \text { SDS } \\
2 \mathrm{ml} 1 \mathrm{~N} \mathrm{NaOH} \\
7 \mathrm{ml} \mathrm{H}_{2} \mathrm{O}\end{array}$ \\
\hline & $\begin{array}{l}\text { Miniprep Solution } 3(500 \\
\mathrm{ml})\end{array}$ & $\begin{array}{l}147.2 \mathrm{~g} 3 \mathrm{M} \text { Potassium } \\
\text { Acetate } \\
120.1 \mathrm{~g} \text { Acetic Acid } \\
500 \mathrm{ml} \mathrm{H}_{2} \mathrm{O}\end{array}$ \\
\hline
\end{tabular}




\begin{tabular}{|c|c|c|}
\hline \multirow[t]{3}{*}{ Western Blotting } & $5 \%$ Blotto $(100 \mathrm{ml})$ & $\begin{array}{l}5 \mathrm{~g} \text { skim milk Powder } \\
100 \mathrm{ml} \text { TBS }\end{array}$ \\
\hline & $5 \%$ Stacking gel $(5 \mathrm{ml})$ & $\begin{array}{l}3.5 \mathrm{ml} \mathrm{H}_{2} \mathrm{O} \\
0.625 \mathrm{ml} \text { 1M TRIS } \mathrm{pH} 6.8 \\
0.95 \mathrm{ml} \text { Acrylamide } 29: 1 \\
0.05 \mathrm{ml} 10 \% \mathrm{SDS} \\
3.75 \mu 1 \mathrm{TEMED} \\
31.25 \mu \mathrm{l} 10 \% \text { APS }\end{array}$ \\
\hline & 10\% Running Gel $(15 \mathrm{ml})$ & 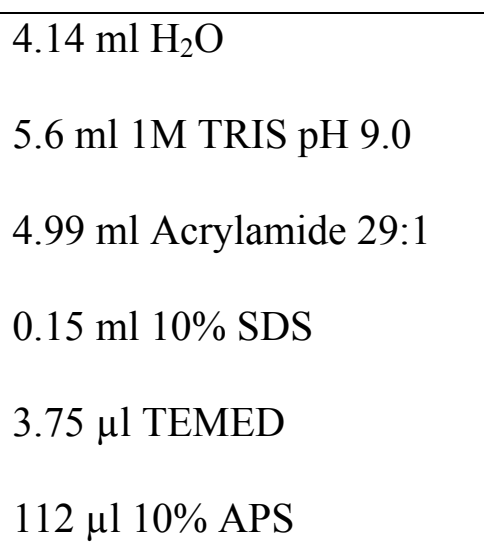 \\
\hline \multirow{3}{*}{$\begin{array}{l}\text { Continued } \\
\text { Western Blotting }\end{array}$} & $10 \%$ APS $(1 \mathrm{ml})$ & $\begin{array}{l}0.1 \mathrm{~g} \text { ammonium persulfate } \\
1 \mathrm{ml} \mathrm{H} \mathrm{O}\end{array}$ \\
\hline & $\begin{array}{l}\text { 2X SDS sample buffer } \\
(100 \mathrm{ml})\end{array}$ & $\begin{array}{l}3 \mathrm{~g} \mathrm{SDS} \\
5 \mathrm{ml} \text { betamercaptoethanol } \\
10 \mathrm{ml} 100 \% \text { glycerol } \\
6 \mathrm{ml} 2 \mathrm{M} \text { TRIS HCL pH } 6.8 \\
50 \mathrm{mg} \text { Bromophenol Blue } \\
\mathrm{H}_{2} \mathrm{O} \text { to } 100 \mathrm{ml}\end{array}$ \\
\hline & $\begin{array}{lll}5 \mathrm{x} & \text { TBS } & \text { (Tris-Buffered }\end{array}$ & $48.44 \mathrm{~g}$ Tris \\
\hline
\end{tabular}




\begin{tabular}{|l|l|l|}
\hline \multirow{5}{*}{$\begin{array}{l}\text { Continued } \\
\text { Western Blotting }\end{array}$} & Saline) & $\begin{array}{l}584.4 \mathrm{NaCl} \\
4 \mathrm{~L} \mathrm{dd} \mathrm{H}_{2} \mathrm{O} \\
\text { Add } \mathrm{HCl} \text { to } \mathrm{pH} 7.5\end{array}$ \\
\cline { 2 - 3 } & Running Buffer (4X) & $48 \mathrm{~g}$ TRIS \\
& $(4 \mathrm{~L})$ & $16 \mathrm{~g}$ SDS \\
& & $\mathrm{H}_{2} \mathrm{O}$ to $4 \mathrm{~L}$ \\
\cline { 2 - 3 } & Transfer Buffer (2L) & $400 \mathrm{ml}$ methanol \\
& & $6.05 \mathrm{~g}$ TRIS base \\
& & $28.84 \mathrm{~g}$ glycine \\
& & $\mathrm{H}_{2} \mathrm{O}$ to $2 \mathrm{~L}$ \\
\hline
\end{tabular}

\subsection{Sequence alignments:}

Protein sequences in FASTA format were obtained for all species from NCBI protein (http://www.ncbi.nlm.nih.gov/) and sequence alignment were run using CLASTALW (http://www.genome.jp/tools/clustalw/). The ALU format for the sequence alignments was then taken for the similar sequences and shaded using BOXSHADE (http://www.ch.embnet.org/software/BOX_form.html). Nuclear localization sequences were predicted using Expasy's ELM tool (http://elm.eu.org/). 


\subsection{E. coli transformation:}

DNA was transformed into DH5-alpha high efficiency competent cells (Lot\#C2987H). $20 \mu 1$ of DNA from ligation reaction, $5 \mu 1$ of pure DNA from supplier, or minipreps, were added to $50 \mu \mathrm{l}$ of competent cells. In all the cases the DNA concentration was around $1 \mu \mathrm{g} / \mathrm{dl}$. The cells were incubated for thirty minutes on ice, followed by a 60 seconds heat shock at $42{ }^{\circ} \mathrm{C}$. After an additional five minutes on ice, $950 \mu \mathrm{l}$ of SOC medium was added and the competent cells were shaken for one hour at $37^{\circ} \mathrm{C}$ to allow for initial expression of the antibiotic resistance marker. One hundred $\mu \mathrm{l}$ of competent cells were plated on YT+ antibiotic at thirty seven degrees overnight. To screen for positive colonies, single colonies were picked from the plate and were grown overnight in YT+ antibiotic broths at thirty $37^{\circ} \mathrm{C}$ for DNA analysis.

\subsection{DNA Isolation from E.coli ( Alkaline Lysis Miniprep Method):}

Twox1.5 $\mathrm{ml}$ E.coli cultures were centrifuged for one minute at $12,000 \mathrm{rpm}$. The supernatant was removed and $100 \mu \mathrm{l}$ of miniprep solution 1 was added to the cell pellet. Following vortexing, the mixture was incubated at room temperature for five minutes, $200 \mu 1$ of miniprep solution 2 was added followed by a five minute incubation on ice, and next $200 \mu 1$ of miniprep solution 3 added. After another five minute incubation on ice, the mixture was centrifuged at $12,000 \mathrm{rpm}$ for ten minutes to remove cellular debris. The supernatant was transferred to another Eppendorf tube and 95\% ethanol was added to precipitate the DNA. After a ten minutes incubation at room temperature, the mix was centrifuged at $12,000 \mathrm{rpm}$ for ten minutes. The supernatant was aspirated and the pellet was washed with $70 \%$ alcohol by adding and aspirating. The pellet is then dried out in a desiccator to dry any extra ethanol. The DNA was 
resuspended in $50 \mu \mathrm{l} \mathrm{H20}$. To remove RNA, $1 \mu 1$ of DNAase free RNAase $(10 \mathrm{mg} / \mathrm{ml})$ was added and then the mix was incubated for two hours at thirty seven degrees.

\subsection{DNA isolation from E. coli for sequencing:}

For small scale minipreps DNA was isolated from three ml cultures of E. coli using the Sigma GenElute Plasmid Miniprep Kit (PLN-701KT) according to the supplier's instructions.

\subsection{Enzymatic restriction digest:}

Plasmid DNA and insert DNA were digested with one unit of restriction enzyme/s per $\mu \mathrm{g}$ of DNA. For small scale digestions a total volume of $10 \mu 1$ was digested for one to two hours. Large scale digestions were done on a volume of $400 \mu 1$ and digested overnight. All restrictions reactions were incubated at the temperature specified by the supplier $\left(37^{\circ} \mathrm{C}\right.$ for $\mathrm{BamHl}$ and Xhol or $25^{\circ} \mathrm{C}$ for Smal).

\subsection{Gel electrophoresis:}

About 0.8 to $1.0 \%$ agarose gel were electrophoresed $100-120$ volts in TBE buffer. Gels were stained by adding Ethidium Bromide ( $0.1 \%$ of the total gel volume) and DNA bands were visualized using an Alpha Innotech FlourChem system in the Core Molecular Facility at York University.

\subsection{Ligation:}

Ligation reactions were performed using $1 \mu l$ (400 units) of T4 DNA Ligase (NEB\#M0202L) in a total volume of $20 \mu \mathrm{l}$ reaction. Equal molar amounts of both DNA 
fragments and plasmid DNA to be ligated were added to the mix and the reactions were incubated at $16{ }^{\circ} \mathrm{C}$ overnight. The next morning the ligation mix was used to transform DH5 alpha cells.

\subsection{PCR "Polymerase Chain Reactions":}

PCR reactions were done in $50 \mu \mathrm{l}$ volumes with $0.5 \mu \mathrm{l}$ (2.5 units) of Phusion Polymerase (NEB, F-530L). Forward and Reverse primers were obtained from Invitrogen. The sequences for primers used are mentioned in the supplemental information.

\subsection{Purification of DNA:}

PCR products as well as DNA from enzymatic reactions "Digestions" were purified using Sigma GenElute PCR Clean-up kit (NA1020-1KIT). DNA extraction from agarose gels were performed using Sigma GenElute Gel Extraction Kit (NA1111-1KIT).

\subsection{Genomic DNA extraction from $S$. cerevisiae:}

Approximately $1.5 \mathrm{ml}$ of dense overnight culture was centrifuged and the supernatant was aspirated off. The pellets were washed in two hundred $\mu \mathrm{lddH_{2 }} O$. The cells were then resuspended in $200 \mu \mathrm{l}$ of solution A (1 M Sorbitol, $100 \mathrm{mM}$ Na citrate $\mathrm{pH}$ 7.0, $60 \mathrm{mM}$ EDTA, $0.1 \mathrm{M} \beta$-mercaptoethanol, and $1 \mathrm{mg} / \mathrm{ml}$ zymolase) and incubated for 30 minutes at $37^{\circ} \mathrm{C}$ to break down the cell wall. $700 \mu \mathrm{l}$ of solution B (0.5\% SDS, $100 \mathrm{mM}$ Tris-HCL pH 8.0 and $50 \mathrm{mM}$ EDTA) was then added to break down the cells. The mixture was then vortexed briefly and incubated at $70{ }^{\circ} \mathrm{C}$ for 20 minutes and then allowed to cool down at room temperature. $200 \mu \mathrm{l}$ of fresh $5 \mathrm{M}$ Pottassium acetate was then added to precipitate all proteins and was centrifuged at 
$12,000 \mathrm{rpm}$. The supernatant was then treated in 2:1 of ice-cold $100 \%$ ethanol. Next the tube was incubated at $-80{ }^{\circ} \mathrm{C}$ for 30 minutes to precipitate nucleic acid. The DNA was then pelleted on at $12,000 \mathrm{rpm}$ for 15 minutes and washed with $750 \mu \mathrm{l}$ of ice cold $70 \%$ ethanol. Next the DNA was vacuum dried for 15 minutes. The DNA was then treated with $500 \mu 1$ of Phenol/chloroform/isoamyl alcohol 25:24:1. Next the tube was pelleted and the upper aqueous phase was obtained. This step was repeated twice. $10 \%$ of the volume was then added with $3 \mathrm{M}$ Na-acetate and two times of $100 \%$ ice cold ethanol and incubated for 30 minutes in $-80{ }^{\circ} \mathrm{C}$. Next the tube was centrifuged and the precipitated DNA was vacuum dried for 15 minutes. The DNA was then resuspended in $200 \mu 1$ of ddH2O.

\subsection{Yeast transformation:}

Cells were grown overnight to saturation. The next morning they were diluted $1 / 20$ and grown to about $1 \mathrm{OD}_{600}$. Approximately $50 \mathrm{ml}$ were pelleted, washed in $10 \mathrm{ml} \mathrm{ddH2O}$, and then washed in $1 \mathrm{ml}$ of $0.1 \mathrm{M}$ Lithium acetate before being resuspended in $400 \mu 1$ of $0.1 \mathrm{M}$ Lithium acetate.

$50 \mu 1$ of the mixture is then taken for transformation and pelleted. To the pellet the

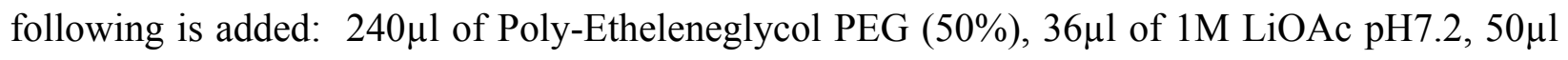
of Salmon Sperm (pre boiled and diluted 1:5) $45 \mu 1$ of sterile ddH2O $5 \mu 1(1 \mu \mathrm{g})$ of plasmid DNA. The tube is vortexed for 1 minutes and placed at $30^{\circ} \mathrm{C}$ for $20 \mathrm{~min}$. After the incubation $40 \mu 1$ of $10 \%$ DMSO is added and the cells are incubated at $42{ }^{\circ} \mathrm{C}$ for $10 \mathrm{~min}$. After second incubation cells are spinned down for 10 seconds at $12,000 \mathrm{rpm}$. The supernatant is removed and cells resuspended in $250 \mu \mathrm{l}$ of sterile ddH2O. The whole volume of the tube is then spread plated onto LEU plates. 


\subsection{Spot tests:}

Yeast cells were grown overnight to saturation. The next morning they were diluted to $0.1 \mathrm{OD}_{600}$ for fast growing cells $(+\mathrm{yASF} 1, \mathrm{yASF} 1 \mathrm{~N},+\mathrm{yGCN} 5,+\mathrm{RTT109}$, single mutants and wild type) and $0.25 \mathrm{OD}$ for slow growing cells (+tASF1, +tASF1N, tGCN5 and double mutants). Cells were then grown to $0.5 \mathrm{OD}_{600}$. Serial dilutions of $1 / 5,1 / 25$ and $1 / 125$ were made in -LEU media. For each strain $5 \mu \mathrm{l}$ of undiluted as well as diluted culture was inoculated in the plate, dried and incubated at $30^{\circ} \mathrm{C}$ for 48 hours and 72 hours.

\subsection{Yeast harvesting and whole cell extract:}

Cells were grown overnight at $30{ }^{\circ} \mathrm{C}$. In the morning the cells were diluted 1:20 and grown to mid $\log$ phase, approximately $0.5 \mathrm{OD}_{600}$. Equal $\mathrm{OD}_{600}$ were then collected and centrifuged. The cells were re-suspended in $10 \mathrm{ml} 20 \%$ TCA, pelleted, and flash frozen in dry ice or liquid nitrogen and kept at $-80{ }^{\circ} \mathrm{C}$ for later use. The cells were then re-suspended in $250 \mu \mathrm{l}$ of $20 \%$ TCA and $350 \mu \mathrm{l}$ of glass beads were added. Next the cells were lysed by hand-vortexting for 1 minute, 4 times with a 1 minute break on ice in between. The whole cell extract was then collected by centrifugation and the beads were washed one more time with $5 \%$ TCA. The precipitated protein is then resuspended in $250 \mu \mathrm{l}$ SDS-PAGE loading buffer and $50 \mu 1$ un-phed Tris buffer.

\subsection{Western Blotting:}

The whole cell extract of yeast was resuspended in a volume of 2x SDS and was then boiled for 5 minutes. $20 \mu \mathrm{l}$ of sample was electrophoresed through an SDS polyacrylamide gel 
(SDS-PAGE), transferred to a nitrocellulose membrane overnight, and blocked in 5\% Blotto. The blots were incubated in primary antibody (diluted according to manufacturer data) in $10 \mathrm{ml}$ of Blotto for one hour at room temperature. Next the blots were washed three time in TBS and at room temperature with 5 minutes for each wash. Next the blots were incubated with horseradish peroxidase-conjugated secondary antibody in PBS for one hour at room temperature. The blots were then washed three times in TBS, again at room temperature with five minutes for each wash. Finally, the blots were visualized using Denville Scientific's HyGLO Chemiluminescent HRP AntiBody detection Kit (E2500) as per the manufacturer's instructions.

\subsection{Protein expression induction:}

Colonies that contained clones of the desired genes were confirmed by gel electrophoresis after restriction digestion. The colonies that contained the inserts were grown in LB+Kanamycin overnight. Then next morning a new culture was inoculated in $\mathrm{LB}+\mathrm{KAN}$ media to $0.05 \mathrm{OD}_{600}$ by diluting the overnight culture 1:100. The culture was then grown to $0.5 \mathrm{OD}$. At 0.5 OD the time zero (t0) control sample was obtained, by centrifuging and freezing the cell pellet at $-80{ }^{\circ} \mathrm{C}$ for next processing. IPTG was then added to a final concentration of $1 \mathrm{mM}$ ( by using $100 \mathrm{mM}$ stock solution) to induce expression. Samples were obtained at $4 \mathrm{~h}$ after induction.

For all samples: $1.5 \mathrm{ml}$ of media was pipetted in Eppenndorf tubes, spun for $1 \mathrm{~min}$ to pellet cells. The supernatant was then aspirated, the pellet was frozen on dry ice and then stored - 80 for further processing (SDS-PAGE or Western Blotting). Note: It was attempted to obtain the same amount of cells in every tube i.e. for $t 0,1.5 \mathrm{ml}$ at $\mathrm{OD}_{600} 0.5=0.75$ total $\mathrm{OD}_{600}$. The $\mathrm{OD}$ was measured at each point of collection. For example at time $4 \mathrm{~h}$ if the OD is 0.75 only $1 \mathrm{ml}$ will be taken to obtain a total of $0.75 \mathrm{OD}_{600}$. 
When ready to run gel (10\% SDS-PAGE) pellets were thawed briefly on ice. Next, $100 \mu 1$ of 1x SDS-PAGE buffer (made fresh) was added and pipetted up and down on ice to resuspend pellet. The samples were boiled for 10 minutes and loaded on the gel.

\subsection{Nickel agarose affinity chromatography (protein purification):}

Purification was done under native conditions. Transformed bacterial cells (BL21 E. coli) were grown overnight to saturation in terrific broth (Sigma). Cells were then diluted 1:20 in the same media and grown to $1.0 \mathrm{OD}_{600}$ and then IPTG added to $1.0 \mathrm{mM}$. Cells were then incubated at $30{ }^{\circ} \mathrm{C}$ for 2 hours, then $24{ }^{\circ} \mathrm{C}$ and then for 4 hours and at $16^{\circ} \mathrm{C}$ overnight. The next morning the cells were harvested by centrifugation and re-suspended in $40 \mathrm{ml}$ of binding buffer $(5 \mathrm{mM}$ imidazole, $500 \mathrm{mM} \mathrm{NaCl}, 50 \mathrm{mM}$ Tris- $\mathrm{HCl} \mathrm{pH} 8.0,0.5 \mathrm{mM}$ phenylmethylsulfonyl fluoride and $1 \mathrm{mM}$ benzamadine). The suspension was then sonicated 12 times with 8 seconds on, 15 seconds off intervals on ice. The mixture was then centrifuged and the supernatant was added to $5 \mathrm{ml}$ of packed nickel beads equilibrated in binding buffer and rotated at $4{ }^{\circ} \mathrm{C}$ for 30 minutes. The mixture was then passed through a column. The remaining beads were washed once with binding buffer and once with wash buffer $(25 \mathrm{mM}$ imidazole, $500 \mathrm{mM} \mathrm{NaCl}, 50 \mathrm{mM}$ Tris- $\mathrm{HCl} \mathrm{pH} 8.0$, $0.5 \mathrm{mM})$. Next beads were eluted with elution buffer $(250 \mathrm{mM}$ imidazole, $500 \mathrm{mM} \mathrm{NaCl}, 50 \mathrm{mM}$ tris-HCL pH 8.0, $0.5 \mathrm{mM}$ phenylmethylsulfonyl fluoride and $1 \mathrm{mM}$ benzamadine) until Bradford analysis of the elute was almost negative. The elute was then dialyzed for six hours in dialysis buffer $(10 \mathrm{mM}$ Tris-HCl pH 7.9, 0.1\% Triton X-100, $0.5 \mathrm{mM}$ DTT, $0.2 \mathrm{mM}$ EDTA, 20\% glycerol, $100 \mathrm{mM} \mathrm{NaCl})$. 


\subsection{HAT assays:}

HAT assays were performed using either chicken core histones or T.thermophila histones. HAT assays were done by incubating for 30 minutes at $30^{\circ} \mathrm{C}$ in a $30 \mu \mathrm{l}$ volume containing $3 \mu \mathrm{g}$ core histones as substrate and $5 \mu \mathrm{l}(2 \mu \mathrm{g})$ aliquots of nickel affinity-purified recombinant protein in HAT assay buffer (50 mM Tris- $\mathrm{HCl} \mathrm{pH} 7.5,50 \mathrm{mM} \mathrm{NaCl}, 5 \mathrm{mM} \mathrm{MgCl}, 1 \mathrm{mM}$ dithiothreitol, $0.1 \mathrm{ug}$ acetyl-CoA and $1 \mathrm{mM}$ phenylmethylsulfonyl fluoride). Reactions were stopped by addition of $30 \mu 12 x$ sodium dodecyl sulfate-polyacrylamide gel electrophoresis (SDS-PAGE) loading dye and boiled. Aliquots (20\% of total volume) were run on several $15 \%$ SDS-PAGE gels. One gel was fixed and stained with Coomassie blue, whereas the other gels were transferred to nitrocellulose for Western blots analysis.

\subsection{Macronuclei isolation from T. thermophila:}

This method was adopted from Gorovsky et al., (1975) T. thermophila cells are grown to about $2 \times 10^{5} / \mathrm{ml}$ and then starved in $10 \mathrm{mM}$ tris-HCL buffer $\mathrm{pH}: 7.5$ overnight. The cells are then harvested by centrifugation. Next the cells were re-suspended in $10 \mathrm{ml} \mathrm{ddH2O}$ and then washed with $100 \mathrm{ml}$ of nuclei wash solution $\left(1 \mathrm{mM} \mathrm{MgCl}_{2}, 0.25 \mathrm{M}\right.$ sucrose, $10 \mathrm{mM}$ Tris- $\mathrm{HCl} \mathrm{pH} 7.5$, $\left.3 \mathrm{mM} \mathrm{CaCl}_{2}\right)$. Protease inhibitors were added at this step $(0.1 \mathrm{mM}$ AEBSF, $10 \mathrm{uM}$ leupeptin, 1 $\mathrm{uM}$ Pepstatin). The cells were then re-suspended in nuclei isolation medium A ( $2 \mathrm{mM} \mathrm{MgCl}_{2}$, 0.1 M Sucrose, $10 \mathrm{mM}$ Tris-HCl pH 6.75, 4\% Gum Arabic). Protease inhibitors were added as above. The cells were then put into a Warring blender and Octanol was added to $1 \%$. The cells were blended 3 times for 30 seconds and chilled for 20 seconds on ice between each blend. EDTA was then added to the mixture to a final concentration of $8 \mathrm{mM}$. The mixture was then 
blended again for another 20 seconds and the yield was checked using methyl green stain. Next the mixture was centrifuged and the supernatant discarded. The pelleted macronuclei were resuspend in $5 \mathrm{ml}$ of medium A with no octanol.

\subsection{Histone purification from T. thermophila:}

Core histones were purified from T. thermophila macronuclei (Macs). The Macs isolation is described later. Purified Macs $\left(1 \times 10^{6}\right)$ were re-suspended to $0.2 \mathrm{M} \mathrm{H}_{2} \mathrm{SO}_{4}$ (or $0.4 \mathrm{~N}$ ) in about 1 $\mathrm{ml}$ and rotated at 4 degrees overnight. In the morning the tube was centrifuged at $13500 \mathrm{rpm}$ at 4 ${ }^{\circ} \mathrm{C}$ for 15 minutes. The supernatant was transferred to a new tube; the core histones are part of the $\mathrm{H}_{2} \mathrm{SO}_{4}$ acid soluble fraction now. $100 \%$ trichloroacetic acid was added to $20 \%$ final concentration (100ul 100\% TCA per 400ul H2SO4 acid supernatant), the tube is then mixed by inversion, and then chilled on ice for 2 hours. Next the tube is spun at $13500 \mathrm{rpm}$ at $4{ }^{\circ} \mathrm{C}$ for 15 minutes; core histones are now part of the pellet so the supernatant was removed and the pellet was then washed with $500 \mu 1$ cold, acidified acetone (0.024M HCL in acetone) to get rid of the TCA. The tube was then spun in $13500 \mathrm{rpm}$ at $4{ }^{\circ} \mathrm{C}$ for 15 minutes and the supernatant was removed. The pellet was then washed once with $500 \mu 1$ cold acetone to get rid of the HCL. Next the tube was spun as above and the supernatant was completely removed. The remaining acetone was evaporated in a vacuum desiccator and the histone pellet was resupended in $200 \mu \mathrm{ddH} 2 \mathrm{O}$ and analysed by SDS-PAGE and WB. 


\subsection{Histone Binding assay:}

In Vitro histone binding was done using chicken core histones as well as T.thermophila core histones. The enzymes were incubated with histones in assay buffer (50 mM Tris- $\mathrm{HCl}(\mathrm{pH} 7.5)$, $500 \mathrm{mM} \mathrm{NaCl}, 5 \mathrm{mM} \mathrm{MgCl}$, $1 \mathrm{mM}$ dithiothreitol, $0.5 \mathrm{mM}$ phenylmethylsulfonyl fluoride and $1 \mathrm{mM}$ benzamadine). Approximately $50 \mu \mathrm{g}$ of histone and $100 \mu \mathrm{g}$ of enzyme were added to a total of $750 \mu 1$. The mixture was then rotated at $30^{\circ} \mathrm{C}$ for 30 minutes. Then $50 \mu 1$ was obtained for input and $20 \mu 1$ of packed nickel beads were added to the remaining mixture followed by a 15 minutes rotation at $4{ }^{\circ} \mathrm{C}$. Next, the beads were washed four times with the assay buffer. The sample was then eluted by boiling the beads in 0.1 M EDTA SDS loading buffer. The eluant was run on $15 \%$ SDS-PAGE and then stained with Commassie blue, protein silver stain or transferred to Nitrocellulose for western blots as needed. 


\section{Chapter 3: Results}

\subsection{Conservation of Asf1 and Gen5 between humans, yeast and T. thermophila :}

Rtt109 is the fungal H3K56 HAT (Fillingham, 2008). In humans p300/CBP (Das et al., 2009) and Gen5 (Tjeertes et al., 2009) are H3K56 HATs. Since T.thermophila appears to encode a homologue only of Gen5 and not Rtt109 or p300/CBP (Karsou and Fillingham, unpublished) we began our analysis with tGcn5. I obtained the Gcn5 amino acid sequences of several species from the NCBI protein database and performed comparative sequence alignments as outlined in materials and methods. Gen5 is very well conserved among eukaryotes (Figure 3). Using the BLASTP function from NCBI (http://blast.ncbi.nlm.nih.gov/Blast.cgi) and by comparing tGen5 with Gcn5 of several species I have calculated the similarity of Gen5 of examined species with the entire region of tGen5 (Table 4). I also used Expasy's ELM tool (http://elm.eu.org/) to predict the nuclear localization signal of each sequence.

\begin{tabular}{|l|l|}
\hline Species & Percentage of similarity with entire region of tGcn5 \\
\hline T. thermophila & $100 \%$ \\
\hline H.sapiens & $85 \%$ \\
\hline G.gallus & $85 \%$ \\
\hline M.musculus & $85 \%$ \\
\hline D.melanogaster & $84 \%$ \\
\hline S.cerevisiae & $83 \%$ \\
\hline S.pombe & $88 \%$ \\
\hline P.tetraurelia & $88 \%$ \\
\hline
\end{tabular}

Table 4: Similarity of Gen5 of indicated species with the entire region of tGen5: FASTA amino acid residue sequences were obtained from NCBI protein database and comparative sequence analyses were performed using BLASTP from NCBI. 
Gen5 [H, sapiens] Gens (M, museulus) Gens (g.gallus) Gen5 (D, mel anogaster gens (s, cerevisiae) gens (s, poebe) Gen5 (T, thermophila) Gens(D,tetraurelia)

Gen5 [H, sapiens] Gens (M, musculus) gens (0.gallus) gens (D, melanogaster) gens $(s$, cereyisiae Gens (s, poube) Gens (T, thermophila) gens (P,tetraurelia)

Gen5 [1, sapiens] Gens (M, enusculus) gens (G.gallus) Gens (D. melanogaster) gens (s, cerevisiae) Gens (s, posbe) GenS (T, thermophila) Gens (D, tetraurelia)

Gen5 (H, sapiens) Gens (M, musculus) Gcns (0,gallus) Gens (D. melanogaster) gens (s, cerevisiae) Gens (s, posbe) gens (T, thermophila) gens (P, tetraure1ia)

Gen5 (H, sapiens) Gens (M, nusculus) Gen5 [0,gallus] Gens (D.melanogaster gens (s, cerevisiae) Gens (s, posbe) Gen5 (T, thermophila) Gens (D, tetraurelia)

Gen5 (H, sapiens) Gen5 (M, museulus) Gens (0.gallus) gens (D, nelanogaster) Gen5 (s, cerevisiae) Gens (s, pombe) GenS (T, thermophila) Gens (D,tetraurelia)

Gen5 (II, sapiens) gens (M, museulus) Gens (G.gallus) Gens (D, melanogast er) cens (s, cerevisiae) gens 5 (s, posbe) Gen5 (T, thermophila) Gens (P, tetraurelia)

Gen5 (H, sapiens) Gen5 (M, musculus) Gen5 [0,gat1us] Gen5 (D. melanogaster) Gens (s, cerevisiae) Gen5 (s, pombe) Gen5 (T, thernophila) Gens (P, tetraurelia)
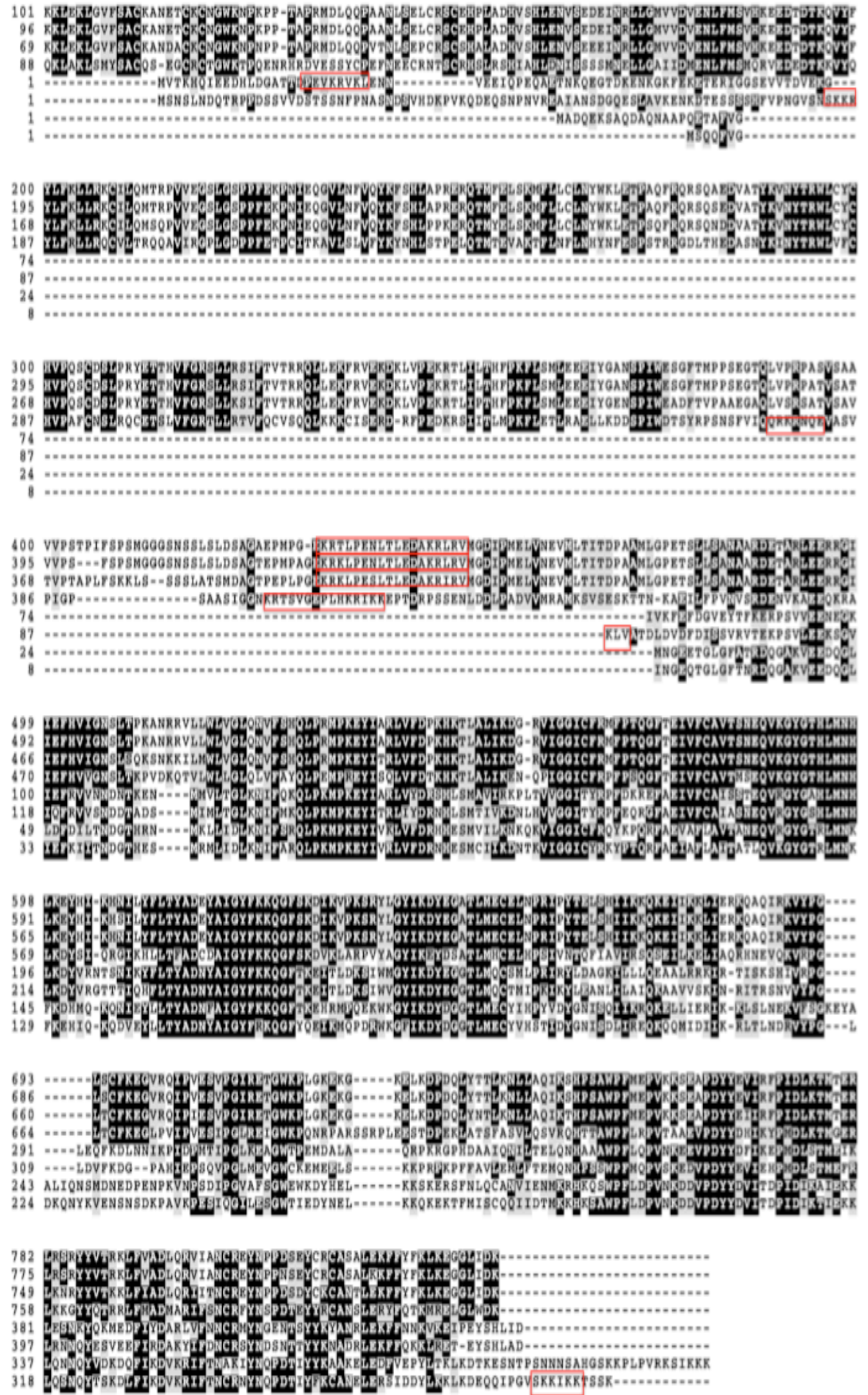

Figure 3:. Gen5 structure is well conserved among eukaryotes: Continues on next page. 
Figure 3: Gen5 primary structure is well conserved among eukaryotes: Gen5 amino acid sequences were obtained for the species shown and sequence alignment is obtained using CLASTALW (http://www.genome.jp/tools/clustalw/). Aligned amino acid residues are shaded using BOXSHADE (http:/www.ch.embnet.org/software/BOX form.html) Black: identical amino acid residues, Grey: Similar amino acid residues. NLSs are predicted using Expasy's ELM tool (http://elm.eu.org/) and are within red rectangles.

Yeast Asf1 functions with the HAT Rtt109 to acetylate H3K56 (Fillingham et al., 2008). In order to discover if tAsf1 has a similar role, I similarly obtained Asf1 amino acid sequences and performed comparative sequence alignments using both the entire region and $\mathrm{N}$-terminal domains (Figure 4). I have found that tAsf1 is very well conserved at its N-terminal domain but not in the C-terminal domain (Table 5), similar to what is known for other organisms. Sequence alignment and domains and of Asf1 for several species as wells as yeast H3-H4 binding sites are shown in Figure 4. I also used Expasy's ELM tool (http://elm.eu.org/) to predict the nuclear localization signal of each sequence. 


\begin{tabular}{|l|l|l|}
\hline Species & Percentage of similarity with & Percentage of similarity within N- \\
entire region of tAsf1 & terminal domain of tAsf1 (tAsf1N) \\
\hline T. Thermophila & $100 \%$ & $100 \%$ \\
\hline H.sapiens Asfla & $85 \%$ & $99 \%$ \\
\hline H.sapiens Asflb & $75 \%$ & $99 \%$ \\
\hline G.gallus & $85 \%$ & $99 \%$ \\
\hline M.musculus & $85 \%$ & $99 \%$ \\
\hline D.melanogaster & $70 \%$ & $99 \%$ \\
\hline S.cerevisiae & $56 \%$ & $99 \%$ \\
\hline S.pombe & $60 \%$ & $99 \%$ \\
\hline P.tetraurelia & $76 \%$ & $100 \%$ \\
\hline
\end{tabular}

Table 5: Similarity of the entire region and N-terminal domain of indicated species with tAsf1: FASTA amino acid sequences were obtained from NCBI protein database and comparative sequence analyses were performed using BLASTP from NCBI. 
Asfla[H.sapiens]

Asf1[G.gallus]

Asf 1 [M. musculus]

Asf 1 b [H.sapiens]

Asf 1 [D.melanogaster]

Asf 1 [S.cerevisiae]

Asf 1 [S. pombe]

Asf1 [T. thermophilla]

As 1 [P.tetraurelia]

Asfla[H.sapiens] Asf 1 [G.gallus]

As $f 1$ [M.musculus]

As $f$ lb [H.sapiens]

As 1 [ D.melanogaster]

Asf1 [S.cerevisiae]

Asf 1 [S. pombe]

Asf 1 [T. thermophilla]

Asf1[P.tetraurelia]

Asf 1 a [H.sapiens] Asf 1 [G.gallus]

Asf 1 [M.musculus]

Asf 1 b [H.sapiens ]

Asf 1 [D.melanogaster]

Asf 1 [S.cerevisiae]

Asf 1 [S.pombe]

As 1 [ T . thermophilla]

Asf 1 [P.tetraurelia]
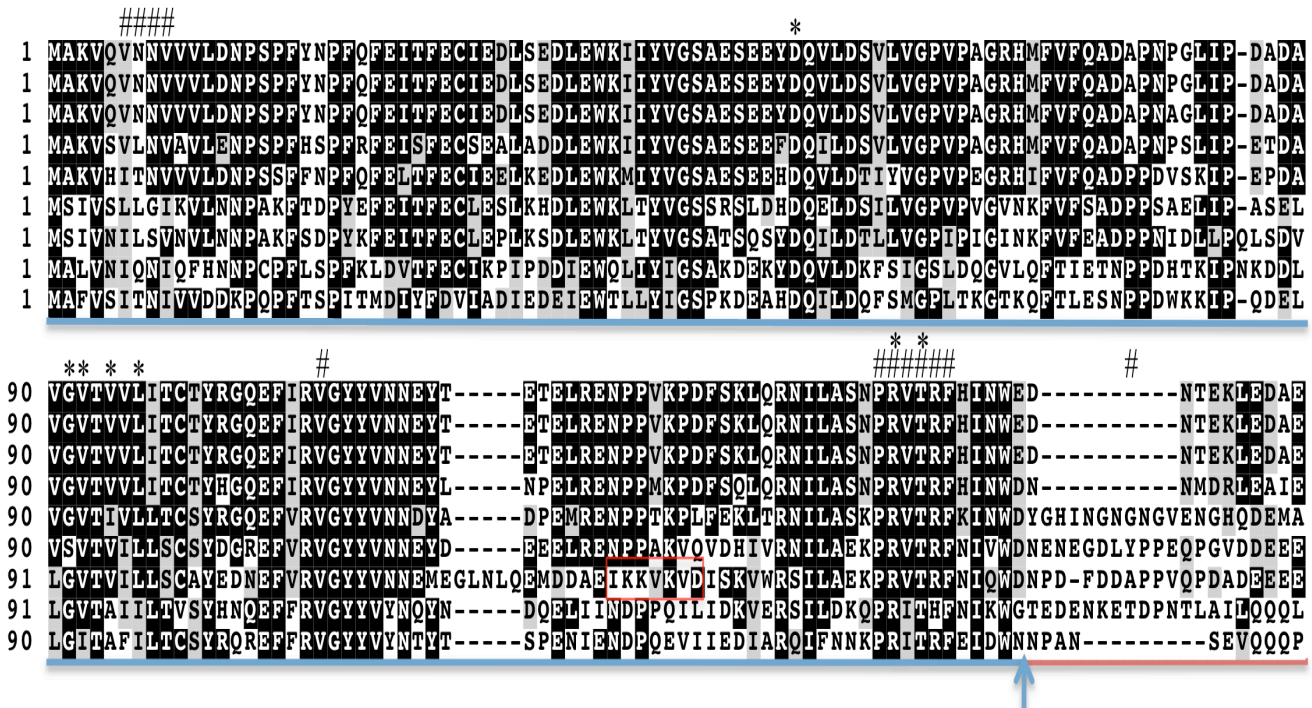

165 SSNPNLQSLITSTDALPSASKGWSTSENSLNVMLESHMDCM-

165 SSNPNLQSLLSTDALPSASKGWSTSENSLNVMLESHMDCM-

165 SSNPNLOSLLSTDALPSASKGWSTSENSLNVMLESHMDCM-

165 TQDPSLGCGIPLNCTP--IKGLGLPGCIPGLLPENSMDCI

175 TDGPSTSEAASAVI HPEDDNSLAMPMENGIKALNENSNSLAMEC

175 EDDEEEDDDEDDEDDEDDDQEDGEGEAEEAAEEREEEEEKTEDNETNLEEEEEDIENSDGDEEEGEEEVGSVDKNEDGNDKKRRKIEGGS

180 EEEADEMEEEFDEEGEGDEEEEEEDDGDGDGEGDGDGEGENDGKGSEEEEEEE----IDIEEEEEESALANASAAEEKPEEKPETSQ---

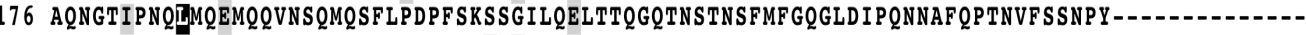

166 IQTKAYMFQEQQERQSADATEVYDAPHQIQNVFDS-

Asfla[H.sapiens]

Asf 1 [G.gallus]

Asf 1 [M. musculus]

As $f 1 b[$ H.sapiens]

Asf 1 [D.melanogaster]

Asf 1 [S.cerevisiae]

Asf 1 [S. pombe]

Asf 1 [T. thermophilla]

Asf 1 [P.tetraurelia]

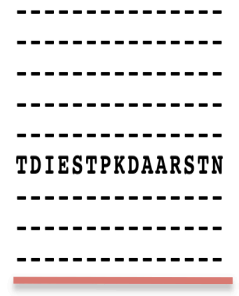

$\uparrow=$ AsflN ends $=$ Highlights the N-terminal domain - Highlights the C-terminal domain

Figure 4: Asf1 is very well conserved at its $\mathbf{N}$-terminal domain: Asf1 amino acid sequences were obtained for the species shown and sequence alignment is obtained using CLASTALW (http://www.genome.jp/tools/clustalw/). Aligned amino acid residues are shaded using BOXSHADE (http://www.ch.embnet.org/software/BOX form.html) Black: identical amino acid residues, Grey: Similar amino acid residues. NLS's are predicted using Expasy's ELM tool (http://elm.eu.org/) and are within red rectangles. AsflN ends are shown in blue arrows. Nterminal highly conserved domain is shown underscored in blue. C-terminal domain is underscored in red. *Residues of yAsf1 involved in interaction with $S$. cerevisiae H3. \# Residues involved in interaction with S. cerevisiae H4. (Reference: Antczak et al., 2006; English et al., 2006) 


\subsection{Construction of T. thermophila synthetic genes (tGCN5,tASF1):}

We constructed synthetic genes for tASF1 and tGCN5. It was previously shown that $T$. thermophila has a slightly different genetic code than the universal genetic code (Horowitz and Gorovsky, 1985). In T. thermophila the TAA and TAG codons specify for glutamic acid (Q), while in the universal genetic code they specify stop codons. Therefore, in order to express $T$. thermophila proteins in bacteria or yeast TAA has to be changed to CAA and TAG changed to CAG. One method to do this is site directed mutagenesis. However, with the 18 codons to change in tASF1 (Figure 5, top sequence) and 21 codons to change in tGCN5 (Figure 6, top sequence) it was easier and cheaper to construct synthetic genes by sending changed cDNA sequences for tASF1 and tGCN5 to GENESCRIPT. Predicted cDNA gene sequences for tASF1 and tGCN5 were obtained from the Tetrahymena genome database (www.cilliate.org) and then modified in silico to produce cDNA sequence that E.coli and Saccharomyces cerevisiae are able to translate (Figure 5 and 6 , bottom sequences). 
Nucleotide 001-120/Amino acid 001-040

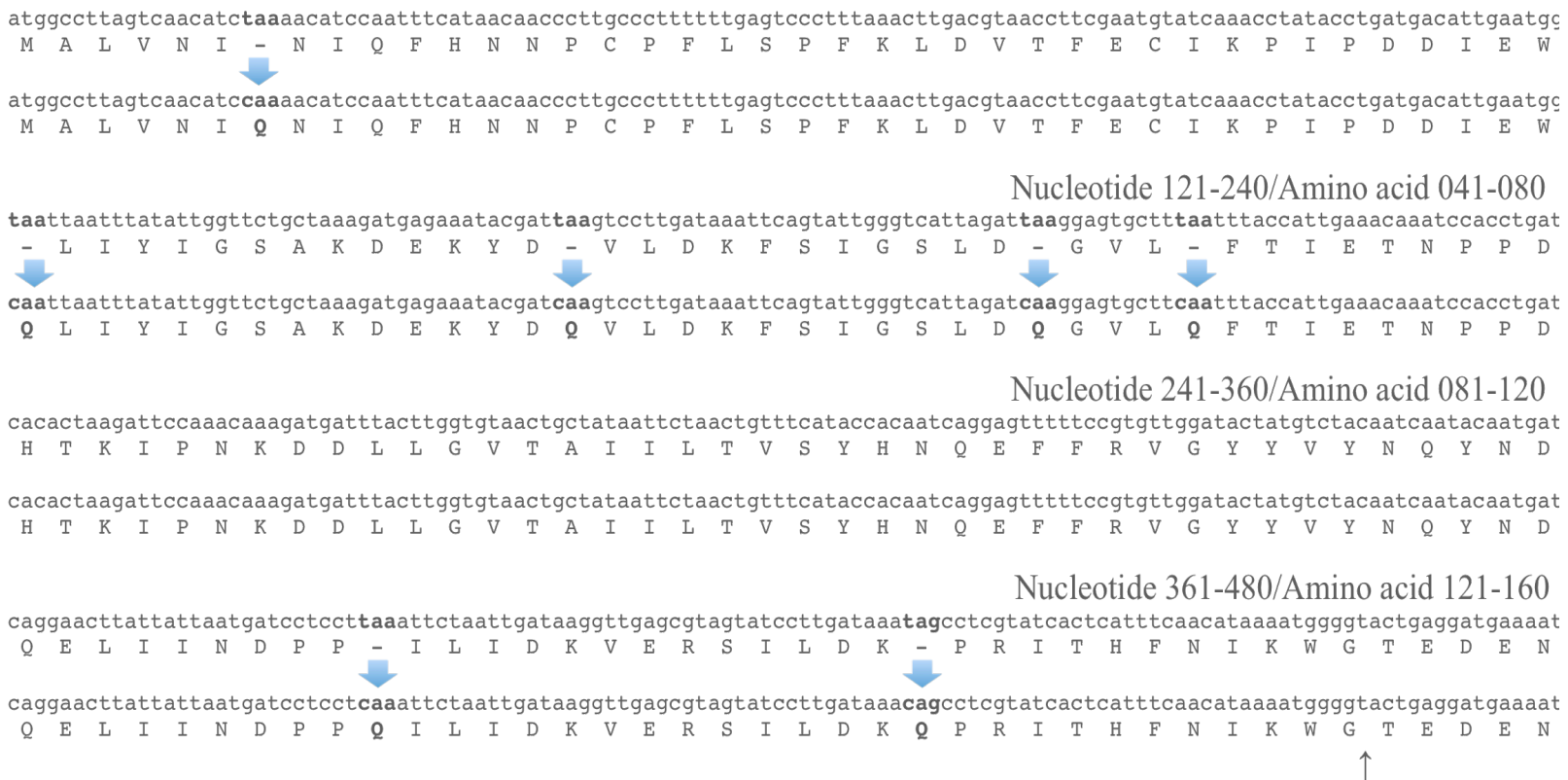
$\underline{\text { tASF1N ends here }}$

Nucleotide 481-600/Amino acid 161-200 aaagaaactgaccctaatactttagctatcctctaacagtaattagcttaaaatggaaccattcctaattaactcatgcaagaaatgcaataagtgaatagctaaatgcaatcttctte

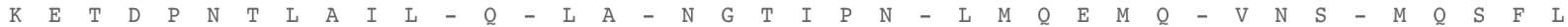
aaagaaactgaccctaatactttagctatcctccaacagcaattagctcaaaatggaaccattcctaatcaactcatgcaagaaatgcaacaagtgaatagccaaatgcaatctttctte

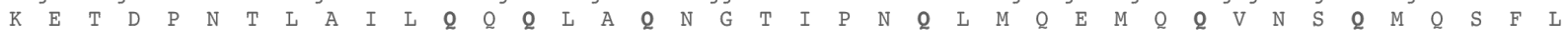

Nucleotide 601-720/Amino acid 201-240 cctgatcctttttctaagtcatcaggaatactctaagagttaacaacataaggatagactaacagcacaaatagtttcatgtttggttaagggctagacataccttaaaataatgcattc

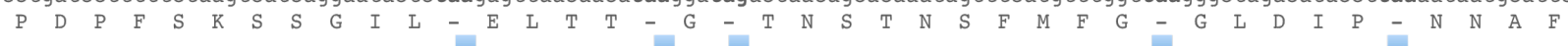
cctgatccttttctaagtcatcaggaatactccaagagttaacaacacaaggacagactaacagcacaaatagtttcatgtttggtcaagggctagacatacctcaaaataatgcattc

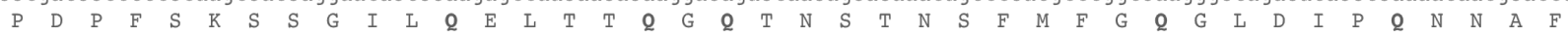

Nucleotide 721-756/Amino acid 241-251

caacctacaaatgtattcagttctaatccttactga

$\begin{array}{llllllllllllll}Q & P & T & N & V & F & S & S & N & P & Y & -\end{array}$

caacctacaaatgtattcagttctaatccttactaa

$\begin{array}{lllllllllllllllll}0 & P & T & N & V & F & S & S & N & P & Y & -\end{array}$

Figure 5: Modifications made to tASF1 to correspond to universal genetic code: Modified TAA and TAG codons in tASF1 are indicated by blue arrows. tASF1 gene $\left(1^{\text {st }}\right.$ sequence) and modified gene $\left(2^{\text {nd }}\right.$ sequence) and their amino acid sequence translation. tAsf $1 \mathrm{~N}$ end is shown by an arrow at amino acid residue 155. 
Nucleotide 001-120/Amino acid 001-040 Atggctgattaagaaaatctgcttaagatgcatagaatgcagcaccataagagactgcatttgtaggaatgaatggtgaagaaactggacttggatttgcaactcgtgattaaggagcc

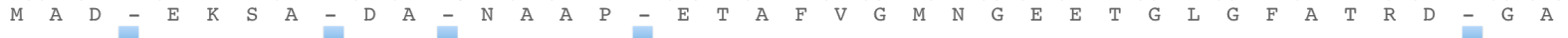
atggctgatcaagaaaatctgcccaagatgcgcagaatgctgcaccacaggaaaccgcatttgttggtatgaatggtgaagaaaccggtctgggttttgccacccgtgatcaaggtgç

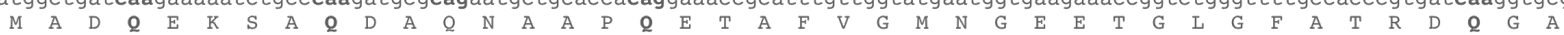

Nucleotide 121-240/Amino acid 041-080

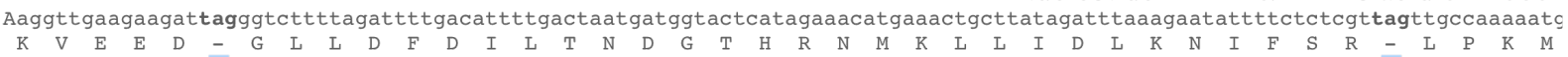

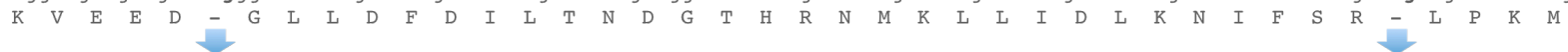
aaagttgaagaagatcagggtctgctggattttgatattctgaccaatgatggtactcatcgtaatatgaaactgctgatcgatctgaagaacatttttagccgtcaactgccaaagatc

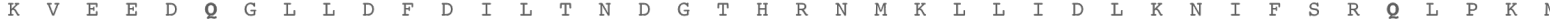

Nucleotide 241-360/Amino acid 081-120

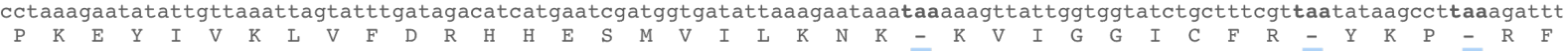
ccgaaggaatacatcgttaaactggttttcgatagacatcatgaatctatggttatcctgaagaacaagcagaaggttattggtggtatttgtttccgtcaatacaaaccgcagagattt

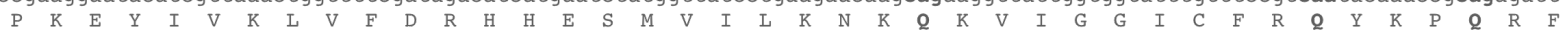

Nucleotide 361-480/Amino acid 121-160 gcagaagtagctttccttgctgtcactgcaaatgaataggttagagggtatggcacaagattgatgaataaatttaaagatcatatgtaaaaatagaatattgaatatcttctcacttat

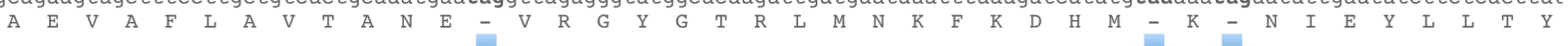
gctgaagttgcatttctggccgttaccgcgaatgaacaagttcgtggttacggtactagactgatgaacaagttcaaggatcacatgcaaaagcagaatattgaatatctgctgacctat

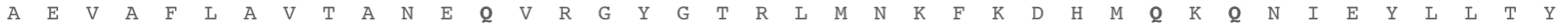

Nucleotide 480-600/Amino acid 161-200 gctgataactttgctattggatactttaagaaataaggttttacaaaagaacatagaatgccataagaaaaatggaagggatatattaaagattatgatggcggtactcttatggagtgc

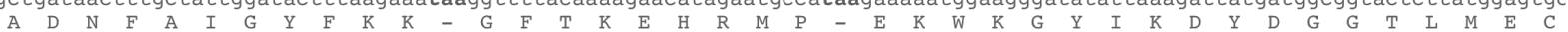
gctgataacttcgcaatcggttacttcaagaaacaaggttttaccaaagaacatcgtatgccacaggaaaagtggaagggttacatcaaggattacgatggtggtactctgatggaatgt

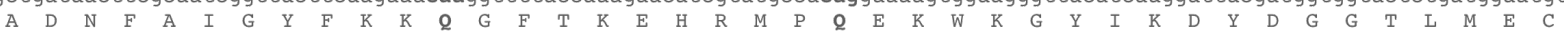

Nucleotide 601-720/Amino acid 201-240

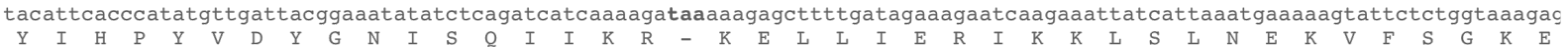
tacatccatccgtatgttgattacggtaacatctctcaaatcatcaascteagac

tacatccatccgtatgttgattacggtaacatctctcaaatcatcaaacgtcagaaggaactgctgatcgaaagaattaaaaactgtctctgaacgaaaaggtgttttctggcaaggaa

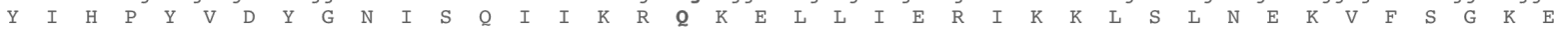

Nucleotide 721-840/Amino acid 241-280 tatgctgcattaatataaaattctatggataatgaggatcctgaaaaccctaaagtgaatccttcagatattcctggagttgcatttagtggttgggagtggaaagactaccatgaactc

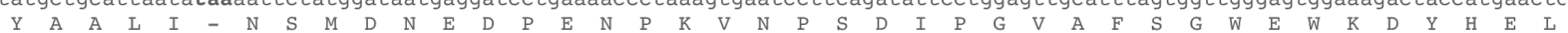
tacgccgcgctgatccaaaattctatggataacgaagatccagaaaatccgaaagttaatccatctgatattccgggtgttgccttttctggttgggaatggaaggattaccatgaactc

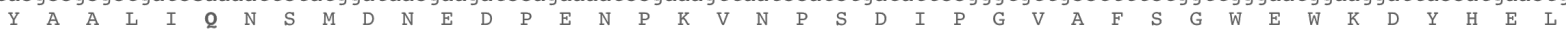

Nucleotide 841-960/Amino acid 281-320 aagaaatcaaaagagagatcattcaatctttagtgtgctaatgttattgaaaatatgaagagacacaaacaatcttggccttcttagatcctgttaataaagatgatgttccagattat

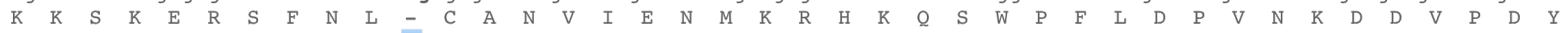
aaaaatctaaggaacgttcttttaatctgcaatgtgcgaacgttatcgaaaacatgaagagacataagcagtcttggccatttttagatccagttaacaaggatgatgttccagattac

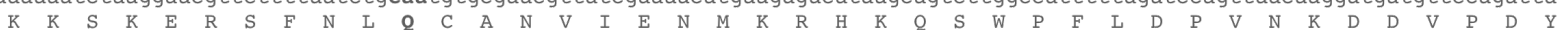

Nucleotide 961-1080/Amino acid 321-360 tatgatgtgattactgatcctatagatattaaagcaatagaaaagaagttataaaataatcaatatgttgacaaagactaatttatcaaagacgtcaaaagaatttttactaatgctaaa

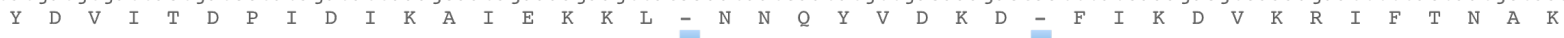
tatgatgttattaccgatccgatcgatattaaggctatcgaaaagaaactgcaaaataatcagtatgttgataaagatcaattcatcaaggatgttaagcgtatcttcaccaatgctaac

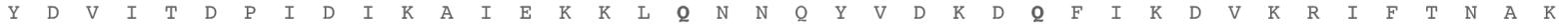

Nucleotide 1081-1200/Amino acid 361-400 atttataactagcccgatactatatattataaagctgctaaagaattagaagattttgttgaaccttatcttactaaacttaaagatactaaagaaagtaatactccatctaataataat $\begin{array}{lllllllllllllllllllllllllllllllllllllllllllllllll}\text { I } & \mathrm{Y} & \mathrm{N} & - & \mathrm{P} & \mathrm{D} & \mathrm{T} & \mathrm{I} & \mathrm{Y} & \mathrm{Y} & \mathrm{K} & \mathrm{A} & \mathrm{A} & \mathrm{K} & \mathrm{E} & \mathrm{L} & \mathrm{E} & \mathrm{D} & \mathrm{F} & \mathrm{V} & \mathrm{E} & \mathrm{P} & \mathrm{Y} & \mathrm{L} & \mathrm{T} & \mathrm{K} & \mathrm{L} & \mathrm{K} & \mathrm{D} & \mathrm{T} & \mathrm{K} & \mathrm{E} & \mathrm{S} & \mathrm{N} & \mathrm{T} & \mathrm{P} & \mathrm{S} & \mathrm{N} & \mathrm{N} & \mathrm{N}\end{array}$ atctacaaccagccagataccatctactacaaggctgcaaaggaactggaagattttgttgaaccatatctgaccaaactgaaagatactaaggaatctaacaccccgtctaacaacaac

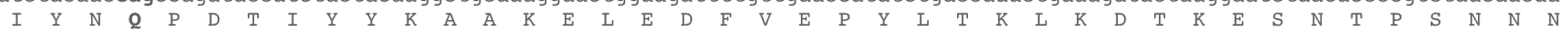

Nucleotide 1201-1257/Amino acid 401-418 tctgcacatggaagtaagaaaccacttcctgttagaaaaagtataaaaagaaatga $\begin{array}{llllllllllllllllllllllll}S & A & H & G & S & K & K & P & L & P & V & R & K & S & I & K & K & K & -\end{array}$

tctgctcatggttctaaaaaaccactgccggttagaaaatctattaagaaaaataa $\begin{array}{lllllllllllllllllllllll}S & A & H & \text { G } & \text { S } & \text { K } & \text { K } & \text { P } & \text { L } & \text { P } & \text { V } & \text { R } & \text { K } & \text { S } & \text { I } & \text { K } & \text { K } & \text { K } & -\end{array}$

Figure 6: Modifications made to tGCN5 to correspond to universal genetic code: Modified TAA and TAG codons in tGCN5 are indicated by blue arrows. tGCN5 gene ( $1^{\text {st }}$ sequence) and modified gene $\left(2^{\text {nd }}\right.$ sequence) and their amino acid sequence translation. 
3.3 Preparation of template DNA for amplification of yeast $A S F 1, A S F 1 N, R T T 109$ and GCN5:

In order to have a template to amplify several yeast genes used in this study, I prepared genomic DNA from $S$. cerevisiae (see materials and methods). Figure 7 shows $1 \mu \mathrm{g}$ of yeast genomic DNA run out on a $0.8 \%$ agarose gel. The DNA was intact and thus appropriate for use as a template for PCR.

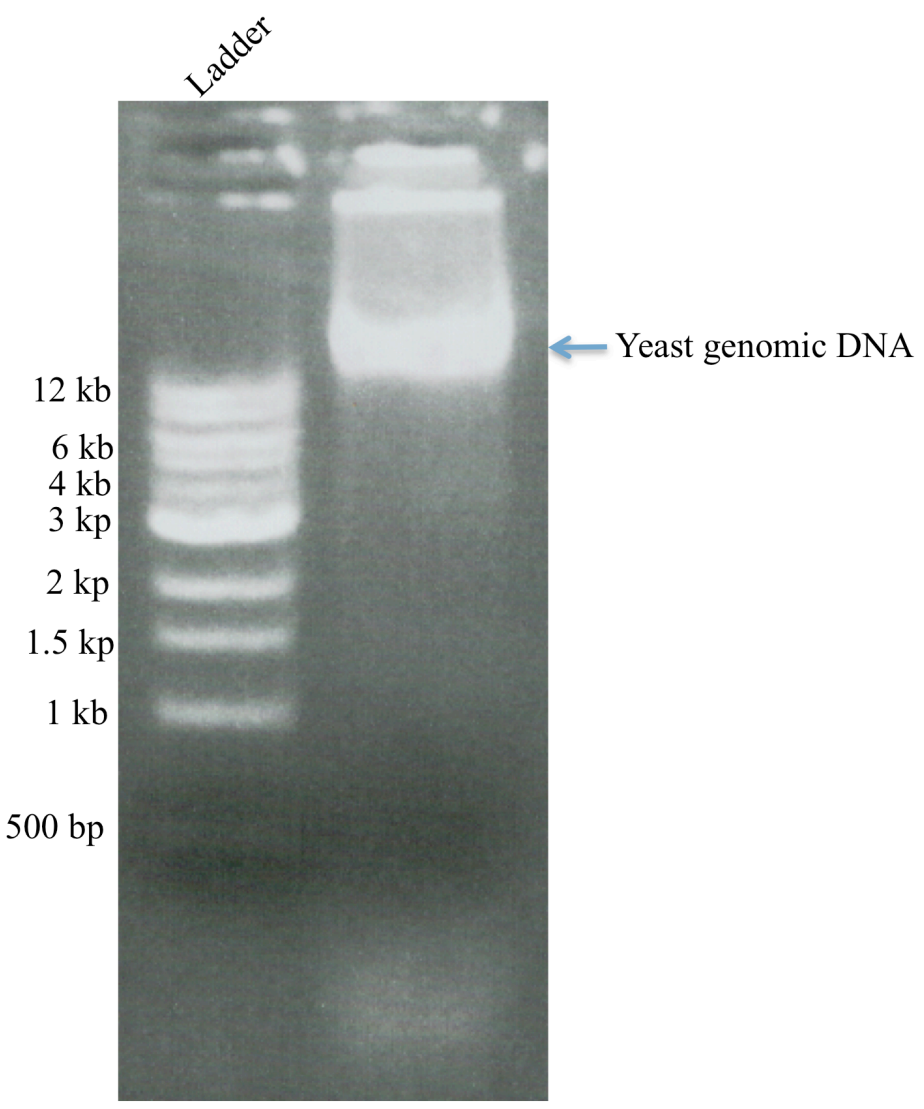

Figure 7: Purified yeast genomic DNA: A $0.8 \%$ agarose gel made in $1 \mathrm{x}$ TBE buffer, embedded with ethidium bromide and visualized by Alpha Innotech FlourChem system. Around 1 $\mu \mathrm{g}$ of genomic DNA was loaded. DNA ladder was obtained from New England Biolab (NEB). 


\subsection{Amplification and molecular cloning of T. thermophila and yeast ASF1, ASF1N and GCN5:}

The T.thermophila and yeast genes were amplified by PCR using either yeast genomic DNA or T. thermophila synthetic genes provided by GENESCRIPT in plasmid pUC57 then cloned into pET28a (Novagen), a bacterial expression vector that contains DNA sequence that will give them an N-terminal 6-histidine tag (6xHIS). Primers were designed with appropriate restriction site on their 5 ends (BamH1 for all except Smal for yGCN5) and their $3 \backslash$ end (Xhol) for cloning purposes. Ligated plasmids were then transformed into E.coli $\mathrm{DH} 5 \alpha$ before being repurified and digested with appropriate restriction enzymes and those with inserts of correct size were sequenced (Lee Wong, York University) to ensure 100\% match to template.

Plasmids were then transformed into BL21 (DE3) E.coli for expression. Plasmid pET28a encodes a lac repressor that control gene expression and is antagonized by IPTG. Thus IPTG is used to induce expression of the recombinant proteins. The pET28a plasmid has a T7 promoter and BL21 (DE3) E. coli cells has a T7 RNA polymerase, which makes expression of proteins in those cells feasible.

The same set of genes were amplified and cloned into pRB415-12myc, a CEN-based plasmid that contains DNA sequence encoding an N-terminal 12-MYC epitope tag and the yeast ADH1 promoter for expression of cloned genes in S. cerevisiae. The plasmids that were obtained were digested with appropriate restriction endonucleases and sequenced as above to make sure that there were no alterations that might have happened during the ligation or PCR. Figure 8 shows the restriction enzyme digestion that confirms successful cloning of tASF1 and tGCN5 into pET28a. 


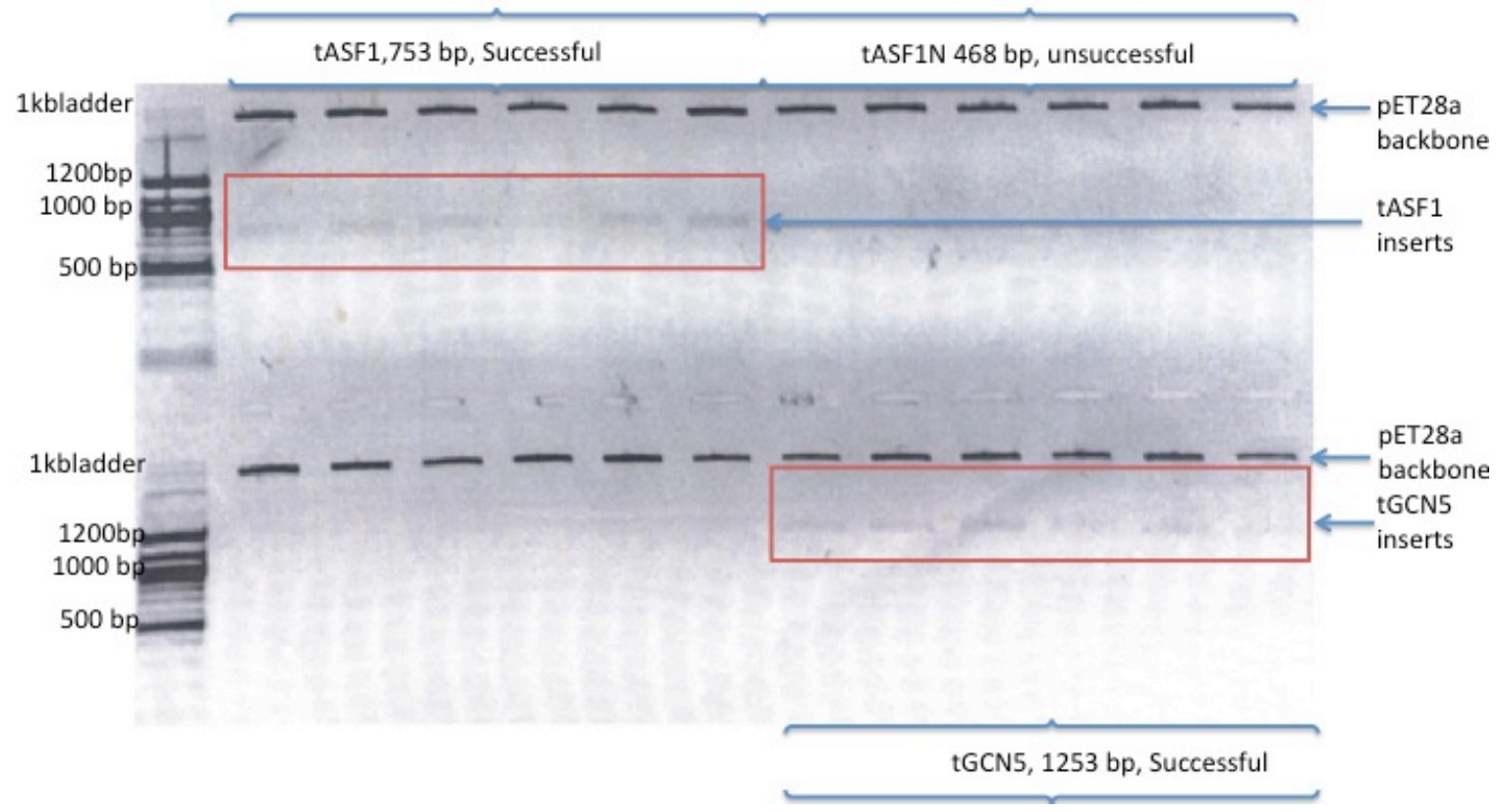

Figure 8: Restriction enzyme digestion for verification of molecular cloning: A $0.8 \%$ agarose gel embedded with ethidium bromide and visualized by Alpha Innotech FlourChem system. $0.25 \mu \mathrm{g}$ of DNA digested with BamHl and Xhol were loaded on each well and arrows shows the inserts of correct size for corresponding genes. $100 \mathrm{bp}$ DNA ladder was used. This particular experiment shows successful cloning of tASF1 and tGCN5 into pET28a in that digestion released a fragment of the expected size.

\subsection{Yeast transformation:}

pRB415-12MYC-based plasmids were used in an in vivo assay to determine if tAsfl or tGen5 could rescue the requirement in yeast of either Asf1 or Rtt109 for H3K56ac. Plasmids were transformed into either asfl/gcn5 or $r t t 109 / g c n 5$ double mutants. As mentioned in the introduction, in addition to their role in H3K56ac, Rtt109 and Asfl together in yeast also acetylate H3K9 in a parallel pathway to Gen5. To be clear, in yeast Rtt109 and Asf1 collaborate together to acetylate all H3K56 and about half H3K9. In yeast Gcn5 acetylates all H3K18 and about half H3K9a. Therefore, the two double mutants are completely null for H3K56ac, H3K9ac and H3K18ac and therefore even partial or weak rescue can be easily assessed. The 
double mutants were made and characterized in Fillingham et al. (2008) (Summarized in Table 6 and 7).

Empty plasmid pRB415-12myc was transformed into both of the double mutants ( $\triangle a s f 1 / g c n 5$ and $\Delta r t t 109 / g c n 5$ ) as well as the single mutants ( $\triangle a s f 1, \Delta g c n 5$ and $\Delta r t t 109$ ). $y A S F 1$, $y A S F 1 N, t A S F 1$, and $t A S F 1 N$ genes cloned into $\mathrm{pRB} 415-12 \mathrm{myc}$ were transformed into a yeast strain that lacks asfl and gcn5. yGCN5, tGCN5 and RTT109 cloned into the same plasmid were transformed into yeast strains lacking $g c n 5$ and $r t t 109$.

\begin{tabular}{|c|c|c|c|}
\hline Modification & $\Delta a s f 1$ & $\Delta g c n 5$ & Aasf1/gcn5 \\
\hline H3K56ac & Null & Normal & Null \\
\hline H3K18ac & Normal & Null & Null \\
\hline H3К9ас & Decreased & Decreased & Null \\
\hline
\end{tabular}

Table 6: Characterization of $\Delta a s f 1$ and $\Delta g c n 5$ single and double mutants: The effect of the respective gene deletion on the shown PTM's is described. Data is summarized from Fillingham et al. (2008).

\begin{tabular}{|c|c|c|c|}
\hline Modification & $\Delta r t t 109$ & $\Delta g c n 5$ & $\Delta r t t 109 / g c n 5$ \\
\hline H3К56ас & Null & Normal & Null \\
\hline H3K18ac & Normal & Null & Null \\
\hline H3К9ас & Decreased & Decreased & Null \\
\hline
\end{tabular}

Table 7: Characterization of $\Delta r t t 109$ and $\Delta g c n 5$ single and double mutants: The effect of the respective gene deletion on the shown PTM's is described. Data is summarized from Fillingham et al. (2008). 


\section{6 tASF1 and tGCN5 do not rescue the growth defect of $\Delta a s f 1$ and $\Delta g c n 5$ in yeast:}

I examined possible interplay between $t G C N 5, y G C N 5$ and $R T T 109$ by determining whether I could rescue $\Delta r t t 109 / g c n 5$ double mutant yeast strains by transforming them with tGCN5 (along with positive controls RTT109 and $y G C N 5$ ) and determining whether it could rescue the mutants slow growth phenotype. I asked a similar question by determining whether tASF1, tASF1N, $y A S F 1$ and $y A S F 1 N$ cloned in pRB4151-2MYC could rescue the $\triangle$ asfl/gcn5 double mutant.

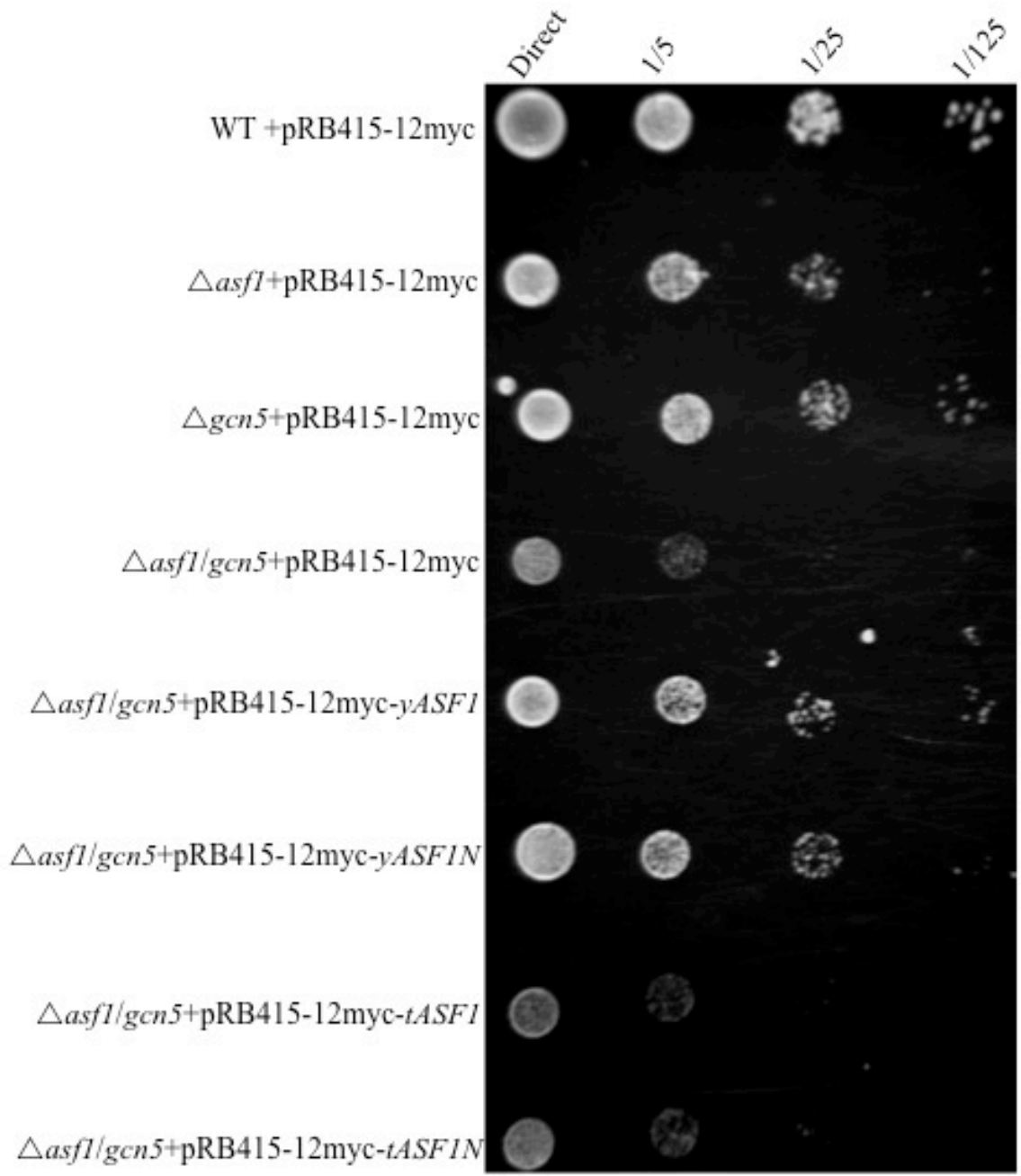

Figure 9: Growth spot tests, Growth comparison for $t A S F 1$ and $t A S F 1 N$ : Media lacking the Leucine amino acid (-Leu ) plates are inoculated with $5 \mu 1$ of culture (direct) plus its serial dilution of $1 / 5,1 / 25$ and $1 / 125$. Growth is compared with indicated strains against wild type (WT) growth. 
The $\triangle$ asfl/gcn 5 strain shows very weak growth compared to that of the wild type (WT) (Figure 9), similar to the growth defect observed on rich media in Fillingham et al. (2008). The $\triangle a s f 1$ and $\triangle g c n 5$ single mutants strains showed intermediate growth between wild type and the $\triangle a s f 1 / g c n 5$ double mutant. The $\triangle a s f 1 / g c n 5$ strain transformed with pRB415-12myc-yASF1 and pRB415-12myc-yASF1N shows growth similar to that of $\triangle g c n 5$ single mutant, indicating the assay is working and there is rescue of the slow growth defect by pRB415-12myc-yASF1 and pRB415-12myc-yASF1N as expected (Daganzo et al., 2003). $\triangle a s f 1 / g c n 5$ showed no significant change in growth rate after being transformed with pRB415-12myc-tASF1 or pRB415-12myctASF1N (Figure 9).

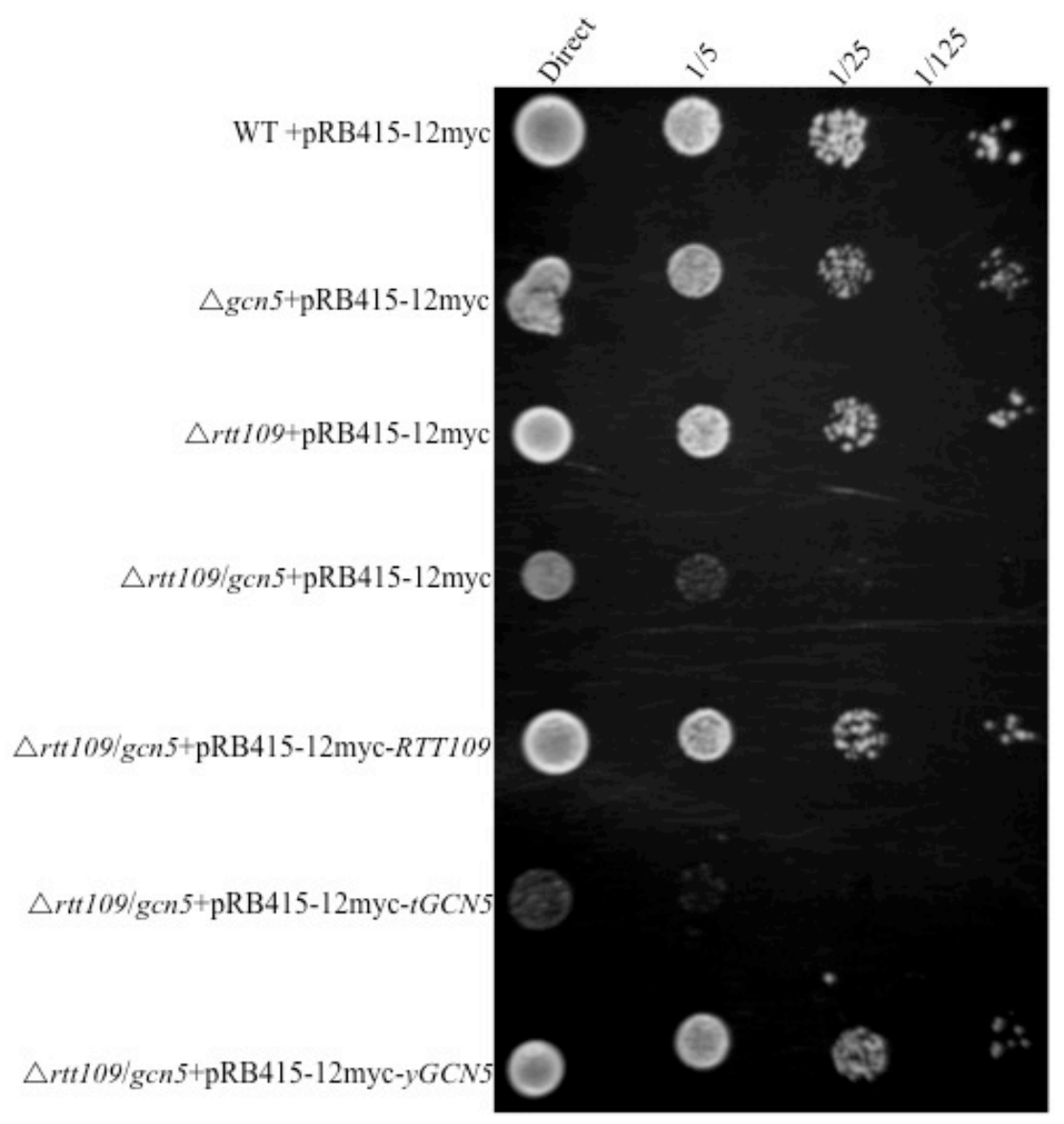

Figure 10: Growth spot tests, Growth comparison for tGCN5:-Leu plates are inoculated with $5 \mu 1$ of culture (direct) plus its serial dilution of $1 / 5,1 / 25$ and $1 / 125$. Growth is compared with indicated strains against wild type (WT) growth. 
The $\triangle r t t 109 / g c n 5$ strain showed very weak growth compared with WT (Figure 11), as also seen on rich media in Fillingham et al. (2008). The $\triangle$ rtt109 and $\triangle$ gcn5 single mutants strains shows intermediate growth compared with WT and the $\triangle$ rtt109/gcn5 double mutant, while the $\triangle r t t 109 / g c n 5$ strain transformed with either pRB415-12myc-yGCN5 or pRB41512myc- RTT109 shows growth similar to either the $\triangle$ rtt109 or $\triangle$ gcn5 single mutants respectively (Figure 11) showing the assay is working. By contrast the $\triangle$ rtt109/gcn5 double mutant showed no change in growth after being transformed with pRB415-12myc- $t G C N 5$ (Figure 11).

Together these data suggest the following:

1. $t G C N 5$ does not rescue the slow growth phenotype of $\Delta r t t 109 / g c n 5$ double mutant and therefore does not substitute for either.

2. $t A S F 1$ or $t A S F 1 N$ does not rescue the slow growth phenotype of $\triangle a s f 1 / g c n 5$ double mutant and therefore does not substitute for either.

Thus, despite the large homology between yAsfl and tAsf1 (Figure 4) on one hand, and yGen5 and tGen5 on the other hand (Figure 3), tAsf1 was unable to rescue the slow growth defect of $\Delta a s f 1$, and tGen5 was unable to rescue the slow growth defect of $\Delta g c n 5$. To further investigate whether any rescue was occurring, we next assessed histone acetylation levels in these strains. 


\subsection{In Vivo acetylation assays on yeast transformed mutants:}

To assess levels of H3K9ac, H3K18ac and H3K56ac in transformed strains, I made whole cell extracts and used Western Blotting (WB). In S. cerevisiae, Rtt109 and Asf1 are required for H3K56ac (Fillingham et al., 2008), and Gen5 for H3K18ac (Grant et al., 1997). In addition, both are required for full H3K9ac (Fillingham et al., 2008) (Table 1).

In this experiment, I also blotted with an antibody that recognizes unmodified histone $\mathrm{H} 3$ to ensure I was comparing roughly equal amount of whole cell extracts (WCE). I also blotted with an antibody that recognizes the N-terminal $12 x$ myc tag to ensure the genes cloned into pRB415-12myc are actually being expressed in $S$. cerevisiae, and that the lack of rescue was not due to a lack of expression. Table 8 lists expected results for the positive controls for this experiment based on Fillingham et al. (2008).

\begin{tabular}{|l|l|l|l|}
\hline $\begin{array}{l}\text { Plasmid Transformed into } \\
\Delta \text { rtt109/gcn5 or } \Delta \text { asf } 1 / g c n 5\end{array}$ & $\alpha$-H3K56ac & $\boldsymbol{\alpha}$-H3K18ac & $\boldsymbol{\alpha}$-H3K9ac \\
\hline pRB415-12myc & Negative & Negative & Negative \\
\hline pRB415-12myc- $R T T 109$ & Positive & Negative & Positive \\
\hline pRB415-12myc- $\boldsymbol{y} \boldsymbol{G C N 5}$ & Negative & Positive & Positive \\
\hline pRB415-12myc- $\boldsymbol{y} \boldsymbol{A S F 1}$ & Positive & - & Positive \\
\hline
\end{tabular}

Table 8: In vivo histone assay controls: Expected acetylation results for the indicated plasmids transformed into either $\Delta a s f 1 / g c n 5$ or $\Delta r t t 109 / g c n 5$. 


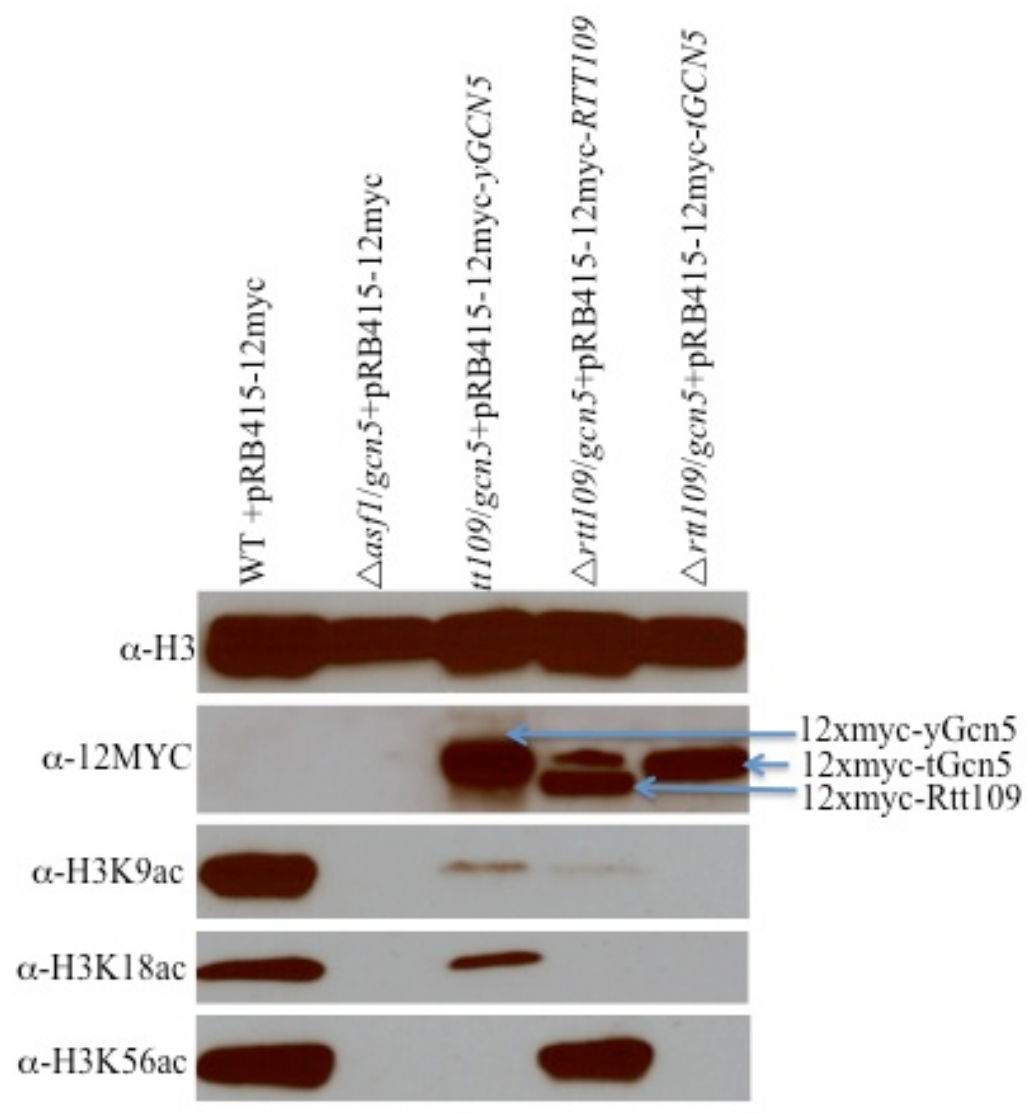

Figure 11: In vivo histone acetylation experiments for $\boldsymbol{t} \boldsymbol{G} \boldsymbol{C N 5}$ : WB comparison of WT, pRB415-12myc- $y G C N 5$, and pRB415-12myc-RTT109 with pRB415-12myc- $t G C N 5$. TCA WCE of indicated strains separated in 15\% SDS-PAGE gel, transferred into nitrocellulose and blotted against indicated antibodies 


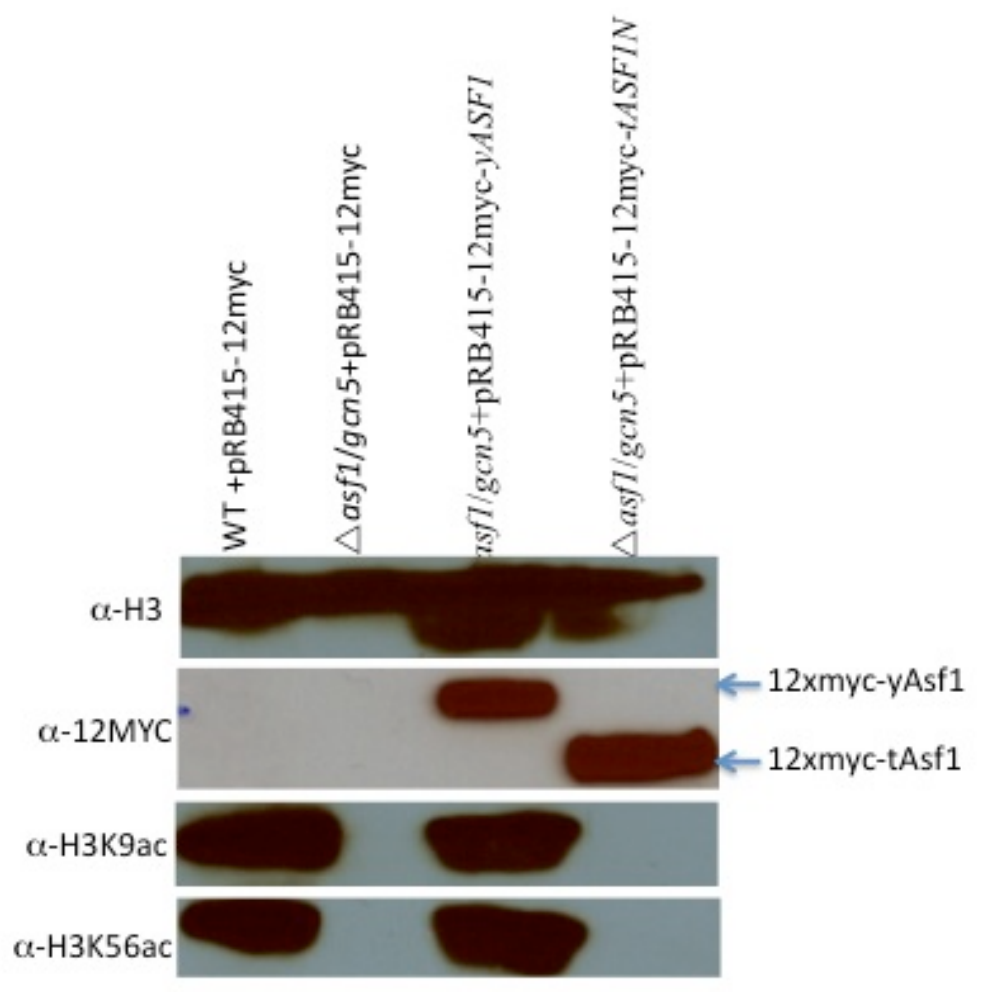

Figure 12: In vivo histone acetylation experiments for $\boldsymbol{t A S F 1}$ : WB comparison of WT and pRB415-12myc- $y A S F 1$, with pRB415-12myc-tASF1. TCA WCE of indicated strains separated in 15\% SDS-PAGE gel, transferred into nitrocellulose and blotted against indicated antibodies 


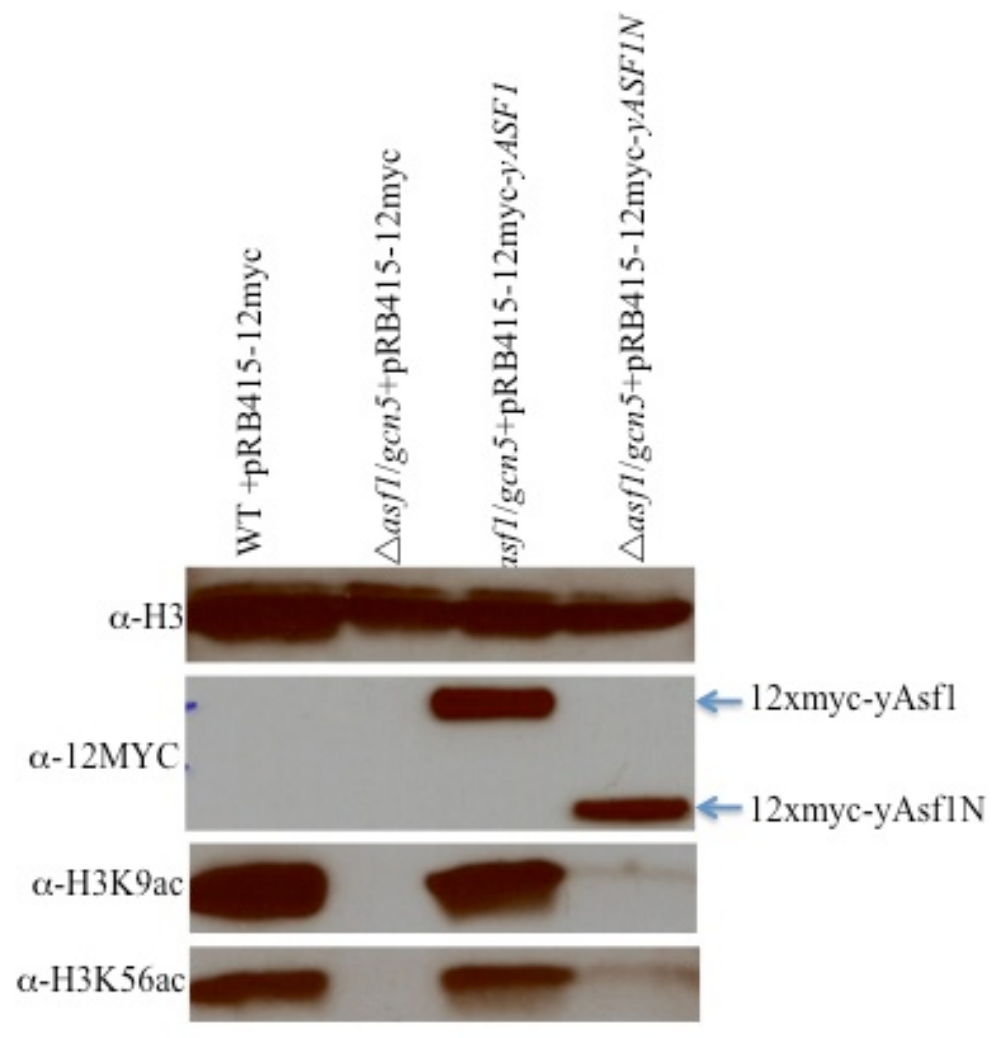

Figure 13: In vivo histone acetylation experiments for $\boldsymbol{y} A$ SF1N: WB comparison of WT and pRB415-12myc- $y A S F 1$, with pRB415-12myc- $y A S F 1 N$. TCA WCE of indicated strains separated in $15 \%$ SDS-PAGE gel, transferred into nitrocellulose and blotted against indicated antibodies

WCE of WT are positive for all three of H3K9ac, H3K18ac, and H3K56ac (Figure 11,12, and 13). WCE from $\triangle a s f 1 / g c n 5 \triangle r t t 109 / g c n 5$ are all negative for the three modifications as expected from Fillingham et al. (2008) (Figure 12,13, and 14 ). The $\triangle r t t 109 / g c n 5$ double mutant transformed with pRB415-12myc-yGCN5 acted as positive control for H3K9ac and H3K18ac and was negative at H3K56ac as expected (Figure 11). The $\triangle$ rtt109/gcn5 double mutant transformed with pRB415-12myc- RTT109 was positive for H3K9ac \& H3K56ac \& negative for 
H3K18ac as expected (Figure 11). The $\triangle a s f 1 / g c n 5$ double mutant transformed with pRB41512myc- $y A S F 1$ was positive for $\mathrm{H} 3 \mathrm{~K} 9 \mathrm{ac} \& \mathrm{H} 3 \mathrm{~K} 56 \mathrm{ac}$ as expected (Figure 12 and 13).

The first set of Western blots showed that $t G C N 5$ expressed in yeast does not rescue the H3K56ac deficiency of the $\triangle r t t 109 / g c n 5$ double mutant phenotype (Figure 11) which is consistent with the spot tests results showing failure to rescue growth (Figure 10). tASF1 did not show any acetylation at $\mathrm{H} 3 \mathrm{~K} 9$ or $\mathrm{H} 3 \mathrm{~K} 56$ (Figure 12). Interestingly, $y A S F 1 N$ shows quite reduced levels of H3K9ac and H3K56ac (Figure 13) despite rescuing the slow growth phenotype (Figure 9). The significance of this is still unclear.

Together these data suggest the following:

1. $y G C N 5$ and $R T T 109$ partially rescues H3K9ac in $\Delta r t t 109 / g c n 5$ double mutants:

It has been demonstrated that yGen5 and Rtt109 act in parallel pathways to fully acetylate global H3K9 in budding yeast (Fillingham et al., 2008. Burgess et al., 2010). The partially acetylated state of H3K9 when either yGen5 (Figure 11) or Rtt109 (Figure 11) is expressed is consistent with this.

\section{2. $t G C N 5$ does not rescue $\mathrm{H3K9/18/56ac}$ in $\Delta r t t 109 / g c n 5$ double mutants:}

Despite the fact that $y G c n 5$, tGen5 and hGen5 share extensive amino acid sequence homology (Figure 3), $t G C N 5$ did not rescue the acetylation defect of the $\Delta r t t 109 / g c n 5$ double mutant. This does not refute my hypothesis that tGen5 is an H3K56ac HAT since this could be due to the inability of $\operatorname{tGcn} 5$ to interact with yeast $\mathrm{H} 3-\mathrm{H} 4$, or its inability to integrate within the SAGA complex, or even a failure to localise to the nucleus. 


\section{3. yASF1N only partially rescues $\mathrm{H} 3 \mathrm{~K} 9 / 56 \mathrm{ac}$ in $\Delta a s f 1 / g c n 5$ double mutants:}

Despite the fact from the growth tests that shows $y A S F 1$ and $y A S F 1 N$ rescue the $\triangle a s f 1$ defect of the double mutant to the same degree, there appears to be a clear difference between these proteins in the ability to rescue H3K9/56ac (Figure 13). Daganzo et al., (2003) has published data indicating that $\mathrm{yAsf} 1 \mathrm{~N}$ functions fully, at least in the context of what was known then. I will talk about the significance of this later in the discussion.

\section{4. $t A S F 1$ doesn't rescue $\mathrm{H} 3 \mathrm{~K} 9 / 56 \mathrm{ac}$ in $\Delta a s f 1 / g c n 5$ double mutants:}

Consistent with its inability to rescue the slow growth defect observed in the spot tests (Figure 9) $t A S F 1$ does not rescue the H3K9/56ac defect of the $\Delta$ asfl/gcn5 double mutants (Figure 12). yAsf1 was shown to interact with $\mathrm{H} 3$ at Aspartic acid (D) 54, Serine (S) 91, Valine (V) 92, Valine (V) 94, Leucine (L) 96, Arginine (R) 145 and Threonine (T) 147(Antczak et al., 2006; English et al., 2006). All these amino acid residues are conserved between S. cerevisiae and T. thermophila except S91, V94 and L96 (Figure 4). One possible explanation of this result is that tAsf1 may not bind yeast histones like yAsf1. Therefore, I moved to a set of in vitro experiments designed to assess histone binding, as well as ability to synergize with Rtt109, by tAsfl, and histone acetylation activity of tGen5.

\subsection{Expression of recombinant tAsf1, tAsf1N, yGen5 and tGen5:}

To produce recombinant proteins, E. coli BL21 (DE3) transformed with the appropriate plasmids (Table 9) were induced using $1 \mathrm{mM} \mathrm{IPTG,} \mathrm{at} 30^{\circ} \mathrm{C}$ for 4 hours before being lysed by suspending cell pellets in SDS sample buffer and boiling for 8 minutes and then checked to see if they express the protein by separating the whole cell lysate on SDS-PAGE and staining the gel 
with Coomassie-Blue stain and comparing it to un-induced state (Figure 14). The results obtained indicate that the strains express proteins of appropriate expected molecular size, tAsf $1=27 \mathrm{kDa}, \mathrm{tAsf} 1 \mathrm{~N}=20 \mathrm{kDa}, \mathrm{tGcn} 5=52 \mathrm{kDa}$. I have also performed the same experiment for yGcn5 which have confirmed that the strain is expressing the protein of expected molecular size, yGcn5=55 $\mathrm{kDa}$. Table 9 summarizes what I have cloned, transformed, expressed, and purified.

\begin{tabular}{|l|l|l|l|l|l|l|l|}
\hline Gene & tASF1 & tASF1N & tGCN5 & yASF1 & yASF1N & yGCN5 & RTT109 \\
\hline $\begin{array}{l}\text { Cloned/ } \\
\text { Bacterial } \\
\text { expression }\end{array}$ & $\checkmark$ & $\checkmark$ & $\checkmark$ & $\begin{array}{l}\text { Fillingham } \\
\text { et al., 2008 }\end{array}$ & $\begin{array}{l}\text { Fillingham et } \\
\text { al., 2008 }\end{array}$ & $\checkmark$ & $\begin{array}{l}\text { Fillingham } \\
\text { et al., 2008 }\end{array}$ \\
\hline Expressed & $\checkmark$ & $\checkmark$ & $\checkmark$ & $\begin{array}{l}\text { Fillingham } \\
\text { et al., 2008 }\end{array}$ & $\begin{array}{l}\text { Fillingham et } \\
\text { al., 2008 }\end{array}$ & $\checkmark$ & $\begin{array}{l}\text { Fillingham } \\
\text { et al., 2008 }\end{array}$ \\
\hline Purified & $\checkmark$ & $\checkmark$ & $\checkmark$ & $\begin{array}{l}\text { Fillingham } \\
\text { et al., 2008 }\end{array}$ & $\begin{array}{l}\text { Fillingham et } \\
\text { al., 2008 }\end{array}$ & $\checkmark$ & $\begin{array}{l}\text { Fillingham } \\
\text { et al., 2008 }\end{array}$ \\
\hline $\begin{array}{l}\text { Cloned/ } \\
\text { Rescue } \\
\text { experiment }\end{array}$ & $\checkmark$ & $\checkmark$ & $\checkmark$ & $\checkmark$ & $\checkmark$ & $\checkmark$ & $\begin{array}{l}\text { Radovani } \\
\text { et al., un- } \\
\text { published }\end{array}$ \\
\hline
\end{tabular}

Table 9: A summary of the expression of clones used in this study. The check mark indicates work specifically constructed in this study. 


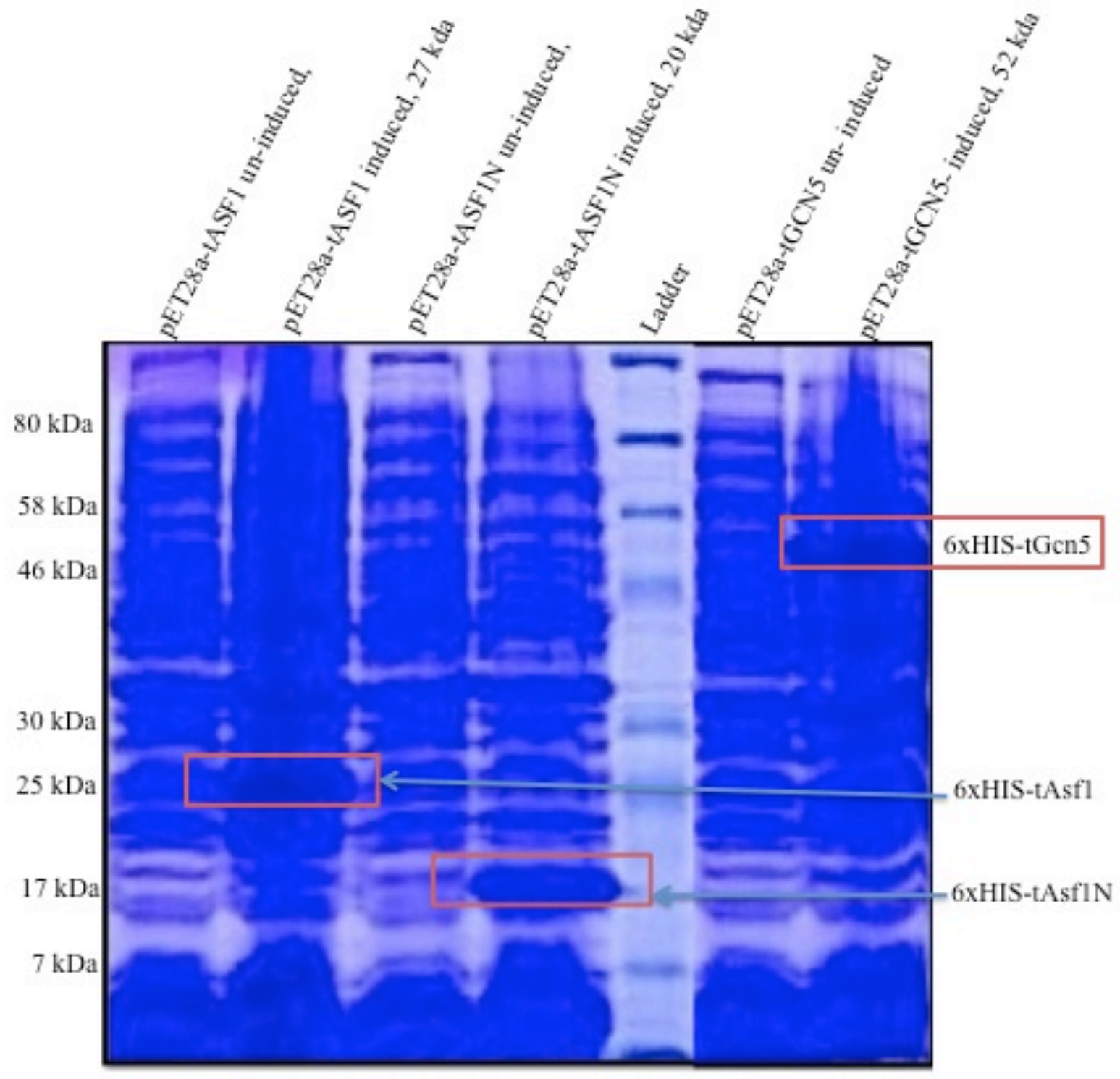

Figure 14: Coomassie-Blue stained SDS-PAGE of whole cell lysates from BL21 (DE3) $E$. coli transformed with indicated plasmids: 10\% SDS-PAGE showing separation of whole cell lysate and $2 \mu 1$ ladder from Invitrogen.

After it was confirmed that the strains expressed the proteins of predicted molecular weight, a series of experiments to test the optimum expression temperature and IPTG concentration were conducted (Figure 15 and Figure 16). Different conditions were analysed using SDS-PAGE to observe if an increase or a decrease of expression resulted from the change in condition. I have found from these data that a temperature of $30{ }^{\circ} \mathrm{C}$ is the most optimum 
among the ones tested $\left(16,24,30^{\circ} \mathrm{C}\right)$ (Figure 15), and that different concentrations of IPTG $(0.4$, $0.8,1.2 \mathrm{mM}$ ) have little effect after growing them at $30{ }^{\circ} \mathrm{C}$ (Figure 16). The rationale for doing these experiments is to optimize the protein expression and solubility. These conditions were used for affinity purification of recombinant proteins in subsequent experiments.

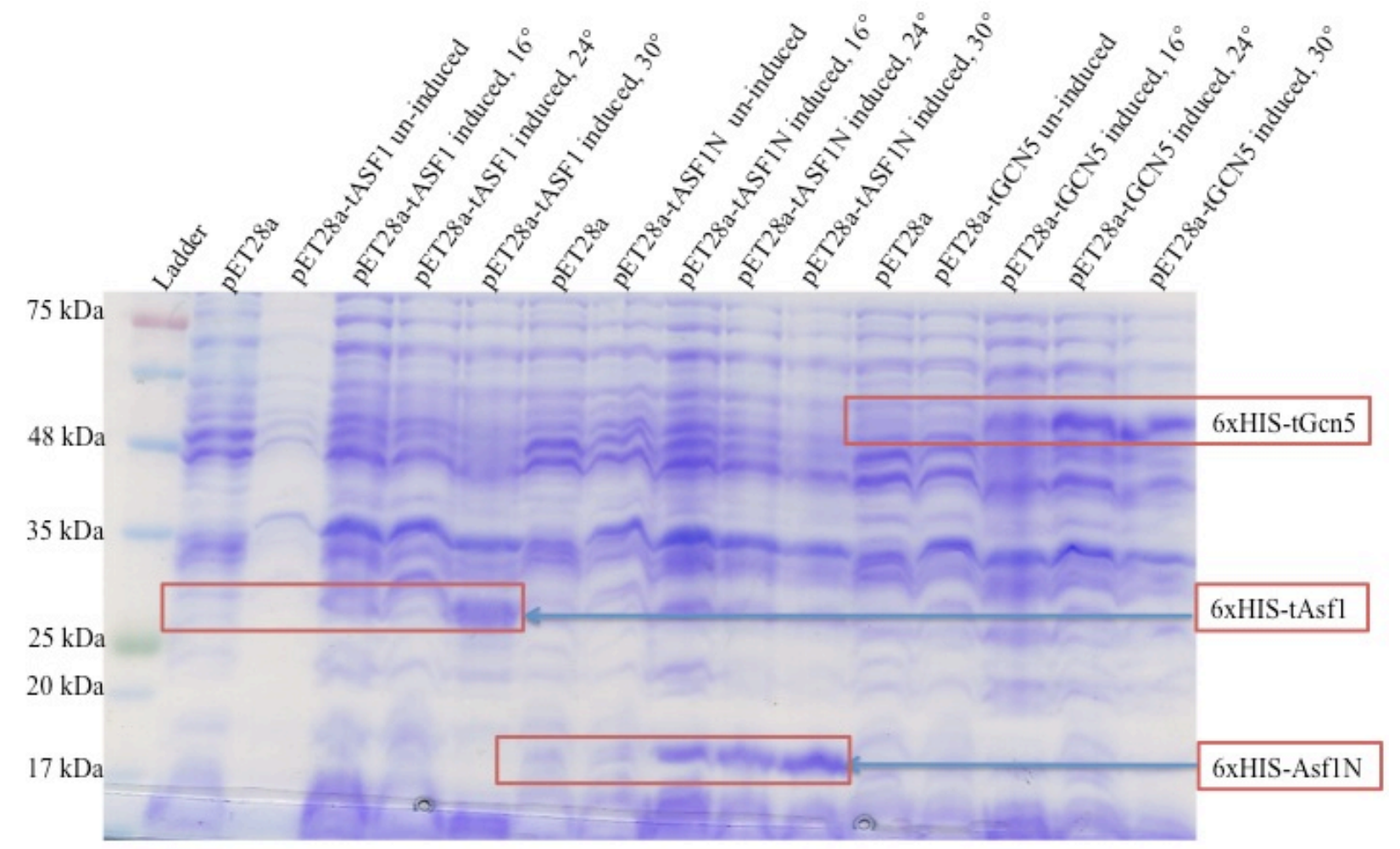

Figure 15: Coomassie-Blue stained SDS-PAGE of whole cell extract of BL21 (DE3) E. coli transformed with indicated plasmids expressed in different temperatures for $\mathbf{4}$ hours at 1 mM IPTG. 10\% SDS-PAGE gel showing separation of whole cells lysate and $2 \mu 1$ ladder from Invitrogen. 


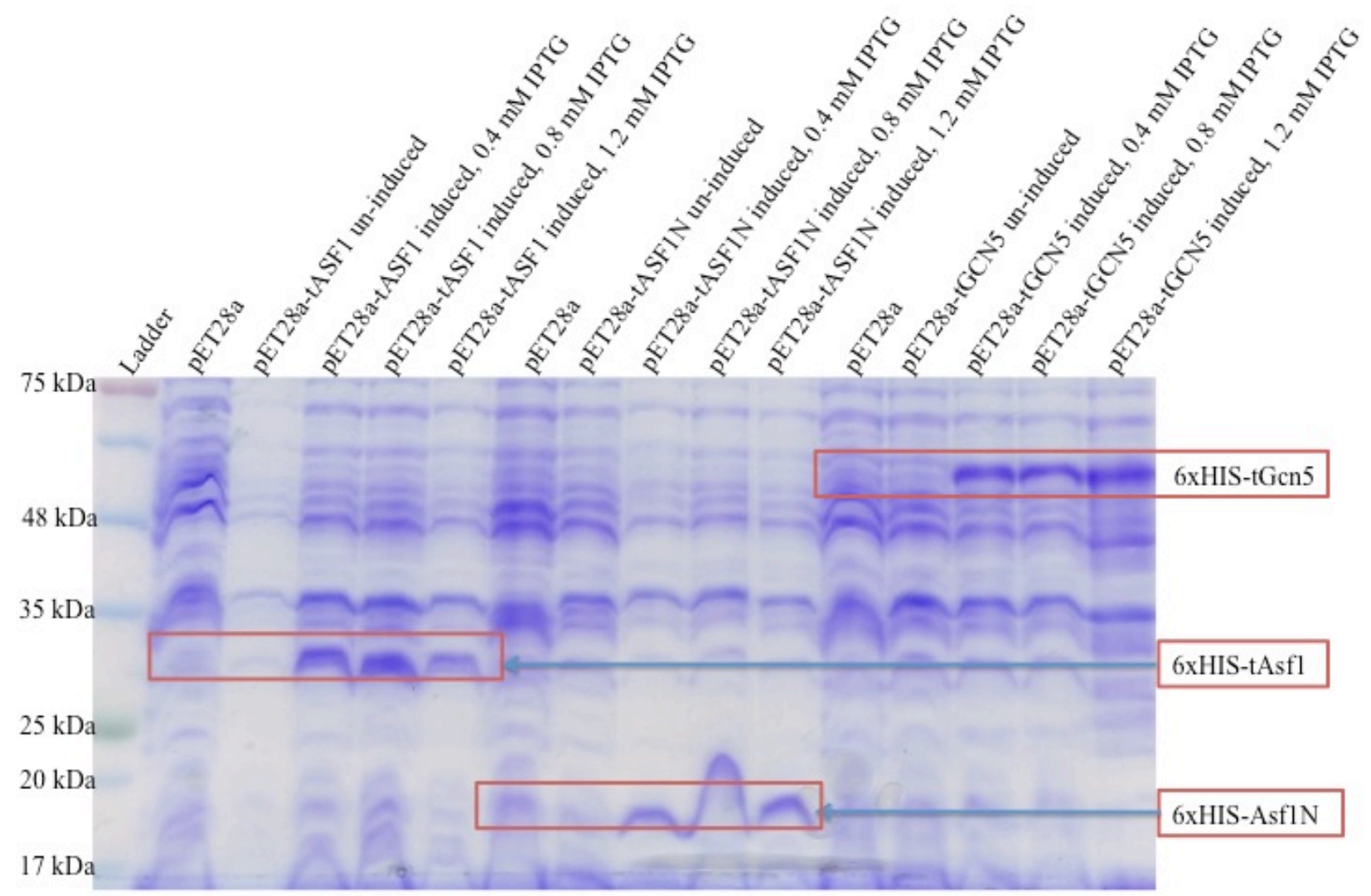

Figure 16: Coomassie-Blue stained SDS-PAGE of whole cell lysate of BL21 (DE3) E. coli transformed with indicated plasmids and expressed in several IPTG concentrations for 4 hours at $30^{\circ} \mathrm{C} .10 \%$ SDS-PAGE showing separation of whole cell lysate and $2 \mu$ ladder from Invitrogen.

\subsection{Purification of recombinant proteins expressed in $E$. coli:}

After I optimized protein expression, I moved on to affinity purification of the recombinant protein. For preparative expression, I used Terrific Broth (TB) instead of LB which I used for small scale expression. Growth in TB optimizes expression and purification by using glycerol as the sole energy source for bacteria thus lowering the amount of toxic metabolic byproducts (Dr. Vivian Saridaskis, York University Department of Biology, personal communication). 
In the initial affinity purification experiment, 6xHIS-tAsf1 was purified. However the 6xHIS-tAsf1N and 6xHIS-tGen5 were lost despite being well-expressed (Figure 17). Therefore in order to optimize 6xHIS-based purifications, in subsequent experiments I adjusted the $\mathrm{pH}$ of the whole cell lysate. In the original protocol, the lysate is mixed with binding buffer that is at $\mathrm{pH}$ 8.0, and thus the nickel bead mixing with the cell lysate also should have a $\mathrm{pH}$ 8.0. However, when I checked the $\mathrm{pH}$ of the lysate I found it to be around 6.5 for $6 \mathrm{xHIS-tGcn} 5$. This lower $\mathrm{pH}$ would cause the 6xHIS tag to be protonated and thus prevent it from binding to the nickel on the beads. I resolved this issue by adjusting the $\mathrm{pH}$ of the mixture by adding Tris-HCl buffer $\mathrm{pH} 9.0$ until the lysate was back to $\mathrm{pH} 8.0$. This has shown to be an effective step to purify 6 xHIStGen5, 6xHIS-yGen5 and 6xHIS-tAsf1N (compare Figure 18 and 19 with Figure 24). 


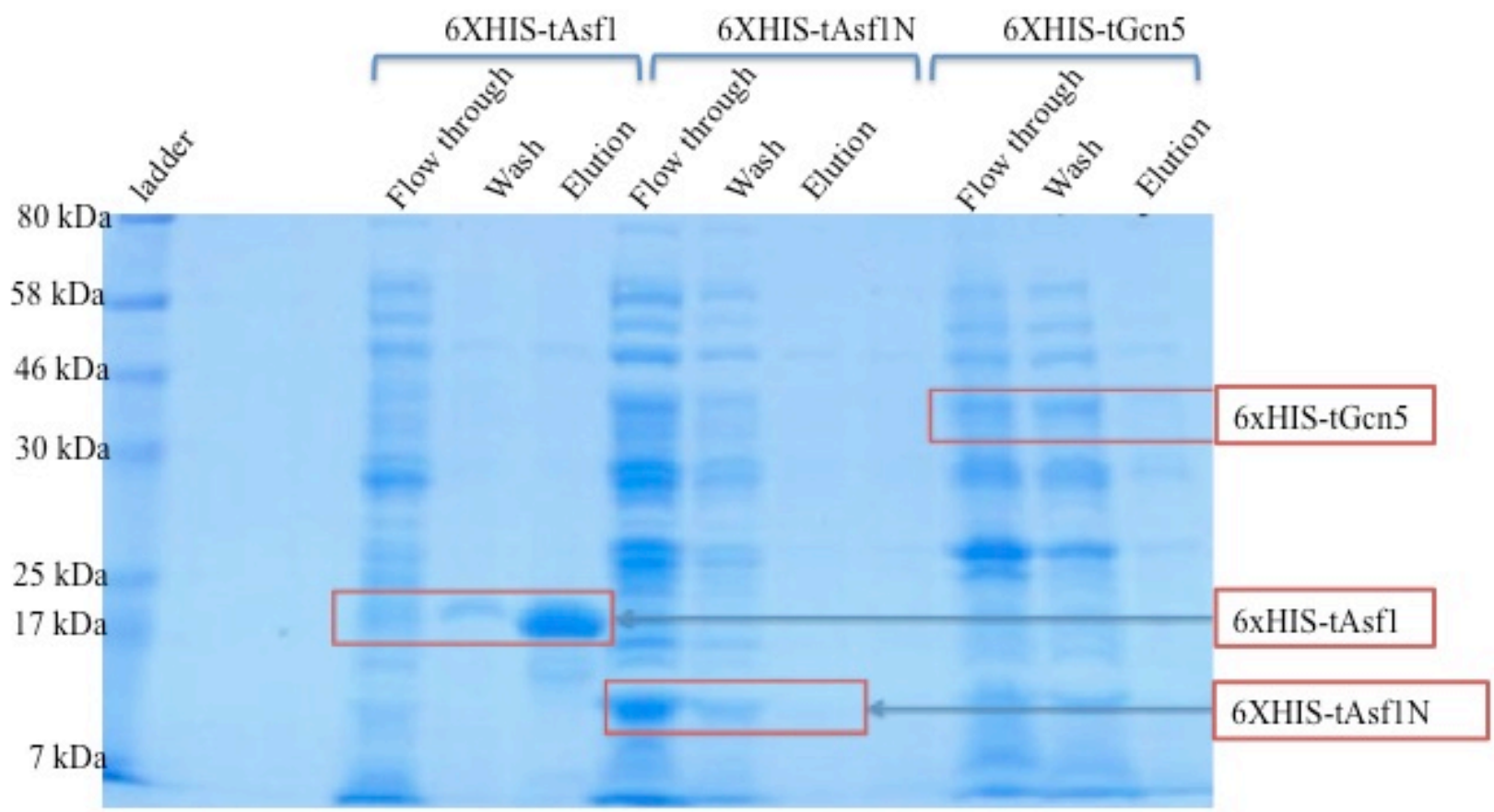

Figure 17: Coomassie-Blue stained SDS-PAGE of different aliquots from the purification of tASF1, tASF1N, tGCN5 at pH 6.5: tASF1N and tGCN5 were not recovered. pH of the cell lysate was not checked as it was not part of the original protocol. 10\% SDS-PAGE showing separation of indicated aliquots and $2 \mu 1$ ladder from Invitrogen. 


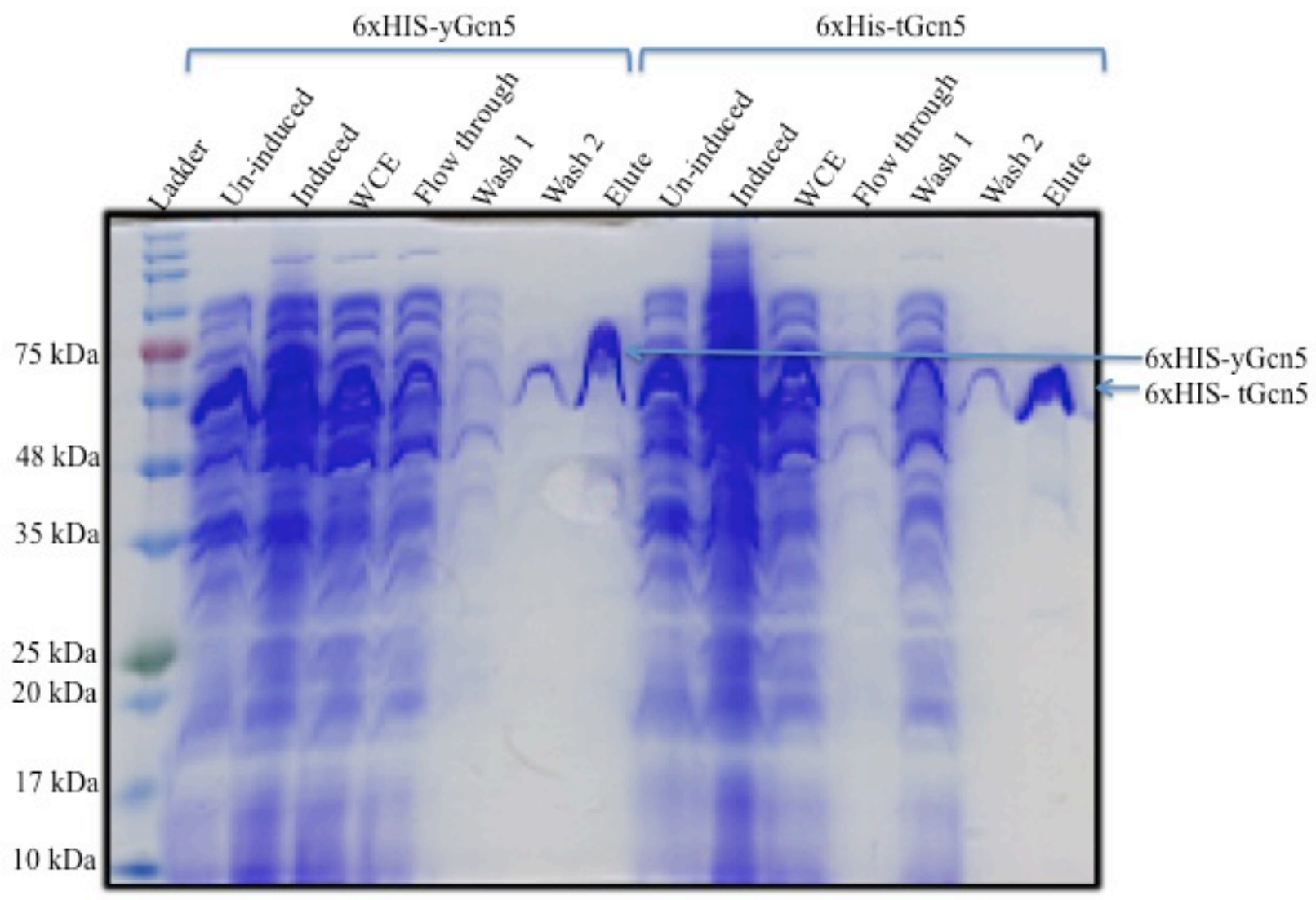

Figure 18: Coomassie-Blue stained SDS-PAGE of different aliquots from the purification of yGen5 and tGen5 with adjusted buffer pH: 10\% SDS-PAGE showing separation of indicated aliquots and $2 \mu 1$ ladder from Invitrogen. 


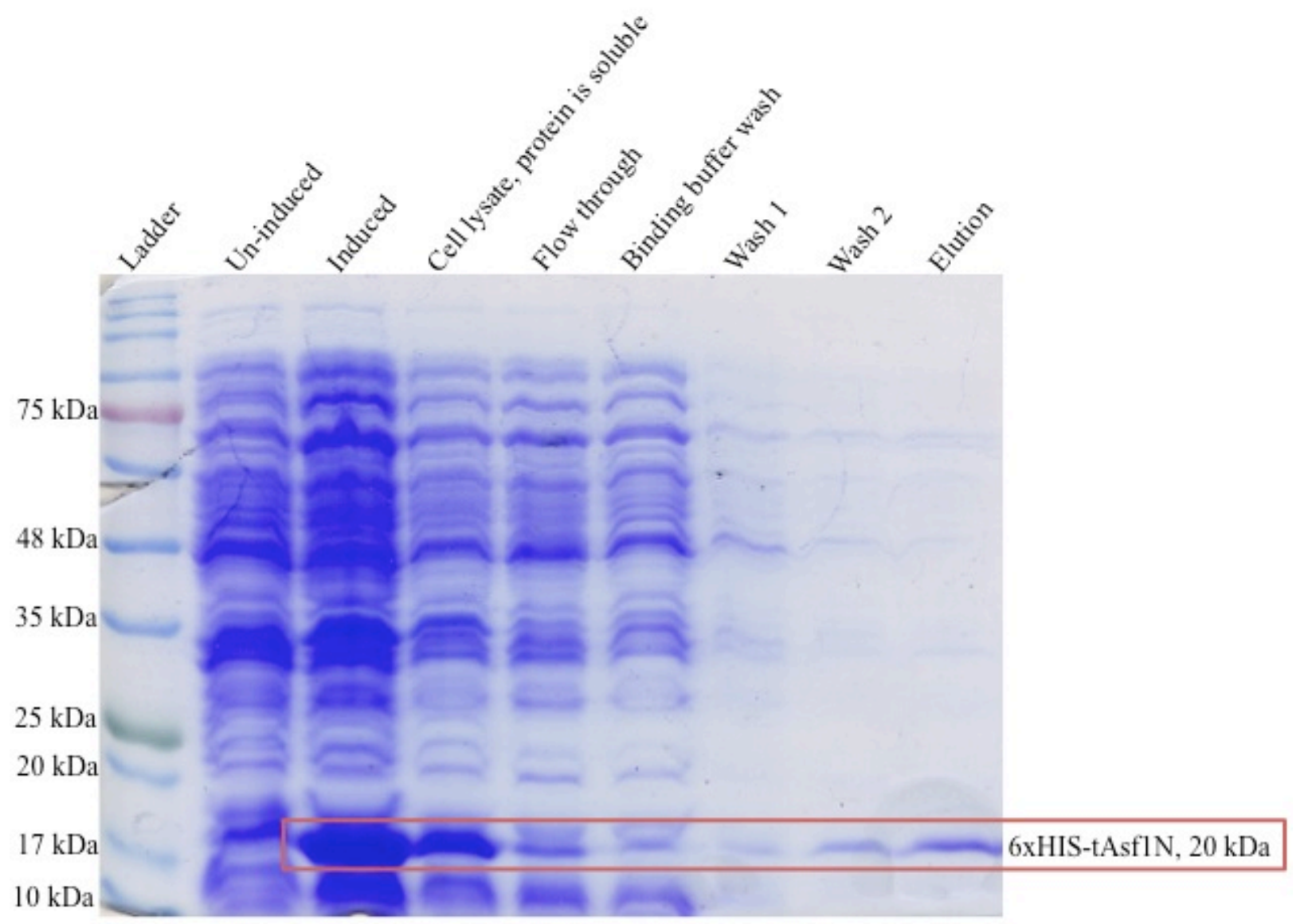

Figure 19: Coomassie-Blue stained SDS-PAGE of different aliquots from the purification of tAsf1N with adjusted buffer pH: $10 \%$ SDS-PAGE showing separation of indicated aliquots and $2 \mu \mathrm{l}$ ladder from Invitrogen. 


\subsection{In Vitro results:}

I expressed recombinant proteins in order to test their function in (A) histone acetylation assays and (B) histone binding assays.

The idea behind the histone acetylation assay is to measure the acetyl group transfer from the acetyl group donor (acetyl-CoA) to the lysine residues on histone H3. In this assay, prospective candidate enzymes (tGen5, yGen5 or Rtt109 with or without either tAsf1/Asf1N or yAsf1/Asf1N) will be incubated with chicken or T. thermophila core histone proteins as substrate (Figure 27). Using WB, I examined the presence of H3K9ac, H3K18ac and H3K56ac marks. H3K18ac is a positive control for yGen5 activity. H3K56ac is positive by Rtt109 with yAsf1 in vitro.

The idea behind the histone-binding assays is to measure the histone chaperone tAsfl ability to bind H3-H4. 6xHIS-tAsf1 or 6xHIS-tAsf1N is incubated with chicken or $T$. thermophila core histone and then the mixture is purified using nickel bead. The elute is then checked using SDS-PAGE to determine if $\mathrm{H} 3-\mathrm{H} 4$ from either source co-purify with the histone chaperone. 6xHIS-yAsf1 was also tested as a positive control. 


\subsection{HAT assay results:}

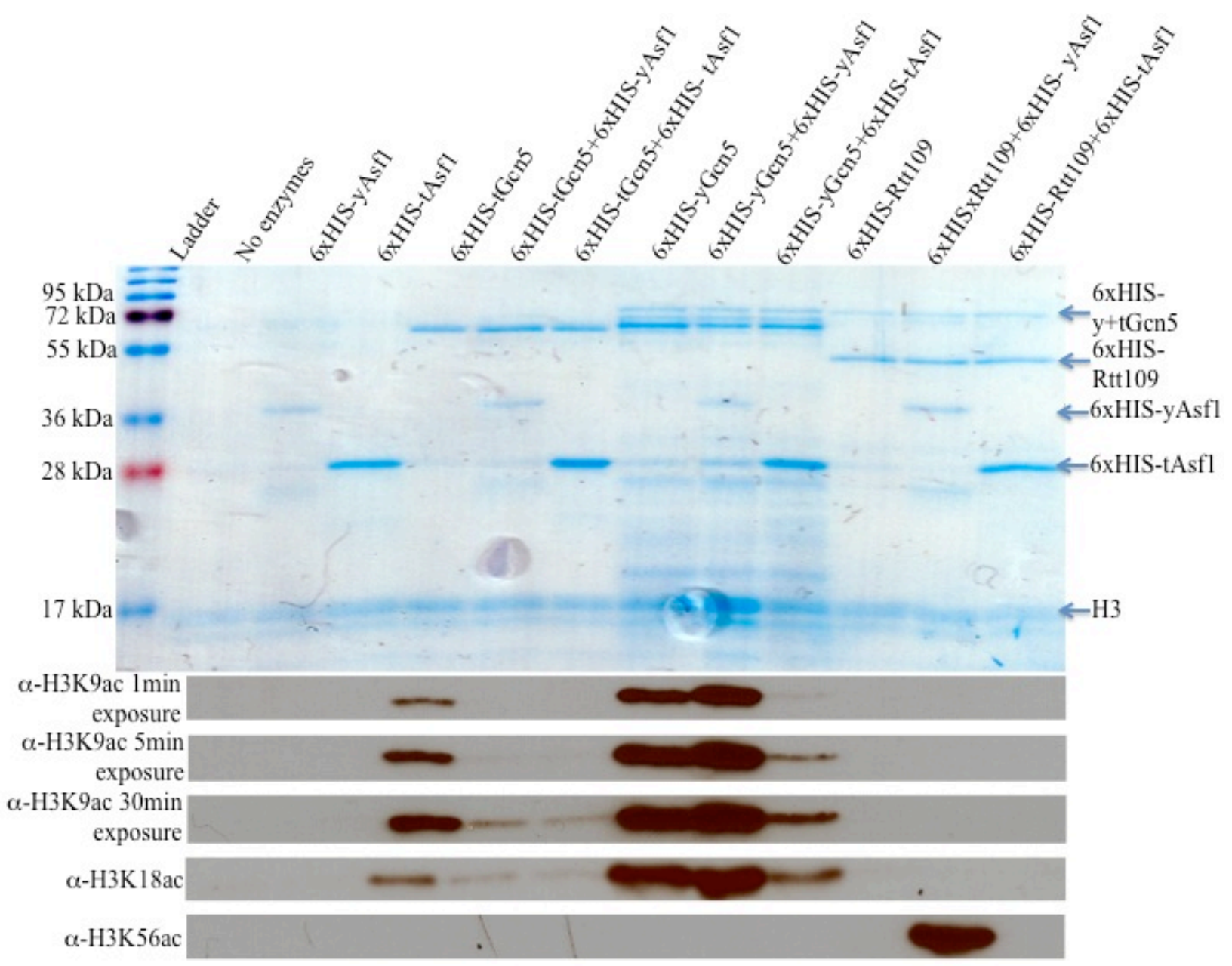

Figure 20. In vitro HAT assays with chicken core histones: recombinant enzymes and chicken core histones are mixed as indicated. $10 \mu \mathrm{l}$ from the reaction is separated on several $15 \%$ SDSPAGE stained with Coomassie-Blue and transferred to nitrocellulose and blotted against indicated antibodies for PTM marks detection.

As expected from previous work, 6xHIS-Rtt109 acetylated H3K56 in presence of 6xHIS-yAsf1 (Figure 20) (Fillingham et al., 2008) but not by itself, nor did it acetylate H3K9 or H3K18 (Figure 20). The lack of H3K18ac is expected since yGen5 does this in yeast. The lack of in vitro H3K9ac by Rtt109-yAsf1 is a consequence of the additional requirement of Vps75 (Fillingham et al., 2008). tAsf1 failed to substitute the role of yAsf1 in H3K56ac in that it did not synergize with Rtt109 (Figure 20). yGen5 was able to acetylate H3K9 and H3K18 by itself 
but not H3K56. yAsf1 seems to have no effect on yGen5 while tAsf1 appears to greatly inhibit it (Figure 20). Interestingly tGen5 in vitro performs the same functions as yGcn5 in H3K9ac and H3K18ac and does not do H3K56ac, however its in vitro activity is almost abolished by the presence of either yAsf1 or tAsf1 (Figure 20).

This experiment can be summarized as follows:

\section{1. tGen5 acetylate chicken $\mathrm{H} 3 \mathrm{~K} 9$ and $\mathrm{H3K18}$ in vitro:}

In the HAT assay, tGen5 has abundant activity on chicken H3K9/18 acetylation (Figure 20). Therefore, my recombinant tGen5 is active and able to acetylate histones.

\section{2. tGen5 does not acetylate chicken H3K56 in vitro:}

In the HAT assay, tGcn5 does not have any activity on H3K56, with or without both tAsf1 or yAsf1 (Figure 20). The in vitro data is consistent with the in vivo phenotype of tGen5 expressed in yeast ( Figure 9 to 13).

\section{3. tAsf1 may inhibit tGen5 acetylation of chicken H3K9/18 in vitro:}

tAsf1 appears to inhibit the activity of tGen5 on chicken core $\mathrm{H} 3$ in that levels of H3K9ac and $\mathrm{H} 3 \mathrm{~K} 18 \mathrm{ac}$ were significantly decreased when tGen5 was incubated in presence of tAsf1 (Figure 20). This could be due to competitive binding from tAsf1 that blocks the function of tGen5, suggesting that tAsf1 is functional and can bind chicken $\mathrm{H} 3$.

\section{4. yAsf1 may inhibit tGen5 acetylation of chicken histone $\mathrm{H} 3$ in vitro:}


Similar to the presence of tAsf1, I observed that yAsf1 inhibited the activity of tGcn5 on chicken core $\mathrm{H} 3$. Both $\mathrm{H} 3 \mathrm{~K} 9$ and $\mathrm{H} 3 \mathrm{~K} 18$ are present within close proximity of each other in the $\mathrm{N}$-terminal tail of H3. This suggests that yAsf1 and tAsf1 could occlude or sequester the Nterminus of $\mathrm{H} 3$ away from tGen5 when it binds histones. Protection of N-terminal tails from spurious post-translational modification has previously been proposed to be a function of histone chaperones (Recht et al., 2006; Fillingham et al., 2008).

\section{5. yAsf1 with tGen5 does not acetylate chicken H3K56 in vitro:}

In yeast yAsf1 is believed to bind to $\mathrm{H} 3-\mathrm{H} 4$ and adjust its structure in such a manner that it exposes H3K56 for acetylation by Rtt109 (Antczak et al., 2006). Even though yAsf1 binds to chicken $\mathrm{H} 3-\mathrm{H} 4$ and in doing this it aid Rtt109 to acetylate H3K56 both in vivo (Figure 12) and in vitro (Figure 20), it has failed to synergize with tGcn5 with respect to H3K56ac (Figure 20). This could be due to tGen5 not being a HAT for H3K56ac, or the physical interaction with chicken histone being different than that of $T$. thermophila histones.

\section{6. tAsf1 doesn't substitute the role of yAsf1 in aiding Rtt109 in the acetylation of} chicken H3K9/56 in vitro:

As discussed above and in the introduction, yAsf1 binds $\mathrm{H} 3$ and $\mathrm{H} 4$ and exposes H3K56 to Rtt109 for acetylation. tAsf1 failed to substitute for yAsf1 in that H3K56 acetylation was not observed when tAsf1 was incubated with Rtt109 (Figure 20). This could be due to differences in the pattern of binding of tAsf1 to H3-H4 than that of yAsf1, or differences in the manner Rtt109 is recruited by Asf1 to acetylate the $\mathrm{H} 3-\mathrm{H} 4$ dimer. 


\section{Rtt109 does not acetylate chicken H3K9 in vitro without Vps75:}

Rtt109 needs Vps75 to acetylate H3K9 in vitro and in vivo (Fillingham et al., 2008). The in vivo requirement of Asf1 in the Rtt109 likely reflects Asf1 binding to the $\mathrm{H} 3-\mathrm{H} 4$ dimer and presenting them to a Rtt109-Vps75 protein complex for acetylation (Fillingham et al., 2008). Hence the result that Rtt109 does not acetylate H3K9 in the in vitro HAT assay without the presence of Vps75, although it clearly requires it in vivo (Figure 12) (Fillingham et al., 2008).

\subsection{T. thermophila histones purified:}

One possible reason that $\mathrm{tGcn} 5$ does not acetylate $\mathrm{H} 3 \mathrm{~K} 56$ in vivo in yeast or in vitro using chicken core histones, is that it requires bona fide T. thermophila histones. Similarly, one reason that tAsfl does not rescue H3K56ac defect of yeast $\Delta a s f 1$ is that it won't synergize with Rtt109 in vitro because it can only bind T. thermophila H3. Because of what was discussed earlier that yAsf1 was shown to interact with $\mathrm{H} 3$ at Aspartic acid (D) 54, Glycine (G) 91, Valine (V) 92, Valine (V) 94, Leucine (L) 96, Arginine (R) 145 and Threonine (T) 147 (Antczak et al., 2006; English et al., 2006) and that all these amino acid residues are conserved between $S$. cerevisiae and T. thermophila except V94 (Figure 4). Therefore, in order to perform HAT assay on T. thermophila core histones, as well as to perform the histone binding assay, core histone from the macronuclei of $T$. thermophila cells was purified (Figure 21). And WB analysis to characterize the prepared histones was performed (Figure $21 \mathrm{~B}$ ). Although the antibody that was used against $\mathrm{H} 3$ did not give any signal, it was shown that it does not work against histones prepared from starved cells (Pearlman Lab, unpublished communication). 


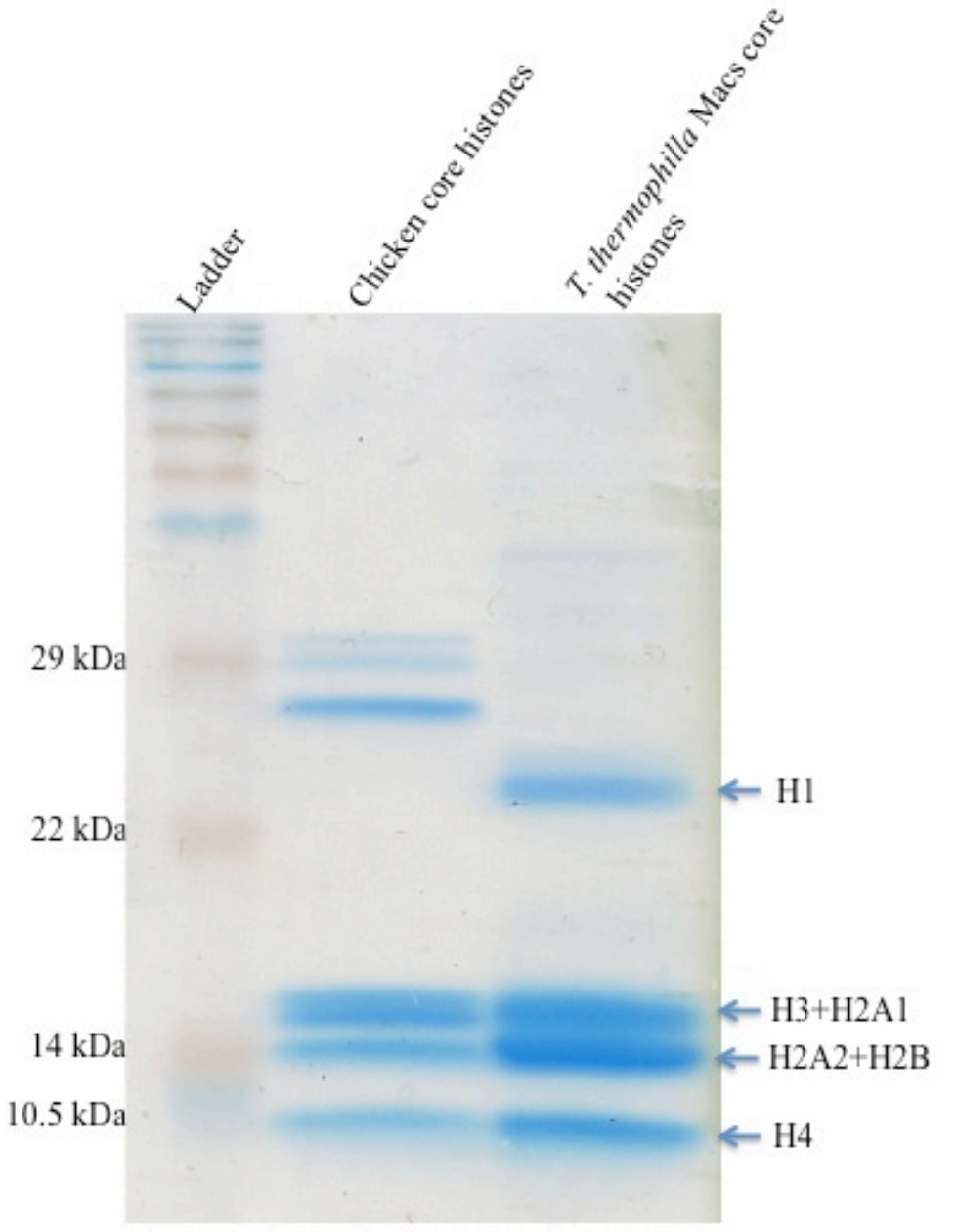

A

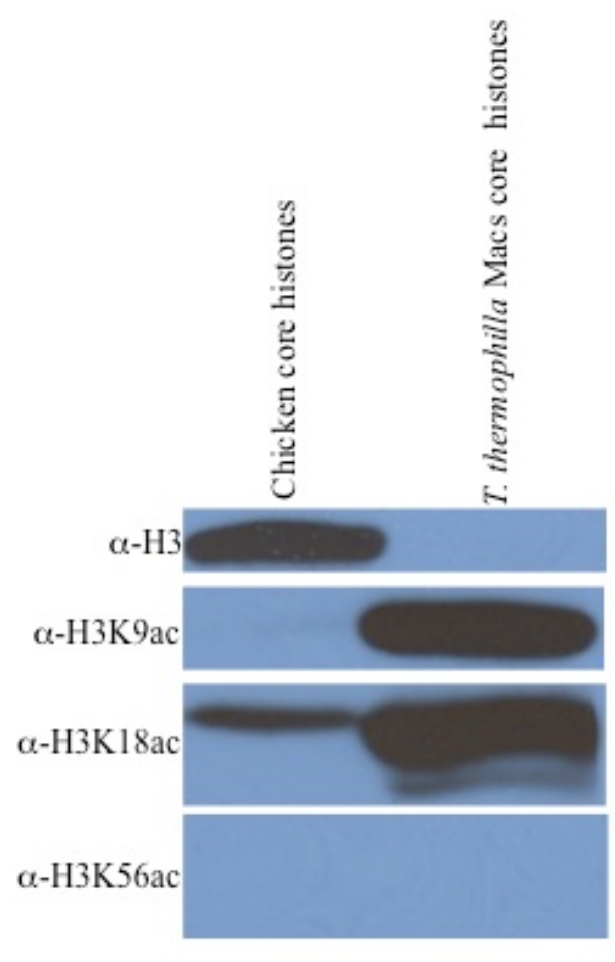

B

Figure 21: Purified T. thermophila histones: A:15\% SDS-PAGE separation of purchased chicken core histone (MilliPore) and core histones prepared form T. thermophila macronuclei (Macs). T. thermophila histones are labelled based on molecular weight; $\mathrm{H} 1=18 \mathrm{kDa}, \mathrm{H} 2 \mathrm{~A} 1$ or $\mathrm{H} 3=15 \mathrm{kDa}, \mathrm{H} 2 \mathrm{~A} 2=14 \mathrm{kDa}, \mathrm{H} 2 \mathrm{~B}=13 \mathrm{kDa}$ and $\mathrm{H} 4=11 \mathrm{kDa} .5 \mu 1$ for each sample and $2 \mu 1$ ladder from Fermnetas is used. B: WB blot analysis of purchased chicken histones and prepared $T$. thermophila hisotones with indicated antibodies for the PTM's. 


\subsection{In Vitro Histone binding assay results:}

An experiment was designed where either 6xHIS tagged tAsf1, tAsf1N or yAsf1N is incubated with chicken or T. thermophila histones at $30{ }^{\circ} \mathrm{C}$ for 30 minutes. The mixture was then incubated with nickel beads for 15 minutes and after several high stringency washes, the beads were treated to elute bound protein and separated by SDS-PAGE. The gel was then either stained with Coomassie, silver stain, or Western blotted as required to see what histones co-purified with the respective enzyme

To ensure that the experiment conditions were appropriate, I used yAsf1N as a positive control as it has been shown to bind H3-H4 in vitro (Daganazo et al., 2003). The experiment was proven to be working by showing that yAsf1N binds to H3-H4 (Figure 22 and Figure 23). 


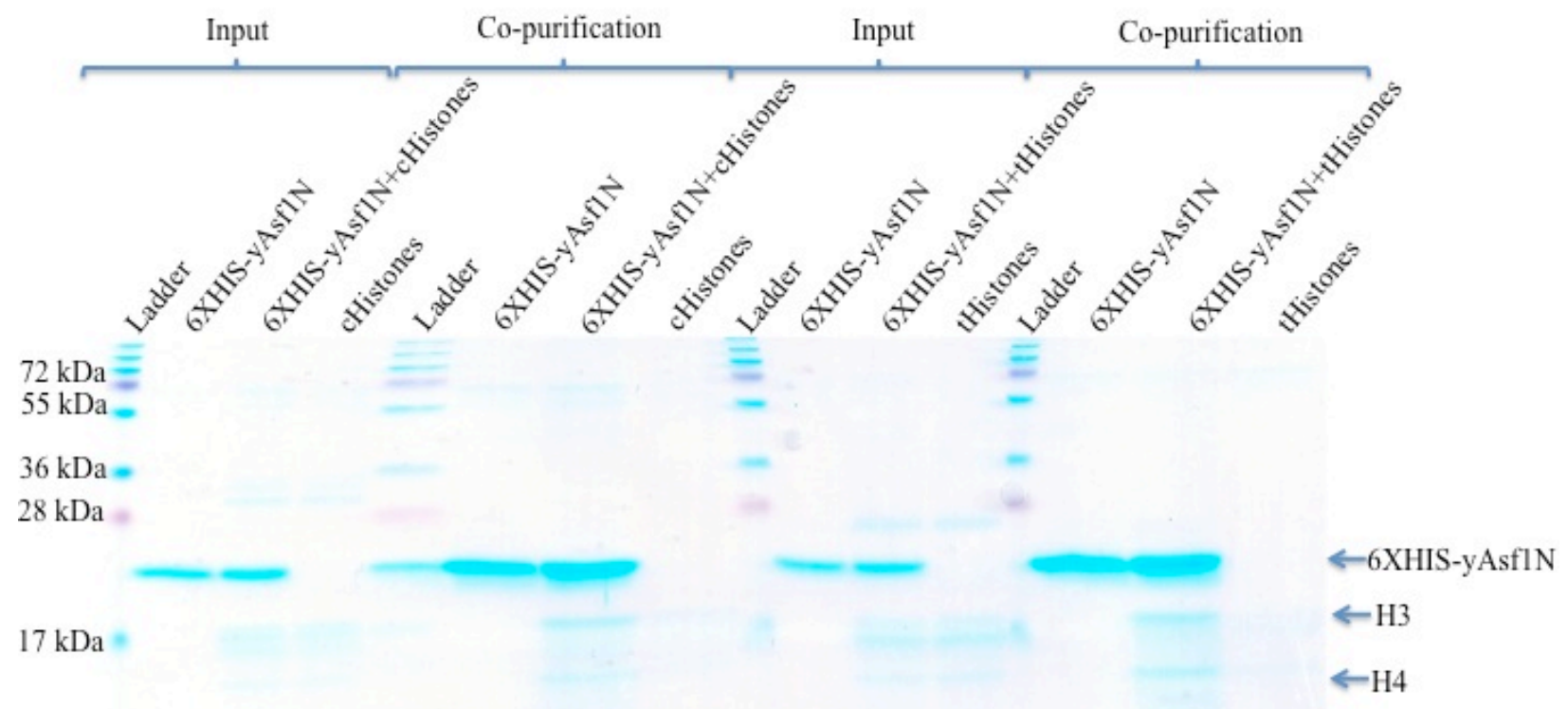

$10 \mathrm{kDa}$

Figure 22: yAsf1N histone binding Assay. Chicken histone or T.thermophila histones and 6xhis-yAsf1N are incubated together or alone as indicated and $10 \mu \mathrm{l}$ is separated for input and the mixture is then purified using nickel beads and the elute is separated to check if histone copurify with yAsf1N. Coomassie stain of 15\% SDS-PAGE gel. Input and co-purification were separated to allow for different development times depending on protein concentration. 


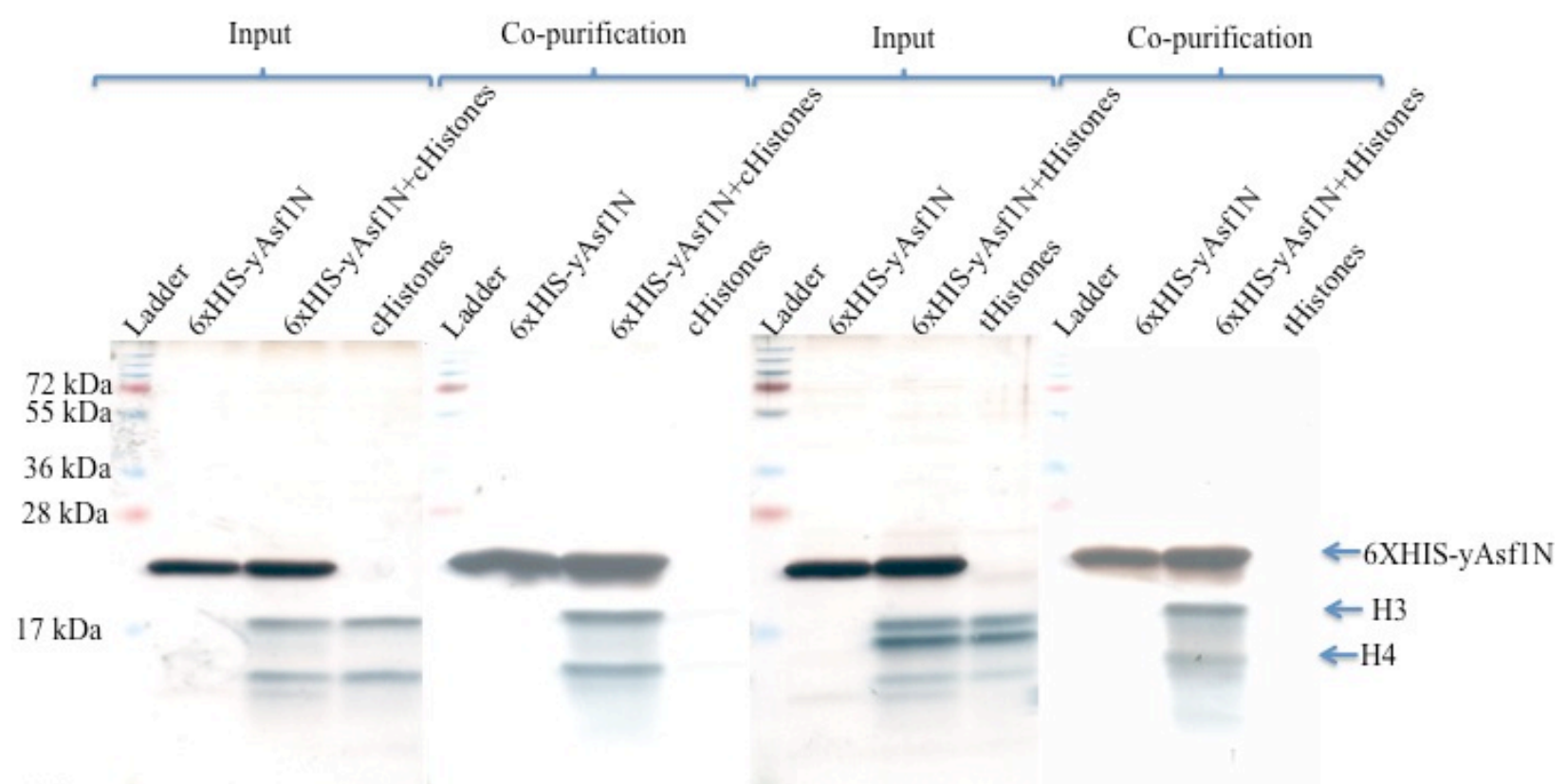

$10 \mathrm{kDa}$

Figure 23: yAsf1N histone binding Assay silver stain. Chicken histone or T.thermophila histones and 6xhis-yAsf1N are incubated together or alone as indicated and $10 \mu l$ is separated for input and the mixture is then purified using nickel beads and the elute is separated to check if histone co-purify with yAsf1N. Silver stain of 15\% SDS-PAGE gel. Input and co-purification were separated to allow for different development times depending on protein concentration.

\subsection{1 tAsf1 binds both chicken and T. thermophila $\mathrm{H} 3-\mathrm{H} 4$ in vitro:}

After performing the histone binding assay on 6xHIS-tAsf1 I have shown that it does bind to H3-H4 (Figure 24), in that 6xHIS-tAsf1 co-purifies with H3-H4. Therefore, the lack of ability of tAsf1 to synergize with Rtt109 in vitro (Figure 20), or in vivo (Figure 12) is not due to lack of H3-H4 binding. 


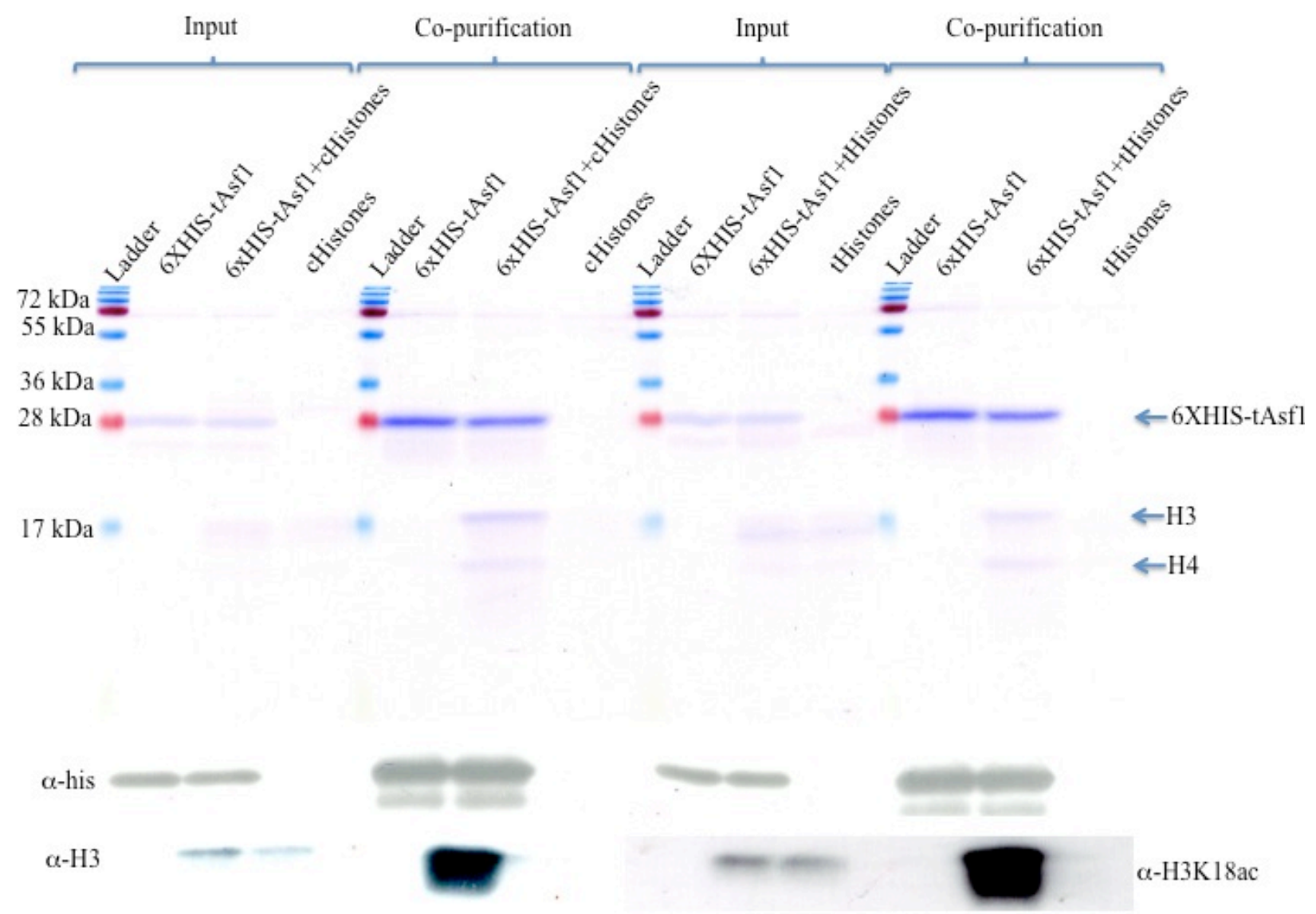

Figure 24: tAsf1 histone binding Assay: Chicken histone or T.thermophila histones and 6xhistAsfl are incubated together or alone as indicated and $10 \mu \mathrm{l}$ is separated for input and the mixture is then purified using nickel beads and the elute is separated to check if histone co-purify with 6xhis-tAsf1. Several 15\% SDS-PAGE gels are used and stained with coomassie and blotted for indicated antibodies.

\subsection{2 tAsf1N binds both chicken and Tetrahymena $\mathrm{H3}-\mathrm{H} 4$ in vitro:}

Since there are differences in the C-terminal domain of tAsfl and yAsf1 (Figure 4). I was interested to see if loss of the C-terminal domain in tAsf1N would affect its binding to H3-H4. I have shown here that it still binds both chicken and T. thermophila $\mathrm{H} 3-\mathrm{H} 4$ (Figure 25), in that affinity purified 6xHIS-tAsf1N co-purifies with H3-H4. It was confirmed by this experiment that tAsfl binds H3-H4 at its highly conserved N-terminal domain. 


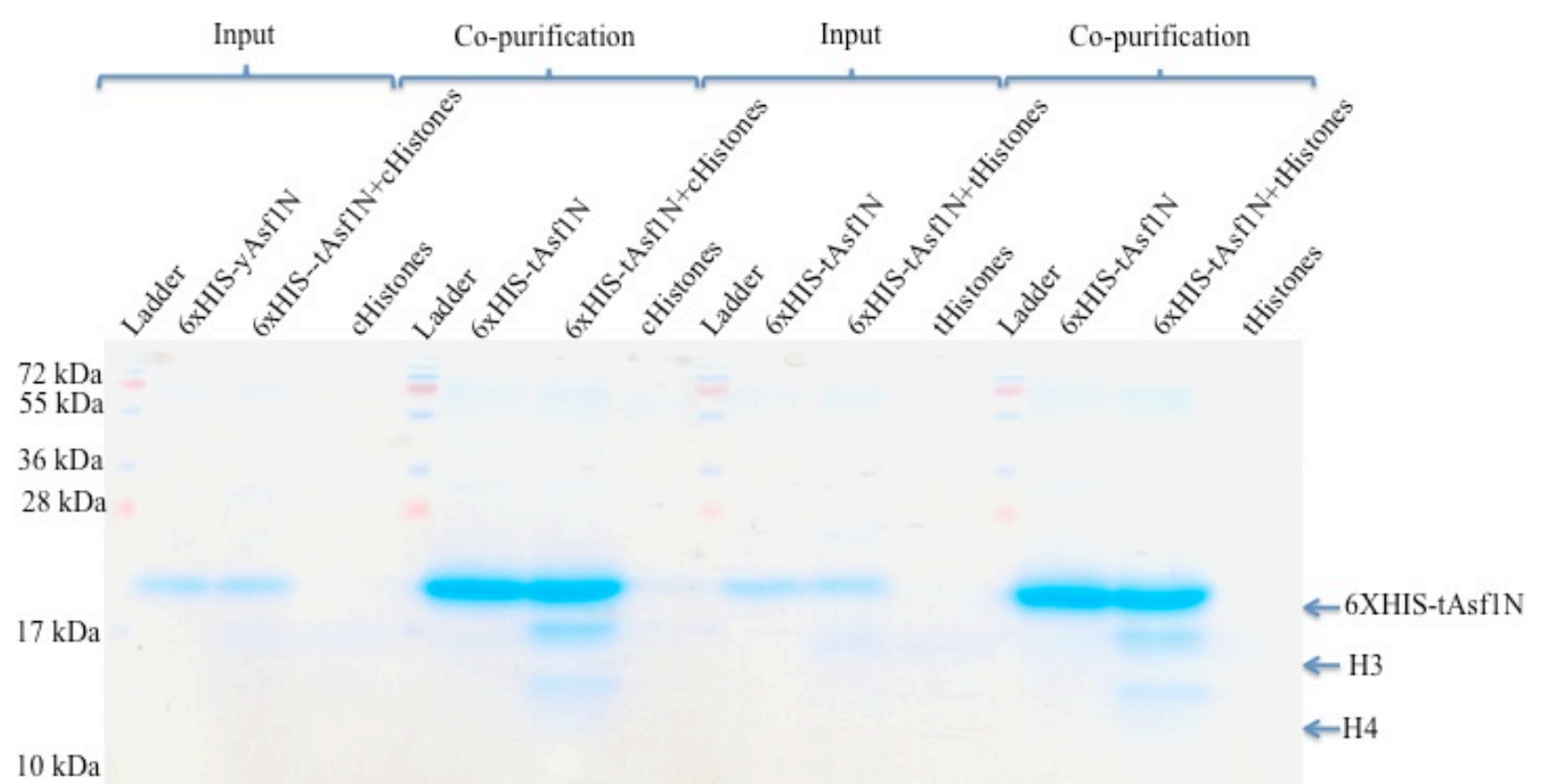

Figure 25: tAsf1N histone binding Assay: Chicken histone or T.thermophila histones and tAsf $1 \mathrm{~N}$ are incubated together or alone as indicated and $10 \mu \mathrm{l}$ is run for input and the mixture is then purified using nickel beads and the elute is separated to check if histone co-purify with tAsf1N. Showing Coomassie stain of 15\% SDS-PAGE gel. 


\section{Chapter 4: Discussion}

\subsection{Rtt109 and yGen5 have two separate pathways for H3K9 acetylation}

As discussed in the introduction, it has been shown that Rtt109 and yGen5 have two distinct pathways for H3K9ac (Fillingham et al., 2008 and Burgess et al., 2010); when $y A S F 1$ was knocked out, the yeast mutants lost some H3K9ac activity by Rtt109 but not from Gen5 (Fillingham et al., 2008). My data suggest the same conclusion; when $\Delta r t t 109 / g c n 5$ was transformed with either RTT109 or $y G C N 5$ some but not all of the H3K9ac activity was restored compared to wild type. Thus either yGen5 or Rtt109 can acetylate H3K9 by themselves without the existence of the other but not to the same extent when both of them are present.

\section{2 tGen5 has HAT activity on $\mathrm{H} 3$ in vitro}

In the in vitro analysis, tGen 5 showed strong $\mathrm{H} 3 \mathrm{~K} 9 \mathrm{ac}$ and $\mathrm{H} 3 \mathrm{~K} 18 \mathrm{ac}$ activity but failed to perform the same functions in vivo in S. cerevisiae. In the sequence alignment analysis I have shown that tGen5 is the only Gen5 homolog that lacks a predicted nuclear localization signal (NLS) (Figure 3). One possible explanation for the lack of acetylation in vivo is that tGen5 does not localize to the nucleus where $\mathrm{H} 3$ is in S. cerevisiae although this needs to be confirmed using GFP analysis (in progress). This could also suggest that nuclear localization may occur differently in T.thermophila than yeast.

\section{3 tAsf1 does not synergize with Rtt109}

In the HAT assay tAsf1 failed to substitute yAsf1 role in aiding Rtt109 to acetylate H3K56 in vitro (Figure 20). Despite the fact that tAsf1 does bind to H3-H4 (Figure 24), this 
binding is probably not performing the same function in exposing H3K56 for aceytelation by Rtt109 as does yAsf1 .

\section{4 tAsf1 binds to $\mathrm{H3}$ in a way that does not resemble yAsf1}

In the HAT assay tAsf1 but not yAsf1 showed an inhibitory effect on H3K18ac activity by tGen5 in vitro (Figure 20). This could be explained by the Asf1 amino acid sequence alignment that shows that some of the H3 binding sites (S91, V94 and L96) of S. cerevisiae Asf1 are not conserved in T. thermophila and thus the binding of tAsf1 with $\mathrm{H} 3$ is different than that of yAsfl.

\section{5 tAsf1 binds $\mathrm{H} 3-\mathrm{H} 4$ through its highly conserved N-terminal domain}

From the histone binding assays. tAsf1, tAsf1N and yAsf1N were all able to bind H3-H4. It is safe to conclude from this experiment that S. cerevisiae and T.thermophila Asf1 bind H3-H4 through the highly conserved $\mathrm{N}$-terminal domain and that the C-terminus, deleted in both yAsf1N and tAsf1N, probably plays no role in this interaction.

\section{6 tGen5 have a different structural mechanism for interacting with $\mathrm{H} 3$ than $\mathrm{yGcn} 5$}

As shown by the in vitro HAT assays, tGen5 can acetylate both H3K9 and H3K18. Interestingly yAsf1 inhibits tGen5 activity but not yGen5. This suggest a difference in the structural interaction of tGen5 than yGen5. 


\subsection{Future experiments}

In the future, work will be done to assess the localization of tAsf1, tAsf1N, tGen5 and yAsf1N within yeast cells. This will be achieved using GFP tagging to examine if these proteins localize within the nucleus or the cytoplasm. The questions that will be asked here are, is tGcn5 able to localize to the nucleus of $S$. cerevisiae as yGen5 does and does any of yAsf1N, tAsf1 and tAsf1N localize to the nucleus of $S$. cerevisiae as does yAsf1. I expect that tGen5, tAsf1 and yAsf1N will fail to localize in the nucleus of S.cerevisiae as predicted by the sequence alignments that shows a lack of predicted NLSs in tGen5, tAsf1 and yAsf1N (Figure 3 and Figure 4).

Another experiment that will be done is the knock out of the tGCN5 gene in T.thermophila in order to study the effect on $\mathrm{H} 3 \mathrm{~K} 9 / 18 / 56$ acetylation in vivo. I expect that all these marks will be substantially if not completely abolished. tAsfl is being knocked out in T.thermophila to study its role in aiding the acetylation of $\mathrm{H} 3 \mathrm{~K} 9 / 18 / 56$ in vivo.

After doing all these experiments, the next question would be is what if tGen5 is not an H3K56 HAT? and then what is?. Other candidates could be Hat1 which was discussed in the introduction or 3 of the EsaI family ESA1 is an essential HAT which has been discovered to acetylate primarily histone H4 (Smith et al., 1998 and Clarke et al., 1999).

Another candidate enzyme is MEC-17 that has shown to be an alpha-tubulin acetyltransferase in T. thermophila and C. elegans (Akella et al., 2010). 


\section{Chapter 5: Conclusions}

These analyses by in vivo and in vitro methods characterized the roles of yAsflN, tGen5 \& tAsf1 in the acetylation of H3K9, H3K18 \& H3K56. tGen5 was able to acetylate H3K9 and H3K18 in vitro but not in vivo in S. cerevisiae, and was unable to acetylate H3K56 in either case. tGen5 was also incapable of rescuing the $\triangle r t t 109 / g c n 5$ S. cerevisiae mutant phenotype. The activity of yAsf1N was greatly decreased in vivo probably due to it is lack of the amino acid sequence ${ }^{255} \mathrm{KKRRKIE}^{261}$ which is a predicted NLS that could be important for the localization of the protein in the nucleus. tAsfl failed to substitute the role of yAsf1 in the acetylation of H3K56 by Rtt109, and even had an inhibitory effect on yGen5 with regards to H3K9 and H3K18 acetylation. tAsf1 was also unable to rescue the $\triangle$ asfl/gcn 5 S. cerevisiae mutant phenotype.

Using database searches I found that $T$. thermophila is the only organism that encodes a Gen5 without a predicted NLS. This can explain the inability of tGen5 to acetylate H3K9 and H3K18 in S.cerevisiae while being capable to acetylate those lysines in vitro, although this needs to be demonstrated. In T.thermophila Gen5 could bind to another protein to localize to the nucleus or even by itself and carry out the acetylation of H3K9 \& H3K18. 


\section{Chapter 6: Appendices}

Appendix 1: The sequences for the Tetrahymena thermophila synthetic genes and all primers

tASF1: 753bp

ATGGCCTTAGTCAACATCCAAAACATCCAATTTCATAACAACCCTTGCCCTTTTTTGA GTCCCTTTAAACTTGACGTAACCTTCGAATGTATCAAACCTATACCTGATGACATTG AATGGCAATTAATTTATATTGGTTCTGCTAAAGATGAGAAATACGATCAAGTCCTTG ATAAATTCAGTATTGGGTCATTAGATCAAGGAGTGCTTCAATTTACCATTGAAACAA ATCCACCTGATCACACTAAGATTCCAAACAAAGATGATTTACTTGGTGTAACTGCTA TAATTCTAACTGTTTCATACCACAATCAGGAGTTTTTCCGTGTTGGATACTATGTCTA CAATCAATACAATGATCAGGAACTTATTATTAATGATCCTCCTCAAATTCTAATTGA TAAGGTTGAGCGTAGTATCCTTGATAAACAGCCTCGTATCACTCATTTCAACATAAA ATGGGGTACTGAGGATGAAAATAAAGAAACTGACCCTAATACTTTAGCTATCCTCCA ACAGCAATTAGCTCAAAATGGAACCATTCCTAATCAACTCATGCAAGAAATGCAAC AAGTGAATAGCCAAATGCAATCTTTCTTACCTGATCCTTTTTCTAAGTCATCAGGAAT ACTCCAAGAGTTAACAACACAAGGACAGACTAACAGCACAAATAGTTTCATGTTTG GTCAAGGGCTAGACATACCTCAAAATAATGCATTCCAACCTACAAATGTATTCAGTT CTAATCCTTACTAA

tASF1N, need to be produced by PCR, $468 \mathrm{bp}$ :

ATGGCCTTAGTCAACATCCAAAACATCCAATTTCATAACAACCCTTGCCCTTTTTTGA GTCCCTTTAAACTTGACGTAACCTTCGAATGTATCAAACCTATACCTGATGACATTG AATGGCAATTAATTTATATTGGTTCTGCTAAAGATGAGAAATACGATCAAGTCCTTG 
ATAAATTCAGTATTGGGTCATTAGATCAAGGAGTGCTTCAATTTACCATTGAAACAA ATCCACCTGATCACACTAAGATTCCAAACAAAGATGATTTACTTGGTGTAACTGCTA TAATTCTAACTGTTTCATACCACAATCAGGAGTTTTTCCGTGTTGGATACTATGTCTA CAATCAATACAATGATCAGGAACTTATTATTAATGATCCTCCTCAAATTCTAATTGA TAAGGTTGAGCGTAGTATCCTTGATAAACAGCCTCGTATCACTCATTTCAACATAAA ATGGGGTACT

tGCN5, 1257 bp:

ATGGCTGATCAAGAAAAATCTGCCCAAGATGCGCAGAATGCTGCACCACAGGAAAC CGCATTTGTTGGTATGAATGGTGAAGAAACCGGTCTGGGTTTTGCCACCCGTGATCA AGGTGCGAAAGTTGAAGAAGATCAGGGTCTGCTGGATTTTGATATTCTGACCAATGA TGGTACTCATCGTAATATGAAACTGCTGATCGATCTGAAGAACATTTTTAGCCGTCA ACTGCCAAAGATGCCGAAGGAATACATCGTTAAACTGGTTTTCGATAGACATCATGA ATCTATGGTTATCCTGAAGAACAAGCAGAAGGTTATTGGTGGTATTTGTTTCCGTCA ATACAAACCGCAGAGATTTGCTGAAGTTGCATTTCTGGCCGTTACCGCGAATGAACA AGTTCGTGGTTACGGTACTAGACTGATGAACAAGTTCAAGGATCACATGCAAAAGC AGAATATTGAATATCTGCTGACCTATGCTGATAACTTCGCAATCGGTTACTTCAAGA AACAAGGTTTTACCAAAGAACATCGTATGCCACAGGAAAAGTGGAAGGGTTACATC AAGGATTACGATGGTGGTACTCTGATGGAATGTTACATCCATCCGTATGTTGATTAC GGTAACATCTCTCAAATCATCAAACGTCAGAAGGAACTGCTGATCGAAAGAATTAA AAAACTGTCTCTGAACGAAAAGGTGTTTTCTGGCAAGGAATACGCCGCGCTGATCCA AAATTCTATGGATAACGAAGATCCAGAAAATCCGAAAGTTAATCCATCTGATATTCC GGGTGTTGCCTTTTCTGGTTGGGAATGGAAGGATTACCATGAACTGAAAAAATCTAA 
GGAACGTTCTTTTAATCTGCAATGTGCGAACGTTATCGAAAACATGAAGAGACATAA GCAGTCTTGGCCATTTTTAGATCCAGTTAACAAGGATGATGTTCCAGATTACTATGA TGTTATTACCGATCCGATCGATATTAAGGCTATCGAAAAGAAACTGCAAAATAATCA GTATGTTGATAAAGATCAATTCATCAAGGATGTTAAGCGTATCTTCACCAATGCTAA GATCTACAACCAGCCAGATACCATCTACTACAAGGCTGCAAAGGAACTGGAAGATT TTGTTGAACCATATCTGACCAAACTGAAAGATACTAAGGAATCTAACACCCCGTCTA ACAACAACTCTGCTCATGGTTCTAAAAAACCACTGCCGGTTAGAAAATCTATTAAGA AAAAATAA

the primers are:

tAsf1F Sequence:

5'- CCC GGA TCC ATG GCC TTA GTC AAC ATC CAA AAC ATC CAA -3'

tAsf1R Sequence:

5'- CCC CTC GAG TTA GTA AGG ATT AGA ACT GAA TAC ATT TGT -3'

tAsf1-N-R Sequence:

5'-CCC CTC GAG TTA AGT ACC CCA TTT TAT GTT GAA -3'

tGen5F Sequence:

5'- CCC GGA TCC ATG GCT GAT CAA GAA AAA TCT GCC CAA GAT -3'

tGcn5R Sequence: 
5'- CCC CTC GAG TTA TTT TTT CTT AAT AGA TTT TCT AAC CGG -3'

yAsf1F Sequence:

5'- CCC GGA TCC ATG TCA ATT GTT TCA CTG TTA GGC ATC AAA -3'

yAsf1R Sequence:

5'- CCC CTC GAG TTA ATT CGT TGA ACG TGC CGC ATC CTT TGG-3'

yAsf1-N-R Sequence:

5'-CCC CTC GAG TTA ATC CCA AAC AAT GTT AAA CCT TGT TAC -3'

yGen5F Sequence:

5'- CCC GGG CCC ATG GTC ACA AAA CAT CAG ATT GAA GAG GAT -3'

yGcn5R Sequence:

5'- CCC CTC GAG TTA ATC AAT AAG GTG AGA ATA TTC AGG TAT -3' 


\begin{tabular}{|c|c|c|}
\hline Strain & Genotype & Source \\
\hline BY4741 & MATa, ura $3 \Delta 0$, leu $2 \Delta 0$, his $3 \Delta 1, \operatorname{met} 15 \Delta 0$ & (Winzler et al., 1999) \\
\hline BY4741-1 & BY4741+ pRB415-12myc $\left[\mathrm{LEU}^{+}\right]$ & This work \\
\hline $\mathrm{SC} 217$ & BY4741, asf $1 \Delta:: \mathrm{KAN}$ & (Winzler et al., 1999) \\
\hline SC217-1 & $\mathrm{SC} 217+\mathrm{pRB} 415-12 \mathrm{myc}\left[\mathrm{LEU}^{+}\right]$ & This work \\
\hline $\mathrm{SC} 218$ & BY4741, rtt109A::KAN & (Winzler et al., 1999) \\
\hline SC218-1 & $\mathrm{SC} 218+\mathrm{pRB} 415-12 \mathrm{myc}\left[\mathrm{LEU}^{+}\right]$ & This work \\
\hline $\mathrm{JF} 81$ & BY $4741, g c n 5 \Delta::$ KAN & (Fillingham et al., 2008) \\
\hline JF81-1 & $\mathrm{JF} 81+\mathrm{pRB} 415-12 \mathrm{myc}\left[\mathrm{LEU}^{+}\right]$ & This work \\
\hline JF101 & BY4741, rtt109A::NAT & (Fillingham et al., 2008) \\
\hline JF101-1 & $\mathrm{JF} 101+\mathrm{pRB} 415-12 \mathrm{myc}\left[\mathrm{LEU}^{+}\right]$ & This work \\
\hline JF103 & 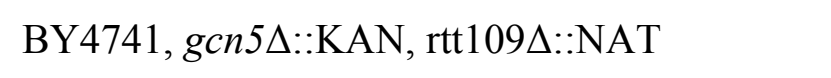 & (Fillingham et al., 2008) \\
\hline JF103-1 & $\mathrm{JF} 103+\mathrm{pRB} 415-12 \mathrm{myc}\left[\mathrm{LEU}^{+}\right]$ & This work \\
\hline $\mathrm{JF} 103-2$ & $\mathrm{JF} 103+\mathrm{pRB} 415-12 \mathrm{myc}\left[\mathrm{LEU}^{+}\right]-y G C N 5$ & This work \\
\hline JF103-3 & JF103+pRB415-12myc $\left[\mathrm{LEU}^{+}\right]-t G C N 5$ & This work \\
\hline JF103-4 & $\mathrm{JF} 103+\mathrm{pRB} 415-12 \mathrm{myc}\left[\mathrm{LEU}^{+}\right]-R T T 109$ & This work \\
\hline $\mathrm{JF} 105$ & $\mathrm{BY} 4741$, asfl $1 \Delta: \mathrm{NAT}$ & (Fillingham et al., 2008) \\
\hline JF105-1 & BY4741, asfl $1 \Delta:: \mathrm{NAT}+\mathrm{pRB} 415-12 \mathrm{myc}\left[\mathrm{LEU}^{+}\right]$ & This work \\
\hline JF109 & BY4741, gcn $5 \Delta:: \mathrm{KAN}$, asf $1 \Delta:: \mathrm{NAT}$ & (Fillingham et al., 2008) \\
\hline JF109-1 & $\mathrm{JF} 109+\mathrm{pRB} 415-12 \mathrm{myc}\left[\mathrm{LEU}^{+}\right]$ & This work \\
\hline JF109-2 & $\mathrm{JF} 109+\mathrm{pRB} 415-12 \mathrm{myc}\left[\mathrm{LEU}^{+}\right]-y A S F 1$ & This work \\
\hline JF109-3 & $\mathrm{JF} 109+\mathrm{pRB} 415-12 \mathrm{myc}\left[\mathrm{LEU}^{+}\right]-y A S F 1 N$ & This work \\
\hline
\end{tabular}


JF109-4 JF109+ pRB415-12myc $\left[\mathrm{LEU}^{+}\right]-t A S F 1$

JF109-5 JF109+ pRB415-12myc $\left[\mathrm{LEU}^{+}\right]-t A S F 1 N$
This work

This work 


\section{Chapter 7. References:}

Ahmad A, Takami Y, Nakayama T (2000). Distinct regions of the chicken p46 polypeptide are required for its in vitro interaction with histones $\mathrm{H} 2 \mathrm{~B}$ and $\mathrm{H} 4$ and histone acetyltransferase-1. Biochem Biophys Res Commun 279, 95-102.

Ai X, Parthun MR. The nuclear Hat1p/Hat2p complex: a molecular link between type B histone acetyltransferases and chromatin assembly. Mol Cell 2004;14:195-205. [PubMed: 15099519]

Akella JS, Wloga D, Kim J, Starostina NG, Lyons-Abbott S, Morrissette NS, Dougan ST, Kipreos ET, Gaertig J.MEC-17 is an alpha-tubulin acetyltransferase.Nature. 2010 Sep 9;467(7312):218-22.

Antczak, A. J., T. Tsubota, P. D. Kaufman, and J. M. Berger. 2006. Structure of the yeast histone H3-ASF1 interaction: implications for chaperone mechanism, species-specific interactions, and epigenetics. BMC Struct. Biol. 6:26.

Annunziato A. T. DNA packaging: nucleosomes and chromatin. Nature Education. 2008

Allis CD, Berger SL, Cote J, Dent S, Jenuwien T, Kouzarides T, Pillus L, Reinberg D, Shi Y, Shiekhattar R, et al. New nomenclature for chromatin-modifying enzymes. Cell 2007;131:633636. [PubMed: 18022353] 
Avvakumov N, Nourani A, Côté J. Histone chaperones: modulators of chromatin marks. Mol Cell. 2011 Mar 4;41(5):502-14.

Barman HK, Takami Y, Ono T, Nishijima H, Sanematsu F, Shibahara K, Nakayama T (2006). Histone acetyltransferase 1 is dispensable for replication-coupled chromatin assembly but contributes to recover DNA damages created following replication blockage in vertebrate cells. Biochem Biophys Res Commun 345, 1547-1557.

Barth TK, Imhof A. Fast signals and slow marks: the dynamics of histone modifications. Trends Biochem Sci. 2010 Nov;35(11):618-26. Epub 2010 Aug 3. Review. [PMID: 20685123]

Benson LJ, Gu Y, Yakovleva T, Tong K, Barrows C, Strack CL, Cook RG, Mizzen CA, Annunziato AT. Modifications of $\mathrm{H} 3$ and $\mathrm{H} 4$ during chromatin replication, nucleosome assembly, and histone exchange. J Biol Chem 2006;281:9287-9296. [PubMed: 16464854]

Berndsen, C.E., Tsubota, T., Lindner, S.E., Lee, S., Holton, J.M., Kaufman, P.D., Keck, J.L., and Denu, J.M. (2008). Molecular functions of the histone acetyltransferase chaperone complex Rtt109-Vps75. Nat. Struct. Mol. Biol.15, 948-956.

Billett M A, and Barry 1 M. Role of histones in chromatin condensation. Eur.J. Biochem. 1979; 49:477-484. 
Blackburn E H, Carol W Greider C W, \& Szostak J W. Telomeres and telomerase: the path from maize, Tetrahymena and yeast to human cancer and aging. NATURE MEDICINE VOLUME 12 ,NUMBER 10 , OCTOBER 2006

Brownell JE, Allis CD. An activity gel assay detects a single, catalytically active histone acetyltransferase subunit in Tetrahymena macronuclei. Proc Natl Acad Sci U S A. 1995 Jul 3;92(14):6364-8.

Brownell JE, Zhou J, Ranalli T, Kobayashi R, Edmondson DG, Roth SY, Allis CD. Tetrahymena histone acetyltransferase A: a homolog to yeast Gcn5p linking histone acetylation to gene activation. Cell. 1996 Mar 22;84(6):843-51.

Burgess RJ, Zhou H, Han J, Zhang Z. A role for Gen5 in replication-coupled nucleosome assembly. Mol Cell. 2010 Feb 26;37(4):469-80.

Cairns BR, Lorch Y, Li Y, et al. RSC, an essential, abundant chromatin-remodeling complex. Cell. 1996; 87:1249-1260. [PubMed: 8980231]

Celic I, Masumoto H, Griffith WP, Meluh P, Cotter RJ, Boeke JD, Verreault A. The sirtuins hst3 and Hst4p preserve genome integrity by controlling histone h3 lysine 56 deacetylation. Curr Biol. 2006 Jul 11;16(13):1280-9. 
Chen C, Joshua J. Carson, Jason Feser, Beth Tamburini, Susan Zabaronick, Jeffrey Linger and Jessica K. Tyler. Acetylated Lysine 56 on Histone H3 Drives Chromatin Assembly after Repair and Signals for the Completion of Repair. Cell, Volume 134, Issue 2, 231-243, 25 July 2008 doi:10.1016/j.cell.2008.06.035

Choy JS, Kron SJ. NuA4 subunit Yng2 function in intra-S-phase DNA damage response. Mol Cell Biol 2002;22:8215-8225. [PubMed: 12417725]

Clarke AS, Lowell JE, Jacobson SJ, Pillus L. Esa1p is an essential histone acetyltransferase required for cell cycle progression. Mol Cell Biol. 1999;19:2515-2526.

Collins SR, Miller KM, Maas NL, Roguev A, Fillingham J, Chu CS, Schuldiner M, Gebbia M, Recht J, Shales M, Ding H, Xu H, Han J, Ingvarsdottir K, Cheng B, Andrews B, Boone C, Berger SL, Hieter P, Zhang Z, Brown GW, Ingles CJ, Emili Functional dissection of protein complexes involved in yeast chromosome biology using a genetic interaction map. Nature. 2007 Apr 12;446(7137):806-10. Epub 2007 Feb 21.

Cockell M, Gasser SM. Nuclear compartments and gene regulation. Curr Opin Genet Dev. 1999 Apr;9(2):199-205.

Cosgrove MS. Histone proteomics and the epigenetic regulation of nucleosome mobility. Expert Rev Proteomics. 2007 Aug;4(4):465-78. 
Daganzo SM, Erzberger JP, Lam WM, Skordalakes E, Zhang R, Franco AA, Brill SJ, Adams PD, Berger JM, Kaufman PD. Structure and function of the conserved core of histone deposition protein Asf1. Curr Biol. 2003 Dec 16;13(24):2148-58.

Dang W, Steffen KK, Perry R, Dorsey JA, Johnson FB, Shilatifard A, Kaerberlein M, Kennedy BK, and Berger SL. Histone H4 lysine 16 acetylation regulates cellular lifespan. Nature 2009;459(7248):802-7.

Das C, Lucia MS, Hansen KC, Tyler JK.. CBP/p300-mediated acetylation of histone H3 on lysine 56. Nature 459, 113-117(7 May 2009) doi:10.1038/nature07861

Draker R, Cheung P. Transcriptional and epigenetic functions of histone variant H2A.Z. Biochem Cell Biol. 2009 Feb;87(1):19-25. Review. [PMID: 19234520]

Driscoll R, Hudson A, Jackson SP. Yeast Rtt109 promotes genome stability by acetylating histone H3 on lysine 56. Science 2007;315:649-652. [PubMed: 17272722]

Eberharter A, Lechner T, Goralik-Schramel M, Loidl P (1996). Purification and characterization of the cytoplasmic histone acetyltransferase B of maize embryos. FEBS Lett 386, 75-81.

Ejlassi-Lassallette A, Mocquard E, Arnaud MC, Thiriet C. H4 replication-dependent diacetylation and Hat1 promote S-phase chromatin assembly in vivo. Mol Biol Cell. 2011 Jan;22(2):245-55. Epub 2010 Nov 30. 
English CM, Adkins MW, Carson JJ, Churchill ME, Tyler JK. Structural basis for the histone chaperone activity of Asf1. Cell. 2006 Nov 3;127(3):495-508.

English CM, Maluf NK, Tripet B, Churchill ME, Tyler JK. ASF1 Binds to a Heterodimer of Histones H3 and H4: A Two-Step Mechanism for the Assembly of the H3-H4 Heterotetramer on DNA. Biochemistry 2005;44:13673-13682. [PubMed: 16229457]

Feser J, Truong D, Das C, Carson JJ, Kieft J, Harkness T, and Tyler JK. Elevated Histone Expression Promotes Life Span Extension. Molcell 2010; 2010.08.015

Fillingham J, Greenblatt JF. A histone code for chromatin assembly. Cell. 2008 Jul 25;134(2):206-8.

Fillingham J, Kainth P, Lambert JP, van Bakel H, Tsui K, Peña-Castillo L, Nislow C, Figeys D, Hughes TR, Greenblatt J, Andrews BJ. Two-color cell array screen reveals interdependent roles for histone chaperones and a chromatin boundary regulator in histone gene repression. Mol Cell. 2009 Aug 14;35(3):340-51. [PMID: 19683497]

Fillingham J, Recht J, Silva A C, Suter B, Emili A, Stagljar I, Krogan NJ, Allis CD, Keogh M-C, and Greenblatt JF. Chaperone Control of the Activity and Specificity of the Histone H3 Acetyltransferase Rtt109. 2008; MCB.00182-08 
Fischle W, Wang Y, Allis CD. Histone and chromatin cross-talk. Curr Opin Cell Biol. 2003 Apr;15(2):172-83. J Biol Chem. 1999 Feb 26;274(9):5895-900.

Gambus, A., Jones, R.C., Sanchez-Diaz, A., Kanemaki, M., van Deursen, F., Edmondson, R.D., and Labib, K. (2006). GINS maintains association of Cdc45 with MCM in replisome progression complexes at eukaryotic DNA replication forks. Nat. Cell Biol. 8, 358-366.

Gao X, Tate P, Hu P, et al. ES cell pluripotency and germlayer formation require the SWI/SNF chromatin remodeling component BAF250a. Proc Natl Acad Sci USA. 2008; 105:6656-6661. [PubMed: 18448678]

Goodman RH, Smolik S. CBP/p300 in cell growth, transformation, and development. Genes Dev 2000;14:1553-1577. [PubMed: 10887150]

Gorovsky MA, Yao MC, Keevert JB, Pleger GL. Isolation of Micro and Macronuclei from Tetrahymena pyriformis. Methods Cell Biol. 1975;9(0):311-27. PMID:805898

Grant, P. A., D. E. Sterner, L. J. Duggan, J. L. Workman, and S. L. Berger. 1998. The SAGA unfolds: convergence of transcription regulators in chro- matin-modifying complexes. Trends Cell Biol. 8:193-197.

Grant PA, Duggan L, Côté J, Roberts SM, Brownell JE, Candau R, Ohba R, Owen-Hughes T, Allis CD, Winston F, Berger SL, Workman JL. Yeast Gen5 functions in two multisubunit 
complexes to acetylate nucleosomal histones: characterization of an Ada complex and the SAGA (Spt/Ada) complex. Genes Dev. 1997 Jul 1;11(13):1640-50.

Grant PA, Eberharter A, John S, Cook RG, Turner BM, Workman JL. Expanded lysine acetylation specificity of Gcn5 in native complexes. J Biol Chem. 1999 Feb 26;274(9):5895-900.

Groth A, Rocha W, Verreault A, Almouzni G. Chromatin challenges during DNA replication and repair. Cell. 2007 Feb 23;128(4):721-33.

Haldar D, Kamakaka RT. Schizosaccharomyces pombe Hst4 functions in DNA damage response by regulating histone H3 K56 acetylation. Eukaryot Cell. 2008 May;7(5):800-13. Epub 2008 Mar 14.

Haigis MC, Guarente LP. Mammalian sirtuins--emerging roles in physiology, aging, and calorie restriction. Genes Dev 2006;20:2913-2921. [PubMed: 17079682]

Hargreaves DC, Crabtree GR. ATP-dependent chromatin remodeling: genetics, genomics and mechanisms. Cell Res. 2011 Mar;21(3):396-420. Epub 2011 Mar 1.

Han J, Zhou H, Horazdovsky B, Zhang K, Xu RM, Zhang Z. Rtt109 acetylates histone H3 lysine 56 and functions in DNA replication. Science 2007a;315:653-655. [PubMed: 17272723] 
Han J, Zhou H, Li Z, Xu RM, Zhang Z. Acetylation of lysine 56 of histone H3 catalyzed by RTT109 and regulated by ASF1 is required for replisome integrity. J Biol Chem 2007b;282:28587-28596. [PubMed: 17690098]

Han J, Zhou H, Li Z, Xu RM, Zhang Z. The Rtt109-Vps75 histone acetyltransferase complex acetylates non-nucleosomal histone H3. J Biol Chem 2007b;282:14158-14164. [PubMed: 17369253]

Haushalter KA, Kadonaga JT. Chromatin assembly by DNA-translocating motors. Nat Rev Mol Cell Biol. 2003 Aug;4(8):613-20.

Hecht A, Laroche T, Strahl-Bolsinger S, Gasser SM, Grunstein M (1995) Histone H3 and H4 Ntermini interact with SIR3 and SIR4 proteins: a molecular model for the formation of heterochromatin in yeast. Cell 80: 583-592.

Hirschhorn JN, Brown SA, Clark CD, Winston F. Evidence that SNF2/SWI2 and SNF5 activate transcription in yeast by altering chromatin structure. Genes Dev. 1992; 6:2288-2298. [PubMed: $1459453] 2007 ; 315: 653-655$

Horowitz S, Gorovsky MA. An unusual genetic code in nuclear genes of Tetrahymena. Proc Natl Acad Sci U S A. 1985 Apr;82(8):2452-5. 
Imai S, Armstrong CM, Kaeberlein M, Guarente L (2000) Transcriptional silencing and longevity protein Sir2 is an NAD-dependent histone deacetylase. Nature 403: 795-800.

Kanikarla-Marie P, Ronald S, De Benedetti A. Nucleosome resection at a double-strand break during Non-Homologous Ends Joining in mammalian cells - implications from repressive chromatin organization and the role of ARTEMIS. BMC Res Notes. 2011 Jan 21;4:13.

Kleff S, Andrulis ED, Anderson CW, Sternglanz R. Identification of a gene encoding a yeast histone H4 acetyltransferase. J Biol Chem 1995;270:24674-24677. [PubMed: 7559580]

Kimura A, Umehara T, Horikoshi M (2002) Chromosomal gradient of histone acetylation established by Sas $2 p$ and Sir2p functions as a shield against gene silencing. Nat Genet 32: 370377.

Kouzarides T. Chromatin modifications and their function. Cell 2007;128:693-705. [PubMed: 17320507]

Kuo MH, Brownell JE, Sobel RE, Ranalli TA, Cook RG, Edmondson DG, Roth SY, Allis CD. Transcription-linked acetylation by Gen5p of histones H3 and H4 at specific lysines. Nature. 1996 Sep 19;383(6597):269-72. 
Layman WS, McEwen DP, Beyer LA, et al. Defects in neural stem cell proliferation and olfaction in Chd7 deficient mice indicate a mechanism for hyposmia in human CHARGE syndrome. Hum Mol Genet. 2009; 18:1909-1923. [PubMed: 19279158]

Lee KK, Workman JL. Histone acetyltransferase complexes: one size doesn't fit all. Nat Rev Mol Cell Biol 2007;8:284-295. [PubMed: 17380162]

Li, B., Carey, M., and Workman, J.L. (2007a). The role of chromatin during transcription. Cell $128,707-719$.

Li Q, Zhou H, Wurtele H, Davies B, Horazdovsky B, Verreault A, and Zhang Z. Acetylation of Histone H3 Lysine 56 Regulates Replication-Coupled Nucleosome Assembly. Cell, Volume 134, Issue 2, 244-255, 25 July 2008 doi:10.1016/j.cell.2008.06.018

Lickert H, Takeuchi JK, Von Both I, et al. Baf60c is essential for function of BAF chromatin remodelling complexes in heart development. Nature. 2004; 432:107-112. [PubMed: 15525990]

Luger K, Mäder AW, Richmond RK, Sargent DF, Richmond TJ. Crystal structure of the nucleosome core particle at 2.8 A resolution. Nature. 1997 Sep 18;389(6648):251-60.

Luger K, Structure and dynamic behaviour of nucleosomes Curr.Opin.Genet. 2003 Dev 13, $127-135$ 
Luo K, Vega-Palas MA, Grunstein M (2002) Rap1-Sir4 binding independent of other Sir, yKu, or histone interactions initiates the assembly of telomeric heterochromatin in yeast. Genes Dev 16: $1528-1539$.

Ma XJ, Wu J, Altheim BA, Schultz MC, Grunstein M. Deposition-related sites K5/K12 in histone $\mathrm{H} 4$ are not required for nucleosome deposition in yeast. Proc Natl Acad Sci U S A 1998;95:6693-6698. [PubMed: 9618474]

Masumoto H, Hawke D, Kobayashi R, and Verreault A. A role for cell-cycle-regulated histone H3 lysine 56 acetylation in the DNA damage response. Nature 2005. 436,294-298.

Miller KM, Maas NL, Toczyski DP. Taking it off: regulation of H3 K56 acetylation by Hst3 and Hst4. Cell Cycle. 2006 Nov;5(22):2561-5. Epub 2006 Nov 15.

Mochizuki K. RNA-directed epigenetic regulation of DNA rearrangements.Essays Biochem. 2010 Sep 20;48(1):89-100. Review. [PMID: 20822488]

Morrison AJ, Shen X. Chromatin remodelling beyond transcription: the INO80 and SWR1 complexes. Nat Rev Mol Cell Biol. 2009 Jun;10(6):373-84. Epub 2009 May 8.

Mousson F, Lautrette A, Thuret JY, Agez M, Courbeyrette R, Amigues B, Becker E, Neumann JM, Guerois R, Mann C, Ochsenbein F. Structural basis for the interaction of Asf1 with histone 
H3 and its functional implications. Proc Natl Acad Sci U S A 2005;102:5975-5980. [PubMed: $15840725]$

Munakata T, Adachi N, Yokoyama N, Kuzuhara T, Horikoshi M. A human homologue of yeast anti- silencing factor has histone chaperone activity. Genes Cells 2000;5:221-233. [PubMed: 10759893]

Naar, A.M., Lemon, B.D., Tjian, R.(2001) Transcriptional coactivator complexes. Annu. Rev. Biochem. 70:475-501.

Nagy Z, Tora L. Distinct GCN5/PCAF-containing complexes function as co-activators and are involved in transcription factor and global histone acetylation. Oncogene. 2007 Aug 13;26(37):5341-57. Review.[PMID: 17694077]

Nakatani Y, Ray-Gallet D, Quivy JP, Tagami H, Almouzni G. Two distinct nucleosome assembly pathways: dependent or independent of DNA synthesis promoted by histone H3.1 and H3.3 complexes. Cold Spring Harb Symp Quant Biol 2004;69:273-280. [PubMed: 16117659]

Ohba R, Steger DJ, Brownell JE, Mizzen CA, Cook RG, Côté J, Workman JL, Allis CD. A novel $\mathrm{H} 2 \mathrm{~A} / \mathrm{H} 4$ nucleosomal histone acetyltransferase in Tetrahymena thermophila. Mol Cell Biol. 1999 Mar;19(3):2061-8. 
Ozdemir A, Spicuglia S, Lasonder E, Vermeulen M, Campsteijn C, Stunnenberg HG, Logie C. Characterization of lysine 56 of histone H3 as an acetylation site in Saccharomyces cerevisiae. J Biol Chem. 2005 Jul 15;280(28):25949-52. Epub 2005 May 10.

Park, Y.J., Sudhoff, K.B., Andrews, A.J., Stargell, L.A., and Luger, K. (2008). Histone chaperone specificity in Rtt109 activation. Nat. Struct. Mol. Biol. 15, 957-964.

Parthun MR (2007). Hat1: the emerging cellular roles of a type B histone acetyltransferase. Oncogene 26, 5319-5328.

Poveda A, Pamblanco M, Tafrov S, Tordera V, Sternglanz R, Sendra R. Hifl is a component of yeast histone acetyltransferase B, a complex mainly localized in the nucleus. J Biol Chem. 2004 Apr 16;279(16):16033-43. Epub 2004 Feb 3.

Qin S, Parthun MR. Histone H3 and the histone acetyltransferase Hatlp contribute to DNA double-strand break repair. Mol Cell Biol 2002;22:8353-8365. [PubMed: 12417736]

Ransom M, Dennehey BK, Tyler JK. Chaperoning histones during DNA replication and repair. Cell. 2010 Jan 22;140(2):183-95.

Rufiange A, Jacques PE, Bhat W, Robert F, Nourani A. Genome-wide replication-independent histone $\mathrm{H} 3$ exchange occurs predominantly at promoters and implicates H3 K56 acetylation and Asf1. Mol Cell. 2007 Aug 3;27(3):393-405. 
Rocha, W., and Verreault, A. (2008). Clothing up DNA for all seasons: Histone chaperones and nucleosome assembly pathways. FEBS Lett. 582, 1938-1949.

Rossetto, D., Truman, A.W., Kron, S.J., and Cote, J. (2010). Epigenetic modifications in doublestrand break DNA damage signaling and repair. Clin. Cancer Res. 16, 4543-4552.

Roth SY, Denu JM, Allis CD. Histone acetyltransferases. Annu Rev Biochem. 2001;70:81-120.

Ruthenburg AJ, Li H, Patel DJ, Allis CD. Multivalent engagement of chromatin modifications by linked binding modules. Nat Rev Mol Cell Biol 2007;8:983-994. [PubMed: 18037899]

Salim HM, Ring KL, Cavalcanti AR. Patterns of codon usage in two ciliates that reassign the genetic code: Tetrahymena thermophila and Paramecium tetraurelia. Protist. 2008 Apr;159(2):283-98. Epub 2008 Jan 22.PMID: 18207458

Santini V, Gozzini A, Ferrari G. Histone deacetylase inhibitors: molecular and biological activity as a premise to clinical application. Curr Drug Metab. 2007 May;8(4):383-93.

Schuettengruber B, Chourrout D, Vervoort M, Leblanc B, Cavalli G. Genome regulation by polycomb and trithorax proteins. Cell 2007;128:735-745. [PubMed: 17320510] 
Selth, L.A., Lorch, Y., Ocampo-Hafalla, M.T., Mitter, R., Shales, M., Krogan, N.J., Kornberg, R.D., and Svejstrup, J.Q. (2009). An rtt109-independent role for vps75 in transcriptionassociated nucleosome dynamics. Mol Cell Biol. 2009 Aug;29(15):4220-34. Epub 2009 May 26.

Selth LA, Lorch Y, Ocampo-Hafalla MT, Mitter R, Shales M, Krogan NJ, Kornberg RD, Svejstrup JQ. An rtt109-independent role for vps75 in transcription-associated nucleosome dynamics.

Selth, L., and J. Q. Svejstrup. 2007. Vps75, a new yeast member of the NAP histone chaperone family. J. Biol. Chem. 282:12358-12362.

Smerdon, M.J. (1991). DNA repair and the role of chromatin structure. Curr. Opin. Cell Biol. 3, $422-428$.

Smith ER, Eisen A, Gu W, Sattah M, Pannuti A, et al. ESA1 is a histone acetyltransferase that is essential for growth in yeast. Proc Natl Acad Sci U S A. 1998;95:3561-3565.

Sobel RE, Cook RG, Perry CA, Annunziato AT, Allis CD. Conservation of deposition-related acetylation sites in newly synthesized histones H3 and H4. Proc Natl Acad Sci U S A. 1995 Feb 14;92(4):1237-41.

Shahbazian MD, Grunstein M. Functions of site-specific histone acetylation and deacetylation. Annu. Rev. Biochem. 2007;76:75-100 
Shibahara K, Stillman B. Replication-dependent marking of DNA by PCNA facilitates CAF-1coupled inheritance of chromatin. Cell. 1999 Feb 19;96(4):575-85.

Schnetz MP, Bartels CF, Shastri K, Balasubramanian D, Zentner GE, et al. (2009) Genomic distribution of CHD7 on chromatin tracks H3K4 methylation patterns. Genome Res 19: 590601.

Stillman, B. Chromatin assembly during SV40 DNA replication in vitro. Cell. 1986 May 23;45(4):555-65.

Strahl BD, Allis CD. The language of covalent histone modifications. Nature. 2000 Jan 6;403(6765):41-5.

Sudarsanam P, Iyer VR, Brown PO, Winston F. Whole-genome expression analysis of snf/swi mutants of Saccharomyces cerevisiae. Proc Natl Acad Sci USA. 2000; 97:3364-3369. [PubMed: 10725359]

Tamburini BA, Carson JJ, Adkins MW, Tyler JK. Functional conservation and specialization among eukaryotic anti-silencing function 1 histone chaperones. Eukaryot Cell. 2005 Sep;4(9):1583-90. 
Tamburini BA, Tyler JK. Localized histone acetylation and deacetylation triggered by the homologous recombination pathway of double-strand DNA repair. Mol Cell Biol 2005;25:49034913. [PubMed: 15923609]

Tang L, Nogales E, Ciferri C. Structure and function of SWI/SNF chromatin remodeling complexes and mechanistic implications for transcription. Prog Biophys Mol Biol 2010 JunJul;102(2-3):122-8. [PMID: 20493208]

Tang Y, Holbert MA, Wurtele H, Meeth K, Rocha W, Gharib M, Jiang E, Thibault P, Verreault A, Cole PA, Marmorstein R. Fungal Rtt109 histone acetyltransferase is an unexpected structural homolog of metazoan p300/CBP. Nat Struct Mol Biol. 2008 Jul;15(7):738-45. Epub 2008 Jun 22.

Tjeertes JV, Miller KM, Jackson SP. Screen for DNA-damage-responsive histone modifications identifies H3K9Ac and H3K56Ac in human cells. EMBO J. 2009 Jul 8;28(13):1878-89. Epub 2009 Apr 30.

Travers A (1999) The location of the linker histone on the nucleosome. Trends Biochem Sci 24: $4-7$.

Tsubota T, et al. Histone H3-K56 acetylation is catalyzed by histone chaperonedependent complexes. Mol. Cell 2007;25:703-712. [PubMed: 17320445] 
Tyler JK, Adams CR, Chen SR, Kobayashi R, Kamakaka RT, Kadonaga JT. The RCAF complex mediates chromatin assembly during DNA replication and repair. Nature. 1999 Dec 2;402(6761):555-60.

Verdone L, Caserta M, Di Mauro E. Role of histone acetylation in the control of gene expression. Biochem Cell Biol. 2005 Jun;83(3):344-53. Review. [PMID: 15959560]

Vermeulen M, Mulder KW, Denissov S, Pijnappel WW, van Schaik FM, Varier RA, Baltissen MP, Stunnenberg HG, Mann M, Timmers HT. Selective anchoring of TFIID to nucleosomes by trimethylation of histone H3 lysine 4. Cell. 2007 Oct 5;131(1):58-69. Epub 2007 Sep 20.

Vissers LE, van Ravenswaaij CM, Admiraal R, et al. Mutations in a new member of the chromodomain gene family cause CHARGE syndrome. Nat Genet. 2004; 36:955-957. [PubMed: 15300250]

Williams, S.K., and Tyler, J.K. (2007). Transcriptional regulation by chromatin disassembly and reassembly. Curr. Opin. Genet. Dev. 17, 88-93.

Winzeler EA, Shoemaker DD, Astromoff A, Liang H, Anderson K, Andre B, Bangham R, Benito R, Boeke JD, Bussey H, Chu AM, Connelly C, Davis K, Dietrich F, Dow SW, El

Wolffe A. The complexities of chromatin. Chromatin structure and function, second edition Academic Press (1995). ISBN 0-12-761912-7 
Wurtele H, Tsao S, Lépine G, Mullick A, Tremblay J, Drogaris P, Lee EH, Thibault P, Verreault A, Raymond M. Modulation of histone $\mathrm{H} 3$ lysine 56 acetylation as an antifungal therapeutic strategy. Nat Med. 2010 Jul;16(7):774-80. Epub 2010 Jul 4.

Xu F, Zhang K, Grunstein M. Acetylation in histone H3 globular domain regulates gene expression in yeast. Cell. 2005;121:375-385

Yao M-C, and Chao J-L. RNA-GUIDED DNA DELETION IN TETRAHYMENA: An RNAiBased Mechanism for Programmed Genome Rearrangements. (Annual Review of Genetics, 2005) DOI: 10.1146/annurev.genet.39.073003.095906

Yang XJ, Seto E. The Rpd3/Hda1 family of lysine deacetylases: from bacteria and yeast to mice and men. Nat Rev Mol Cell Biol 2008;9:206-218. [PubMed: 18292778]

Yoo AS, Staahl BT, Chen L, Crabtree GR. MicroRNA-mediated switching of chromatinremodelling complexes in neural development. Nature. 2009; 460:642-646. [PubMed: 19561591]

Zentner GE, Layman WS, Martin DM, Scacheri PC (2010) Molecular and phenotypic aspects of CHD7 mutation in CHARGE syn- drome. Am J Med Genet A 152A: 674- 686. 
Zhou Z, Feng H, Hansen DF, Kato H, Luk E, Freedberg DI, Kay LE, Wu C, Bai Y. NMR structure of chaperone Chz1 complexed with histones H2A.Z-H2B. Nat Struct Mol Biol. 2008 Aug;15(8):868-9. Epub 2008 Jul 20. 